\title{
Regulatory DQO Test Plan for Determining Method Detection Limits, Estimated Quantitation Limits, and Quality Assurance Criteria for Specified Analytes
}

PNNL

G. K. Patello

C. Z. Soderquist

T. L. Almeida

R. G. Swoboda

J. A. Campbell

M. W. Urie

O. T. Farmer

E. W. Hoppe

J. J. Wagner

CHG

D. Blumenkranz

January 2001

Prepared for CH2M Hill Hanford Group, Inc. under Project Number 42039 


\section{DISCLAIMER}

This report was prepared as an account of work sponsored by an agency of the United States Government. Neither the United States Government nor any agency thereof, nor Battelle Memorial Institute, nor any of their employees, makes any warranty, express or implied, or assumes any legal liability or responsibility for the accuracy, completeness, or usefulness of any information, apparatus, product, or process disclosed, or represents that its use would not infringe privately owned rights. Reference herein to any specific commercial product, process, or service by trade name, trademark, manufacturer, or otherwise does not necessarily constitute or imply its endorsement, recommendation, or favoring by the United States Government or any agency thereof, or Battelle Memorial Institute. The views and opinions of authors expressed herein do not necessarily state or reflect those of the United States Government or any agency thereof.

\section{PACIFIC NORTHWEST NATIONAL LABORATORY \\ operated by \\ BATTELLE \\ for the \\ UNITED STATES DEPARTMENT OF ENERGY under Contract DE-AC06-76RL01830}

Printed in the United States of America

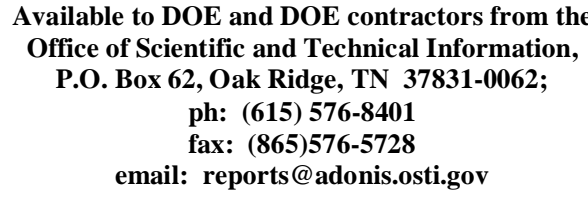

Available to the public from the National Technical Information Service, U.S. Department of Commerce, 5285 Port Royal Rd., Springfield, VA 22161

ph: (800) 553-6847

fax: $(703) 605-6900$

email: orders@ntis.fedworld.gov

online ordering: http://www.ntisgov/ordering.htm

This document was printed on recycled paper. 
PNNL - 13429

TP-41500-003 -Rev 0

\section{Regulatory DQO Test Plan for Determining Method Detection Limits, Estimated Quantitation Limits, and Quality Assurance Criteria for Specified Analytes}

PNNL
G. K. Patello
C. Z. Soderquist
T. L. Almeida
R. G. Swoboda
J. A. Campbell
M. W. Urie
O. T. Farmer
J. J. Wagner
E. W. Hoppe

CHG

D. Blumenkranz

January 2001

Prepared for

the CH2M Hill Hanford Group, Inc.

under Project Number 42039

Pacific Northwest National Laboratory

Richland, Washington 99352 


\section{Summary}

The Regulatory Data Quality Objectives (DQO) Supporting Tank Waste Remediation System

Privatization Project (Wiemers et al. 1998a) was prepared to address the regulatory data needs for waste currently stored in double-shell and single-shell tanks that was generated by the U.S. Department of Energy (DOE) and its predecessors. In the Regulatory DQO, 125 organic compounds and 48 inorganic constituents were identified as priority regulated constituents requiring additional tank waste characterization.

The Washington State Administrative Code (WAC 173-303-110) requires the use of the methods described in SW-846 (EPA 1997) to analyze many of these compounds and constituents to meet the regulatory data needs. Due to the radioactivity and complex sample matrix for the tank waste, it is likely that the SW-846 methods will need to be modified or alternative methods selected as stipulated under WAC 173-303-110. SW-846 allows some flexibility for using other established methods that have been developed by the U.S. Environmental Protection Agency (EPA) or the American Society for Testing and Materials (ASTM).

The objective of this test plan is to lay the foundation for initiating laboratory studies to determine method detection limits (MDLs), estimated quantitation limits (EQLs), and quality assurance (QA) criteria for the 173 constituents identified in the Regulatory DQO. For analytes in which adequate methods exist to meet target MDLs and EQLs, this plan describes the approach for the applicable methods and addresses minor changes in method implementation that are necessary to maintain doses as low as reasonable achievable (ALARA). Only minor modifications will be discussed in this test plan.

The plan describes the strategy of determining MDLs for sand and water to show that the EPA methods with minor modifications will meet expected MDLs or EQLs as published in the individual methods. Then MDLs will be determined on the waste matrices, and EQLs will be estimated. The waste matrices will include a low-activity waste (LAW) to represent a liquid waste matrix and a high-level waste (HLW) to represent the solids waste matrix. Table S.1 summarizes the proposed approaches for determining the MDLs and EQLs. The strategy outlined in this plan is dynamic and may change as information is gathered through literature search and laboratory investigations.

Table S.1. Summary of Proposed Approaches to MDL/EQL Determination

\begin{tabular}{|c|c|c|c|c|c|}
\hline $\begin{array}{l}\text { Analytes of } \\
\text { Interest }\end{array}$ & $\begin{array}{l}\text { Reg. DQO } \\
\text { Proposed } \\
\text { Analytical } \\
\text { Method }\end{array}$ & $\begin{array}{l}\text { Test Plan } \\
\text { Proposed } \\
\text { Prep } \\
\text { Method }\end{array}$ & $\begin{array}{l}\text { Test Plan } \\
\text { Proposed } \\
\text { Analytical } \\
\text { Method }\end{array}$ & $\begin{array}{l}\text { Degree of } \\
\text { Modification }\end{array}$ & Modification Summary \\
\hline \multicolumn{6}{|c|}{ Organics } \\
\hline Volatiles & 8260B & 5035 & $8260 \mathrm{~B}$ & minor & $\begin{array}{l}\text { Minor modifications include } \\
\text { using isotope dilution (EPA } \\
1989 \text { Method 1624) and ion } \\
\text { monitoring. Use of alternative } \\
\text { sample preparations may } \\
\text { include the use of SW-846 } \\
\text { methods or development of } \\
\text { new methods. }\end{array}$ \\
\hline Semivolatiles & $\begin{array}{l}8270 \mathrm{C} \\
8151 \mathrm{~A} \\
\text { (Dinoseb) }\end{array}$ & $\begin{array}{l}\text { Liquids: } \\
\text { 3510C } \\
\text { Solids: 3550B }\end{array}$ & $8270 \mathrm{C}$ & minor & $\begin{array}{l}\text { Preparation includes } \mathrm{pH} \\
\text { determination by titration with } \\
\text { phosphoric acid and } \\
\text { ultrsonification methylene } \\
\text { chloride:acetone. }\end{array}$ \\
\hline
\end{tabular}




\begin{tabular}{|c|c|c|c|c|c|}
\hline $\begin{array}{l}\text { Analytes of } \\
\text { Interest }\end{array}$ & $\begin{array}{l}\text { Reg. DQO } \\
\text { Proposed } \\
\text { Analytical } \\
\text { Method }\end{array}$ & $\begin{array}{l}\text { Test Plan } \\
\text { Proposed } \\
\text { Prep } \\
\text { Method }\end{array}$ & $\begin{array}{l}\text { Test Plan } \\
\text { Proposed } \\
\text { Analytical } \\
\text { Method }\end{array}$ & $\begin{array}{l}\text { Degree of } \\
\text { Modification }\end{array}$ & Modification Summary \\
\hline & & & & & $\begin{array}{l}\text { GC/MS } \\
\text { Method } 8270 \mathrm{C} \text {. } \\
\text { N-nitroso compound extraction } \\
\text { under basic conditions. }\end{array}$ \\
\hline $\begin{array}{l}\text { Pesticides and } \\
\text { PCBs }\end{array}$ & $\begin{array}{l}8081 \mathrm{~A} \text { and } \\
8082\end{array}$ & $\begin{array}{l}\text { Liquids: } \\
\text { 3510C } \\
\text { Solids: 3550B }\end{array}$ & $\begin{array}{l}8081 \mathrm{~A} \text { and } \\
8082\end{array}$ & minor & $\begin{array}{l}\text { Minor modifications may } \\
\text { include modified preparation or } \\
\text { clean-up method to improve } \\
\text { sensitivity. }\end{array}$ \\
\hline $\begin{array}{l}\text { Polar } \\
\text { Volatiles }\end{array}$ & $8260 \mathrm{~B}$ & $8260 \mathrm{~B}$ & 5021 & minor & $\begin{array}{l}\text { Isotope dilution and ion } \\
\text { monitoring (EPA } 1989 \text { Method } \\
\text { 1624) }\end{array}$ \\
\hline $\begin{array}{l}\text { Organic } \\
\text { Acids }\end{array}$ & 9056 & $\begin{array}{l}\text { clean up ion } \\
\text { exchange }\end{array}$ & 9056 & minor & $\begin{array}{l}\text { IX for radionuclide } \\
\text { reduction/removal. Optimized } \\
\text { instrument settings. }\end{array}$ \\
\hline \multicolumn{6}{|c|}{ Inorganics } \\
\hline Metals & 6010B & $\begin{array}{l}\text { Liquids: } \\
\text { 3005A, 3010A } \\
\text { or equivalent } \\
\text { Solids: 3052, } \\
\text { ASTM D4503 } \\
\text { or D4698 }\end{array}$ & $\begin{array}{l}6020 \\
\left(^{\text {ICP/MS }}\right)^{(\mathrm{b})} \\
6010 \mathrm{~B} \\
\left(\text { ICP/AES) }^{(\mathrm{c})}\right.\end{array}$ & minor & $\begin{array}{l}\text { For liquids, only minor } \\
\text { modifications to accommodate } \\
\text { processing small samples. } \\
\text { For solids, fusion techniques } \\
\text { would use Na and } \mathrm{K} \text { based } \\
\text { caustic flux agents instead of } \\
\text { lithium metaborate. } \\
\text { Microwave digestion (3052) } \\
\text { would need to be adapted to } \\
\text { remote processing. }\end{array}$ \\
\hline Anions & 9056 & $\begin{array}{l}\text { ASTM } \\
\text { D3987-85 }\end{array}$ & 9056 & $\begin{array}{l}\text { Minor or } \\
\text { alternate EPA } \\
\text { method }\end{array}$ & $\begin{array}{l}\mathrm{IC}^{\mathrm{dd})} \text { parameter adjustment to } \\
\text { optimize method. Possible } \\
\text { methods development for } \mathrm{Br} \text {, } \\
\mathrm{Cl}, \mathrm{NO}_{3}^{-}, \mathrm{NO}_{2}^{-} \text {. }\end{array}$ \\
\hline Ammonia & $\begin{array}{l}\text { EPA/600 } \\
\text { Method } \\
350.3\end{array}$ & $\begin{array}{l}\text { EPA/ } 600 \\
\text { Method } 350.2 \\
\text { if needed }\end{array}$ & $\begin{array}{l}\text { EPA 600/ } \\
\text { Methods } \\
350.1, \\
350.2,350.3\end{array}$ & minor & Only sample size modifications \\
\hline Cyanide & $9010 \mathrm{~B}$ & $\begin{array}{l}\text { EDTA }^{(\mathrm{e})} / \text { Ethyl } \\
\text { enediamine } \\
\text { pretreatment } \\
\text { for waste with } \\
\text { ferrocyanide }\end{array}$ & $\begin{array}{l}9010 \mathrm{~B} \\
9012 \mathrm{~A} \\
9013,9014 \\
\text { or } 9213\end{array}$ & minor & $\begin{array}{l}\text { Pretreatment for ferrocyanide } \\
\text { waste }\end{array}$ \\
\hline Hydroxide & $\begin{array}{l}\text { EPA/600 } \\
\text { Method } \\
310.1\end{array}$ & None required & $\begin{array}{l}\text { EPA/600 } \\
\text { Method } \\
310.1 \text { or } \\
310.2\end{array}$ & minor & $\begin{array}{l}\text { Data interpretation to determine } \\
\text { hydroxide concentration instead } \\
\text { of alkalinity. }\end{array}$ \\
\hline Mercury & 7470/7471A & 7470/7471A & 7470/7471A & minor & $\begin{array}{l}\text { Equipment parameter } \\
\text { modifications to optimize the } \\
\text { analysis. }\end{array}$ \\
\hline
\end{tabular}

(a) $\mathrm{GC} / \mathrm{MS}$ = gas chromatography/mass spectroscopy

(b) ICP/MS = inductively coupled plasma/mass spectroscopy

(c) ICP/AES = inductively coupled plasma/atomic emission spectroscopy

(d) IC = ion chromatography

(e) EDTA = ethylenediaminetetraacetic acid 


\section{Contents}

Symbols, Abbreviations, Acronyms......................................................................................................

1.0 Introduction .................................................................................................................... 1-1

2.0 Method Detection Limit and Estimated Quantitation Limit Determination ................ 2-1

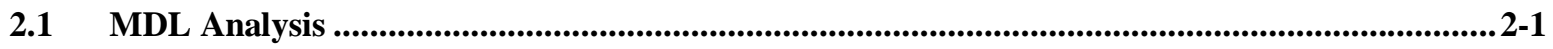

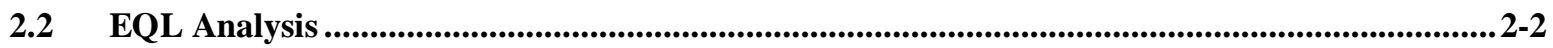

3.0 Quality Assurance Criteria Determination ............................................................................... 3-1

3.1 Quality-Control Samples .....................................................................................................................3-1

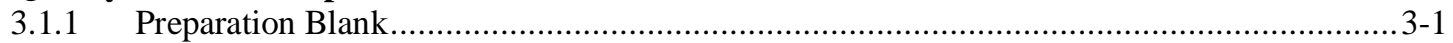

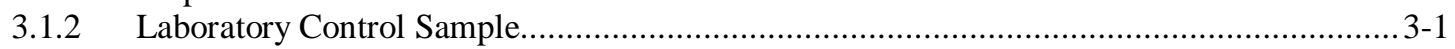

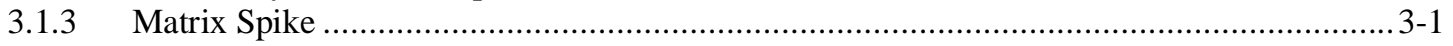

3.1.4 Laboratory Sample Duplicate or Matrix Spike Duplicate ................................................. 3-2

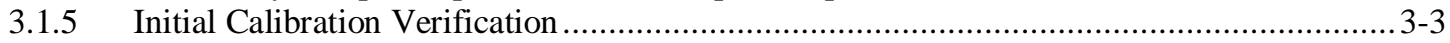

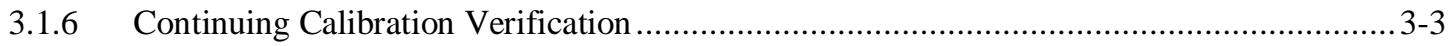

3.1.7 Initial Calibration Blank and Continuing Calibration Blank.............................................3-3

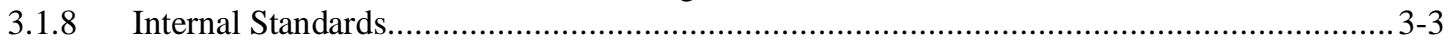

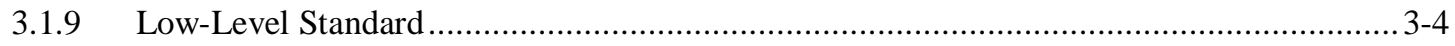

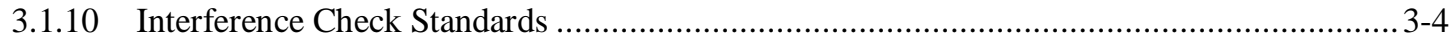

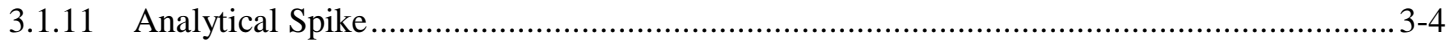

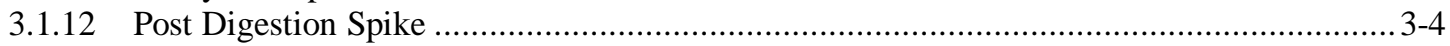

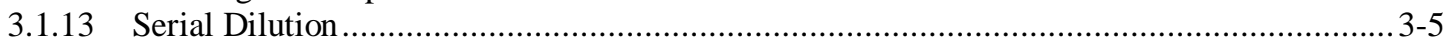

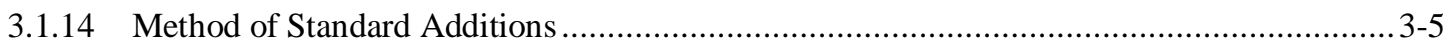

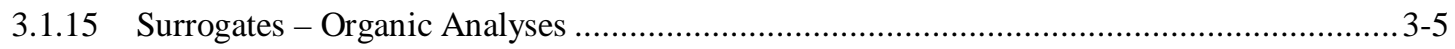

3.2 Control Limits....................................................................................................................................3-5

3.3 Method-Specific QC.................................................................................................................................3-6

4.0 Organic Analysis ...................................................................................................................... 4-1

4.1 Volatile Organics Analysis (79) ...............................................................................................................4-1

4.1.1 Regulatory DQO Recommended Method ..................................................................... 4-1

4.1.2 Target MDLs and EQLs for Volatiles ....................................................................... $4-2$

4.1.3 Preparative Methods for Liquids and Solids ................................................................ 4

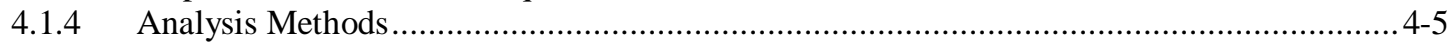

4.1.5 Modification to Regulatory DQO Recommended Method ............................................ 4-5

4.1.6 Experience with Analysis of Tank Waste Matrices ............................................................. 4-5

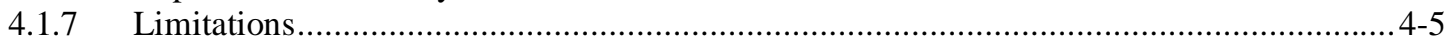

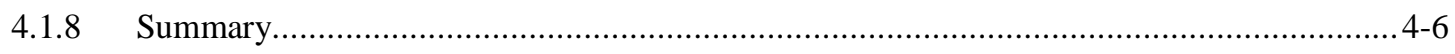

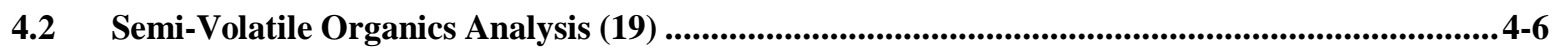

4.2.1 Regulatory DQO Recommended Method .....................................................................

4.2.2 Target MDLs and EQLs for Semivolatiles .................................................................... $4-6$

4.2.3 Preparative Methods for Liquids and Solids .................................................................. 4-7

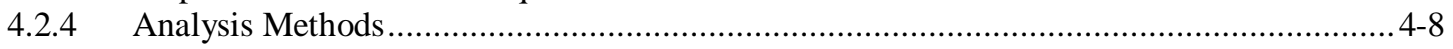

4.2.5 Modification to Regulatory DQO Recommended Method …........................................... 4-8

4.2.6 Experience with Analysis of Tank Waste Matrices .............................................................. 4-9

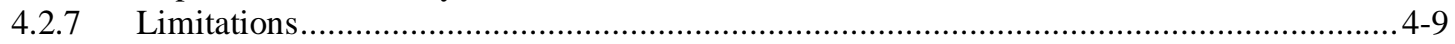

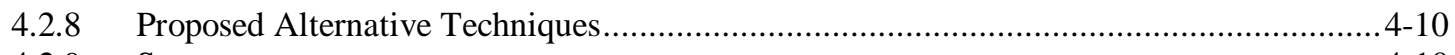

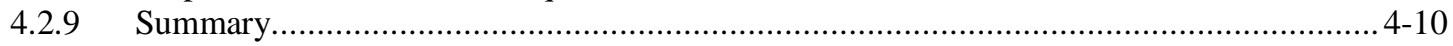




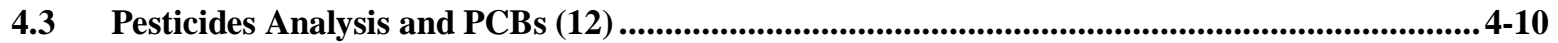

4.3.1 Regulatory DQO Recommended Method ................................................................... 4-10

4.3.2 Target MDLs and EQLs for Pesticides and PCBs .........................................................4-11

4.3.3 Preparative Methods for Liquids and Solids ................................................................. $4-11$

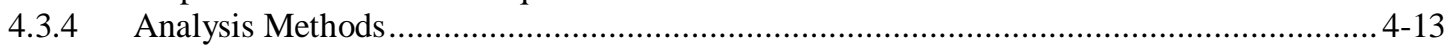

4.3.5 Modification to Regulatory DQO Recommended Method ............................................. 4-14

4.3.6 Experience with Analysis of Tank Waste Matrices.......................................................... $4-14$

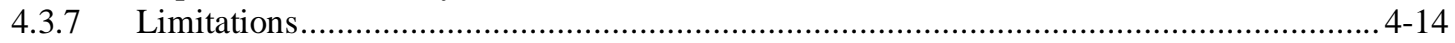

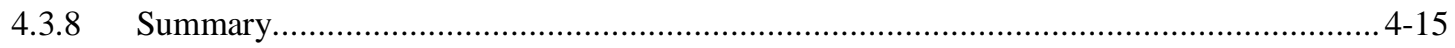

4.4 Polar Volatiles Analysis (8) .......................................................................................................................... 4-15

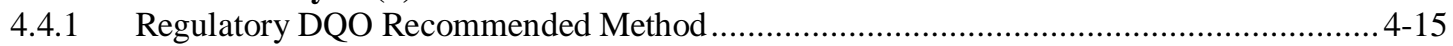

4.4.2 Target MDLs and EQLs for Polar Volatiles .................................................................. 4-15

4.4.3 Preparative Methods for Liquids and Solids ...............................................................

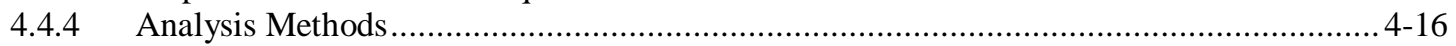

4.4.5 Modification to Regulatory DQO Recommended Method ..............................................4-17

4.4.6 Experience with Analysis of Tank Waste Matrices ........................................................... 4-18

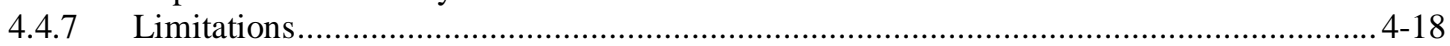

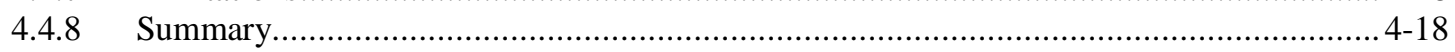

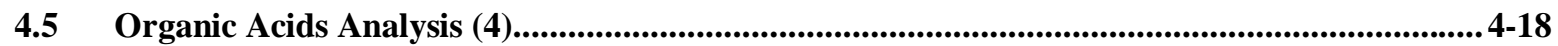

4.5.1 Regulatory DQO Recommended Method ................................................................. 4-18

4.5.2 Target MDLs and EQLs for Organic Acids ................................................................. 4-19

4.5.3 Preparative Methods for Liquids and Solids ............................................................... 4

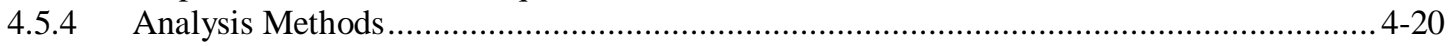

4.5.5 Modification to Regulatory DQO Recommended Method .............................................. 4-21

4.5.6 Experience with Analysis of Tank Waste Matrices .......................................................... 4-21

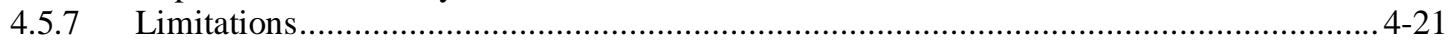

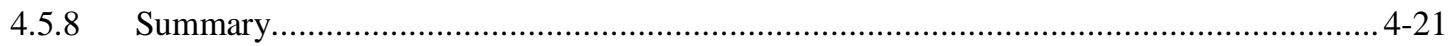

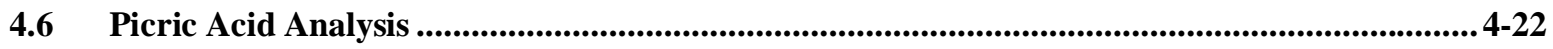

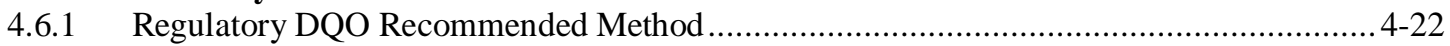

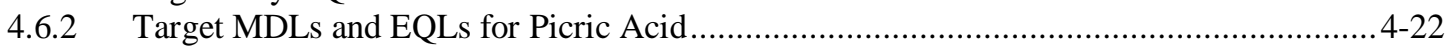

4.6.3 Preparative Methods for Liquids and Solids ...................................................... $4-22$

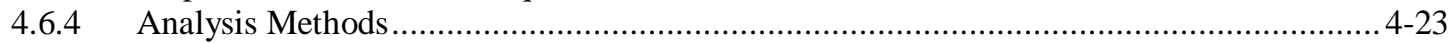

4.6.5 Modification to Regulatory DQO Recommended Method .............................................. 4-23

4.6.6 Experience with Analysis of Tank Waste Matrices.......................................................... 4-23

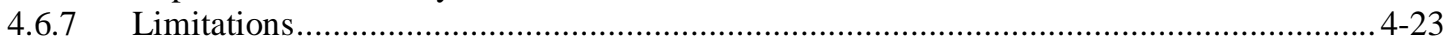

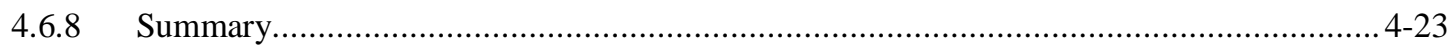

4.7 Ammonium Perfluorooctanoate and Methyl Isocyanate........................................................4-23

5.0 Inorganic Analysis........................................................................................................... 5-1

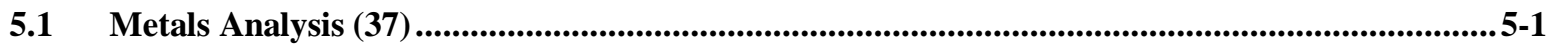

5.1.1 Regulatory DQO Recommended Method .................................................................... 5-1

5.1.2 Target MDLs and EQLs for Metals............................................................................

5.1.3 Preparative Methods for Liquids and Solids .............................................................. 5-3

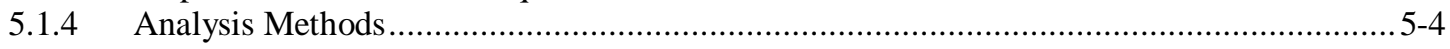

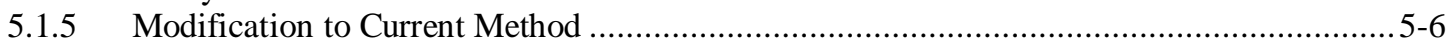

5.1.6 Experience with Analysis of Tank Waste Matrices ............................................................ 5-7

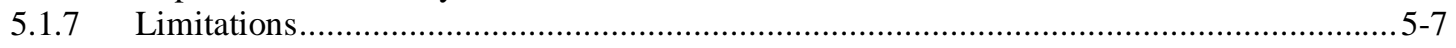

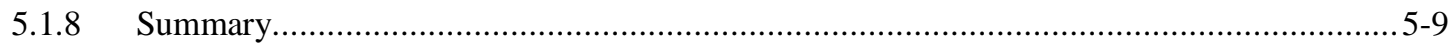

5.2 Anions Analysis (7) ..........................................................................................................................5 5-10

5.2.1 Regulatory DQO Recommended Method ……...........................................................

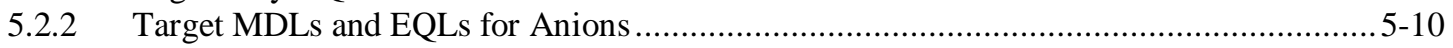

5.2.3 Preparative Methods for Liquids and Solids ............................................................. 
5.2.4 Analysis Methods

5.2.5 Modification to Regulatory DQO Recommended Method …..........................................5-12

5.2.6 Experience with Analysis of Tank Waste Matrices ............................................................5-13

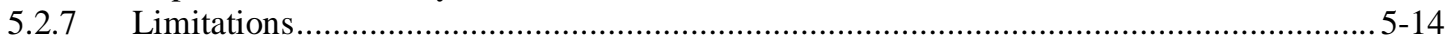

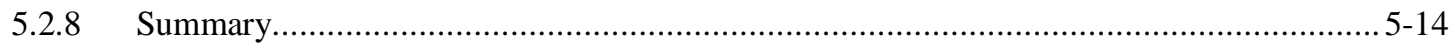

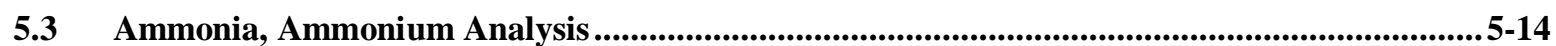

5.3.1 Regulatory DQO Recommended Method ................................................................. $5-14$

5.3.2 Target MDLs and EQLs for Ammonia/Ammonium.................................................... 5-15

5.3.3 Preparative Methods for Liquids and Solids ................................................................ $5-15$

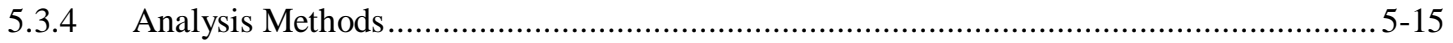

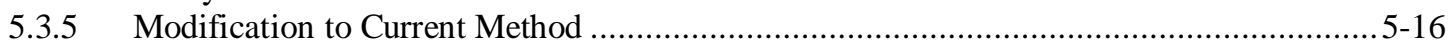

5.3.6 Experience with Analysis of Tank Waste Matrices ................................................... 5-16

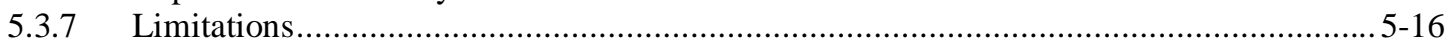

5.3.8 Summary

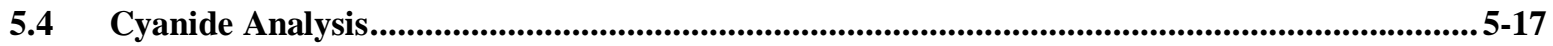

5.4.1 Regulatory DQO Recommended Method .................................................................5-17

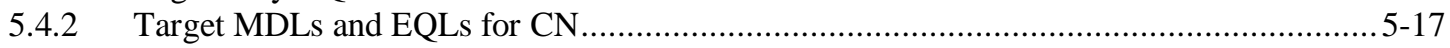

5.4.3 Preparative Methods for Liquids and Solids ................................................................ 5-18

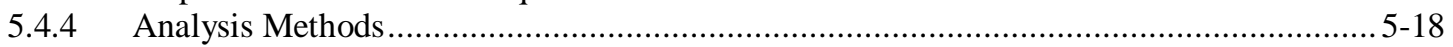

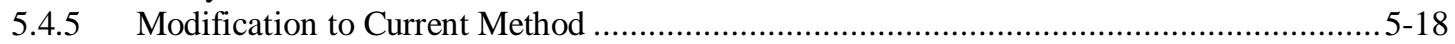

5.4.6 Experience with Analysis of Tank Waste Matrices......................................................... 5-19

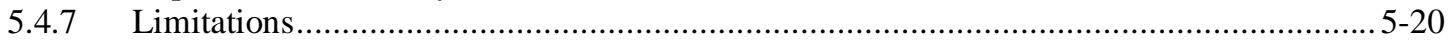

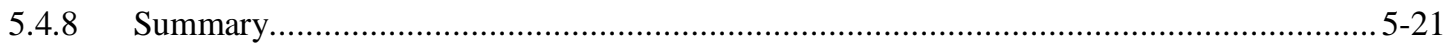

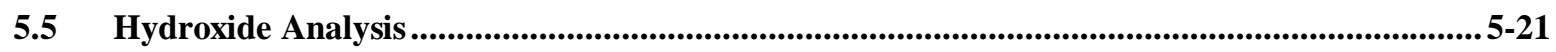

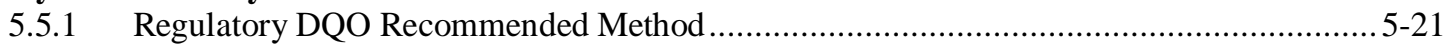

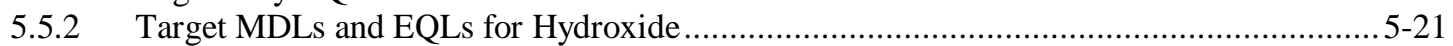

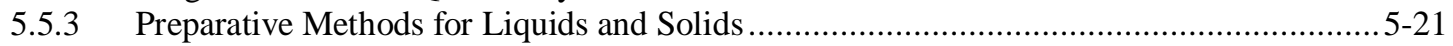

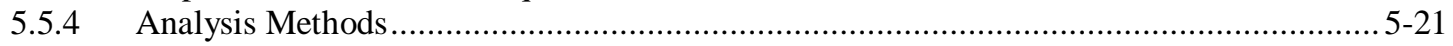

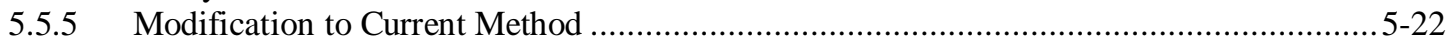

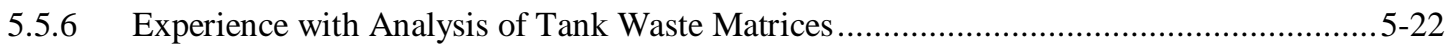

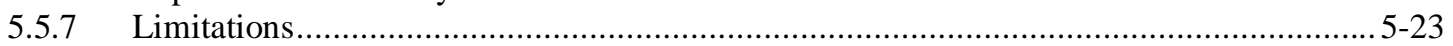

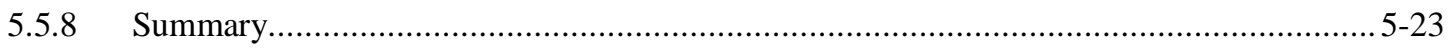

5.6 Mercury Analysis..................................................................................................................................5 5-23

5.6.1 Regulatory DQO Recommended Method .................................................................. 5-23

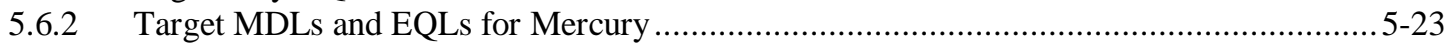

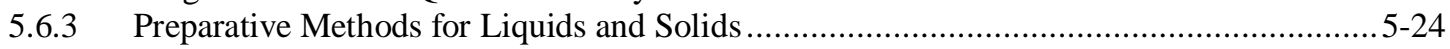

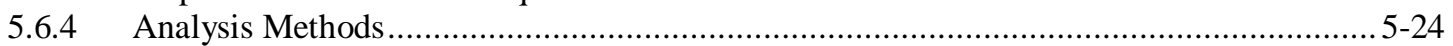

5.6.5 Modification to Regulatory DQO Recommended Method .............................................5-24

5.6.6 Experience with Analysis of Tank Waste Matrices .......................................................5-25

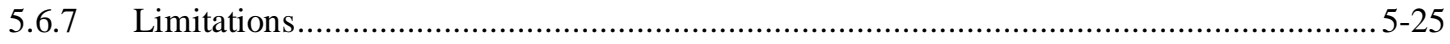

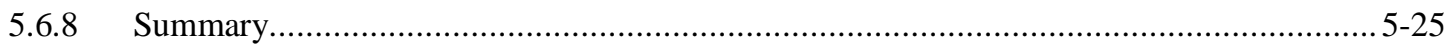

6.0 References .................................................................................................................................. 6-1

Appendix A - Summary Tables for Method and Sample Requirements..........................A.1 


\section{Tables}

Table 3-1. Inorganic Preparative QC - All Inorganic Analytical Techniques (except pH)................. 3-6

Table 3-2. Inorganic Analytical QC - All Inorganic Analytical Techniques (except pH) ................. 3-7

Table 3-3. Preparative Requirements for Volatile, Semivolatile, and Gas Chromatography (GC) QC... 3-9

Table 3-4. Analytical Requirements for Volatile, Semivolatile, and GC QC.................................... 3-10

Table 4-1. Target MDLs for Volatile Compounds as Published in SW-846 Method 8260B ................ 4-2

Table 4-2. Target EQLs for Semivolatile Compounds in Groundwater and Soil as Published in SW-846,

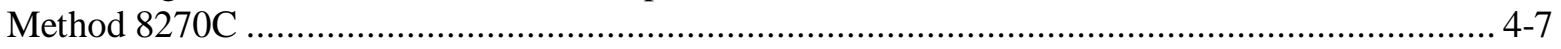

Table 4-3. Pesticides and PCBs on the Regulatory DQO Priority Compound List ............................ 4-11

Table 4-4. Polar Volatile Compounds on the Regulatory DQO Priority Compound List..................... 4-16

Table 4-5. Organic Acids on the Regulatory DQO Priority Compound List .................................. 4-19

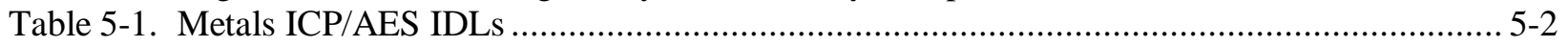

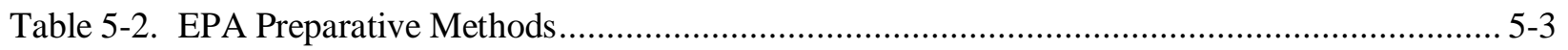

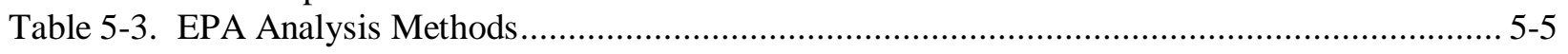

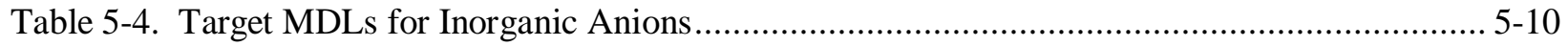

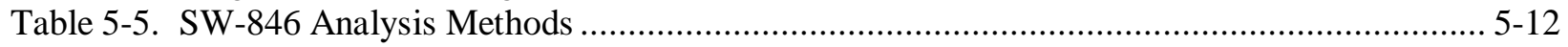

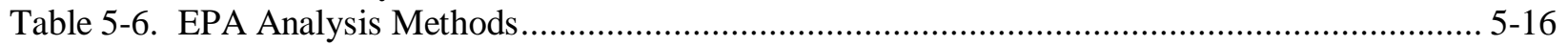

Table 5-7. CN Target MDLs as Published in Method 9010B ....................................................... 5-17

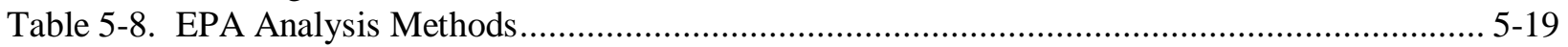

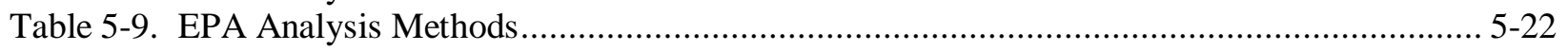

Table 5-10. Mercury Target MDL for Method 7470 and Target IDL for Method 7471A.................. 5-24

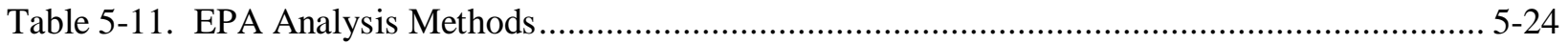




\section{Symbols, Abbreviations, Acronyms}

\begin{tabular}{|c|c|}
\hline ALARA & as low as reasonably achievable \\
\hline ASTM & American Society for Testing and Materials \\
\hline $\mathrm{BS}$ & blank spike \\
\hline $\mathrm{CCB}$ & continuing calibration blank \\
\hline $\mathrm{CCV}$ & continuing calibration verification \\
\hline CFR & Code of Federal Regulations \\
\hline CIE & capillary ion electrophoresis \\
\hline $\mathrm{CN}$ & cyanide \\
\hline $\mathrm{COC}$ & chain of custody \\
\hline CVAA & cold vapor atomic absorption \\
\hline DCB & decachlorobiphenyl \\
\hline DFTPP & decafluorotriphenylphosphine \\
\hline DI & deionized \\
\hline DOE & Department of Energy \\
\hline DQO & data quality objectives \\
\hline ECD & electron capture detector \\
\hline EDTA & ethylenediaminetetraacetic acid \\
\hline EPA & Environmental Protection Agency \\
\hline EQL & estimated quantitation limit \\
\hline FAA & flame atomic absorption \\
\hline FLAA & flame atomic absorption spectroscopy \\
\hline GC & gas chromatography \\
\hline GC/ECD & gas chromatography/electron capture detector \\
\hline GC/MS & gas chromatography/mass spectroscopy \\
\hline GFAA & graphite furnace atomic absorption \\
\hline HAS & Hanford Analytical Services \\
\hline HASQARD & Hanford Analytical Services Quality Assurance Requirements Document \\
\hline $\mathrm{HCN}$ & hydrocyanic acid \\
\hline HLW & high-level waste \\
\hline HPIC & high-pressure ion chromatography \\
\hline HR & high resolution \\
\hline
\end{tabular}




\begin{tabular}{|c|c|}
\hline IC & ion chromatography \\
\hline ICB & initial calibration blank \\
\hline $\mathrm{ICP}$ & inductively coupled plasma \\
\hline ICP/AES & inductively coupled plasma atomic emission spectroscopy \\
\hline $\mathrm{ICP} / \mathrm{MS}$ & inductively coupled plasma mass spectroscopy \\
\hline ICV & initial calibration verification \\
\hline IDL & instrument detection limit \\
\hline ISE & ion selective electrode \\
\hline LAW & low-activity waste \\
\hline LCS & laboratory control sample \\
\hline LDR & land disposal restrictions \\
\hline LLS & low-level standard \\
\hline LMW & low molecular weight \\
\hline LSD & laboratory sample duplicate \\
\hline MDL & method detection limit \\
\hline MEK & methyl ethyl ketone \\
\hline MIBK & methyl isobutyl ketone \\
\hline MS & matrix spike \\
\hline MSD & matrix spike duplicate \\
\hline NPH & normal paraffin hydrocarbons \\
\hline ORP & Office of River Protection \\
\hline PB & preparation blank \\
\hline PCB & polychlorinated biphenyl \\
\hline PCBN & pentachloronitrobenzene \\
\hline PDS & post digestion spike \\
\hline PNNL & Pacific Northwest National Laboratory \\
\hline QA & quality assurance \\
\hline QC & quality control \\
\hline RCRA & Resource Conservation and Recovery Act \\
\hline RPD & relative percent difference \\
\hline RRF & relative response factor \\
\hline RSD & relative standard deviation \\
\hline TCLP & Toxicity Characteristic Leach Procedure \\
\hline TCX & tetrachloro-m-xylene \\
\hline
\end{tabular}


TDS

TIC

UV

VOA

WAC total dissolved solids

tentatively identified compounds

ultraviolet

volatile organic analysis

Washington Administrative Code 


\subsection{Introduction}

The Regulatory Data Quality Objectives (DQO) Supporting Tank Waste Remediation System Privatization Project (Wiemers et al. 1998a) was prepared to address the regulatory data needs for waste currently stored in double-shell and single-shell tanks that was generated by the Department of Energy (DOE) and its predecessors. The need to characterize this waste is driven by

- toxicity characteristics and land disposal restrictions (LDR) under the Resource Conservation and Recovery Act (RCRA)

- treatment plant permitting

- contract requirements

- risk assessment.

In the Regulatory DQO, 125 organic compounds and 48 inorganic constituents were identified as priority regulated constituents requiring additional tank waste characterization to support the issues listed above. These compounds/constituents were identified by a methodology described in the Regulatory DQO. The Washington State Administrative Code (WAC 173-303-110) requires the use of the methods described in SW-846 (EPA 1997) to analyze many of these compounds and constituents to meet the regulatory data needs.

The U.S. Environmental Protection Agency (EPA) analytical methods have not been validated for Hanford's high-level radioactive tank waste. The methods in SW-846 have been developed to analyze water and soils. Due to the radioactivity and complex sample matrix for the tank waste, it is likely that the SW-846 methods will need to be modified or alternative methods selected as stipulated under WAC 173-303-110. For most of the compounds/constituents, minor to major modifications to the analysis methods will be required, or methods will need to be developed. Preparation methods may need modification or development to accommodate the analysis in the complex tank waste matrix. An additional challenge is analyzing radioactive waste samples, which requires balancing the need to use large samples to achieve lower detection limits and the need to keep dose rates as low as reasonably achievable (ALARA). SW-846 allows some flexibility for using other established methods that have been developed by the EPA or the American Society for Testing and Materials (ASTM). These methods will be considered when selecting methods if an appropriate SW-846 method is not available. The WAC 173-303-910 indicates that if alternative methods are required, one must explain or show with data why the SW-846 methods are not acceptable. Specific method limitations may include sample size, holding time, storage requirements, and matrix interference.

This document describes the strategy that will be used to determine method detection limits (MDLs) in water, sand, and liquid and solid waste matrices, estimated quantitation limits (EQLs) for the waste matrices, and quality assurance (QA) criteria for the methods for the 125 organic compounds and 48 inorganic constituents. Sections 2.0 through 3.0 describe general established approaches for determining MDLs, EQLs, and QA criteria. Section 4 identifies the methods that will be used for the organic compounds. Section 5 identifies the methods that will be used for the inorganic constituents. These latter two sections will discuss preparatory methods, analytical methods, minor method modifications, method limitations, past experience with a tank waste matrix, and ability to achieve target MDLs and EQLs. Table A-2 in the appendix summarizes the preparatory and analysis methods. Target MDLs and EQLs in sand and water will be based on the published MDLs and EQLs in SW-846 Methods. The published values are summarized in Tables A-3 through A-11.

The objective of this plan is to lay the foundation for initiating laboratory studies on MDL, EQL, and QA criteria determination for Step 1 of the Regulatory DQO. It is intended to only address methods that 
require minor modifications. For analytes in which adequate methods exist to meet target MDLs and EQLs, this plan describes the approach for the applicable methods and addresses minor changes in method implementation that are necessary to maintain doses ALARA. The strategy outlined in this plan is dynamic and may change as information is gathered.

This plan is a precursor to additional planning efforts that will be required. This initial strategy is needed to identify potential technical issues and determine the appropriate sample preparation and analytical methods that meet the target EQLs. They should also adequately address potential matrix interferences and sample preparation/analysis logistics. The purpose of this plan is to present results of an analysis of the adequacy of the SW-846 methodology with respect to these issues and document an agreed-upon approach to achieving the target MDLs/EQLs.

The determination of MDLs and EQLs will focus on detection and quantification of individual analytes. In this step, more detailed test plans or procedures will be developed, as appropriate, to govern laboratory work intended to determine MDLs, EQLs, and QC criteria. Based upon the agreed-to approach presented in the sections that follow, the subsequent detailed test plans will identify the procedural steps (including quality control $[\mathrm{QC}]$ ) and equipment requirements for equivalent analytical methods as required by WAC 173-303-910. Upon acceptance of the detailed test plan, laboratory work will commence, and analytical results (from the proposed methods) will be compared with available results obtained by using the SW-846 methods. This data will be used to establish method equivalency to SW-846 methods (where available) and provide the data necessary to evaluate the need to conduct a possible hold time/storage condition study as stipulated by the Regulatory DQO (Wiemers et al. 1998a). 


\subsection{Method Detection Limit and Estimated Quantitation Limit Determination}

The objective of Step 1 of the Regulatory DQO is to establish the current laboratory capability (the optimum that can be routinely performed) against the requested analytes using the stipulated SW-846 methods. Step 1 establishes the optimized performance with currently available facilities. Target MDLs have been established based on those published in SW-846. The desired target EQLs are to be established based upon the MDLs using the matrix-appropriate method-specific EQL factors from the applicable SW-846 test methods. These EQLs are to be subsequently evaluated against the regulatory requirements for overall optimization of tank waste characterization for implementing Step 2. It is expected that if the current laboratory capability is better than would be established using the SW-846 test method factors, then the better value would be used. If the SW-846 method-specific target EQLs cannot be met, then the target EQL shall be based on optimization of the existing capability.

\subsection{Analysis}

The MDL of an analyte is the minimum concentration that can be measured and reported with $99 \%$ confidence that the analyte concentration is greater than zero and is determined from analysis of a sample in a given matrix type containing the analyte. The Regulatory DQO specifies that MDLs be determined in spiked water for the liquid matrix and spiked sand for the solid matrix. For those target analytes typically present in sand (e.g., $\mathrm{Si}, \mathrm{Al}, \mathrm{Fe}$, and $\mathrm{Zr}$ ), an alternate solid matrix will be used to establish the MDLs as necessary. Analysis must show that applicable SW-846 target MDLs are achieved before determining EQLs and QC criteria.

Sand- and water-derived MDLs will be used to establish the viability of existing SW-846 methods used to characterize tank waste. Sand/water derived MDLs will represent the MDL that could be achieved with an ideal matrix and should be comparable to MDLs published in SW-846 for the applicable analysis. Since the tank waste matrix is much more complex, there will be a need to establish a matrix-specific MDL that will provide meaningful data with regards to the value reported for waste analysis. Accordingly, samples of tank waste will be spiked and a corresponding MDL will be determined that is specific to the analytical technique as it applies to the waste-specific matrix.

The approach for determining the MDL will follow the procedure presented in 40 CFR 136 Appendix B. This procedure is compliant with SW-846 methods for establishing MDLs; however, 40 CFR 136 provides the analyst with specifics that are absent from SW-846. In the selected matrix, the MDL is determined by multiplying the appropriate one-sided $99 \% \mathrm{t}$-statistic (3.14) by the standard deviation obtained from seven analyses of a matrix spike (MS) containing the analyte of interest at a concentration three to five times the estimated MDL.

An initial estimate of the detection limit is made using one of the following:

a) an instrument signal/noise ratio within the range of 2.5 to 5.0

b) the concentration equivalent of three times the standard deviation of replicate instrumental measurements of the analyte

c) the region of the standard curve where there is a significant change in sensitivity (i.e., a break in the slope of the standard curve)

d) instrumental limitations.

This estimate provides that starting point for spike levels used in preparing the matrix spike. 
The variance of the sample is determined using Equation 2-1.

$$
S^{2}=\frac{1}{n-1} \sum_{i=1}^{n}\left(x_{i}-\bar{x}\right)^{2}
$$

where:

$\mathrm{n}$ is the number of samples

$\mathrm{x}_{\mathrm{i}}$ is the $\mathrm{i}^{\text {th }}$ measurement of the variable $\mathrm{x}$

$\bar{x}$ is the average value of $x$

The average value of $\overline{\mathrm{x}}$ is determined by Equation $2-2$.

$$
\overline{\mathrm{x}}=\frac{1}{\mathrm{n}} \sum_{\mathrm{i}-1}^{\mathrm{n}} \mathrm{x}_{\mathrm{i}}
$$

The standard deviation is determined from the variance according to Equation 2-3.

$$
\mathrm{S}=\left(\mathrm{S}^{2}\right)^{1 / 2}
$$

From the variance and the t-statistic, the MDL is determined according to Equation 2-4.

$$
\mathrm{MDL}=\mathrm{t}_{(\mathrm{n}-1, \alpha=0.99)}(\mathrm{s})
$$

where:

$$
\begin{aligned}
& \mathrm{t}_{(\mathrm{n}-1, \alpha=.99)} \text { is the one-sided t-statistic appropriate for the number of } \\
& \text { samples used to determine (s), at the } 99 \text { percent level. }
\end{aligned}
$$

Determination of a matrix-specific MDL may not be feasible for certain constituents that are in excess of the recommended range for MDL determination (e.g., concentration is greater than the specified instrument signal/noise; concentration corresponds to a point well above the standard calibration curve where there is a significant change in sensitivity). In situations where the amount of constituent " $X$ " in the waste matrix exceeds 10 times the MDL of the analyte in reagent water, the MDL shall not be reported. This is based on direction provided by 40 CFR 136 Appendix B.

\subsection{EQL Analysis}

The EQL is defined as the lowest concentration that can be reliably achieved within specified limits of precision and accuracy during routine laboratory operating conditions. Sample EQLs are highly matrixdependent. The EQL in a simple matrix is generally a factor of 5 to 10 times the MDL (i.e., the matrix factor equals 5 to 10). Reported values from analysis of the tank sample shall be deemed acceptable provided the required QA criteria are met.

The target EQLs provide a starting point for evaluating SW-846 methods (preparation and analysis) for adequacy. In some cases, minor SW-846 method modification will be required to achieve the desired EQLs. Final EQLs will be determined as defined by SW-846, based on the analytical work to be performed in support of the Regulatory DQO and the technical expertise of the scientist. 


\subsection{Quality Assurance Criteria Determination}

The work performed under this test plan will be conducted in accordance with the Regulatory DQO quality assurance requirements. Various quality-control samples that can be used to ensure control over the laboratory, sample preparation, and analysis are described in the following sections. These definitions are in agreement with those in the Hanford Analytical Services Quality Assurance Requirements Document (HASQARD) (DOE 1998). The application of these samples to various types of methods is also discussed. For some methods, control limits have already been established through experience with running the method on tank waste matrixes.

\subsection{Quality-Control Samples}

To assess the precision, accuracy, and sensitivity of a reported result, QC checks are incorporated throughout the data-collection process (e.g., sample preparation/separation, analysis, reporting) to provide a measurement tool for evaluating the effectiveness of the process and to show process control. Quality control checks provide information with regard to performance of the measurement system and environmental as well as matrix-related impacts on the measurement system.

\subsubsection{Preparation Blank}

The sample preparation blank (PB) or method blank is used to monitor contamination resulting from the sample-preparation process. The PB is generally distilled or deionized (DI) water, which is subjected to the same processing as the samples, including all reagent additions. The laboratory is also free to use a matrix more closely related to the actual samples processed, provided the matrix is free of contamination from analytes of interest (e.g., clean soil or sand for solid matrices). Interferences and/or unique ancillary contaminants produced by the blank matrix would be expected to be similar to that of the sample.

The PB volume or weight shall be approximately equal to the sample weight or volume being processed and shall be presented in the same context as the samples. Preparation or method blanks shall be prepared with each batch of samples processed at the same time.

\subsubsection{Laboratory Control Sample}

A laboratory control sample (LCS) or blank spike (BS) is used to monitor the effectiveness of the samplepreparation process. The LCS is a material similar in nature to the sample being processed containing the analyte(s) of interest (e.g., standard reference material). A LCS, if available, shall be prepared with each batch of samples processed at the same time. The BS is distilled or DI water or other suitable substrate spiked with the analytes(s) of interest. A BS is normally used when an appropriate LCS is unavailable.

\subsubsection{Matrix Spike}

A MS is a waste sample that has been spiked with the analyte(s) of interest and processed in the same manner as the samples in the sample set. The MS is used to monitor method performance in a specific sample matrix. The MS results are a measure of the accuracy in the measurement of the analyte(s) of interest present in the sample matrix.

When the sample concentration is unknown, spiking is typically performed at one of the following levels: 1) equivalent to the regulatory threshold, 2) specified by method, or 3) 1 to 5 times the EQL. Otherwise, the spiking should be performed at a level equivalent to 1 to 2 times that of the sample. When the 
concentration of the analyte in the original sample is greater than $0.1 \%$, no MS is required unless specified.

The MS can also be used to evaluate the bias of a method. Bias is a systematic error inherent in a method or caused by some artifact or idiosyncrasy of the measurement system. Bias can be assessed by comparing a measured value to an accepted reference value in a sample of known concentration or by determining the recovery of a known amount of contaminant spiked into a sample. Thus the bias, caused by matrix effects, as reflected by the MS is calculated as follows:

$$
\mathrm{B}=\left(\mathrm{x}_{\mathrm{s}}-\mathrm{x}_{\mathrm{u}}\right)-\mathrm{K}
$$

where:

$\mathrm{x}_{\mathrm{s}}$ is the measured value of the spiked sample

$\mathrm{x}_{\mathrm{u}}$ is the sample or miscellaneous contribution

$\mathrm{K}$ is the known value of spike added.

If no sample or miscellaneous contributions exist, $\mathrm{x}_{\mathrm{u}}$ would be zero.

\subsubsection{Laboratory Sample Duplicate or Matrix Spike Duplicate}

Laboratory sample duplicates (LSDs) are two aliquots of the same sample (intra-laboratory split) that are taken through the entire process of preparing and analyzing samples. Laboratory duplicates are used to assess the precision of the preparation and analysis process in a specific matrix.

The matrix spike duplicates (MSDs) are two spiked aliquots of the same sample that are taken through the entire process of preparing and analyzing samples. In cases where the sample is not expected to contain reasonable concentrations (analyte concentrations greater than ten times the instrument detection limit [IDL]) of the analytes of interest, duplicate sample results will not provide a reliable estimate of precision. In these cases, MSDs are used to demonstrate analytical precision in the sample.

The IDL is calculated statistically like an MDL; however, it is determined on samples of spiked reagent water containing each analyte of concern that have not be subjected to preliminary preparation. The MDL would be determined on samples that are subjected to procedures for preparing samples.

The degree of agreement between duplicates indicates reproducibility of the combined preparation/separation and measurement process (precision). Precision is expressed as either the percent relative standard deviation (RSD) or the relative percent difference (RPD).

\subsubsection{Percent Relative Standard Deviation}

The percent RSD, which is used when there are at least three measurements, is calculated as follows:

$$
\% \mathrm{RSD}=\frac{\mathrm{s}}{\mathrm{x}} * 100 \%
$$

where:

$\mathrm{s}$ is the standard deviation with $\mathrm{n}-1$ degrees of freedom $(\mathrm{n}=$ total number of observed values)

$\overline{\mathrm{X}}$ is the mean of observed values. 


\subsubsection{Relative Percent Difference}

The RPD is used when two measurements exist. The RPD expresses the precision of duplicates and is calculated as follows:

$$
\mathrm{RPD}=\frac{\left|\mathrm{x}_{1}-\mathrm{x}_{2}\right|}{\overline{\mathrm{x}}} * 100 \%
$$

where:

$\mathrm{x}_{1,2}$ is the observed values of measurements 1 and 2 , respectively

$\overline{\mathrm{x}}$ is the mean of observed values

\subsubsection{Initial Calibration Verification}

The initial calibration verification (ICV) analytical standard is used to confirm the accuracy of the calibration and the standards used for calibration. Acceptable performance of the ICV demonstrates that both the standards used and the instrument are functioning properly. The ICV is prepared from a source other than that used to prepare the calibration standards.

\subsubsection{Continuing Calibration Verification}

The continuing calibration verification (CCV) analytical standard is used to monitor instrument stability over time. Acceptable performance demonstrates continued appropriateness of the calibration, indicating that the system is still in control. The CCV may be prepared from any reliable source and need not be nationally or internationally traceable. The ICV standard may also be used as the CCV.

\subsubsection{Initial Calibration Blank and Continuing Calibration Blank}

Initial calibration blank (ICB) and continuing calibration blank (CCB) monitor effects such as contamination and instrument-response drift during routine operations. The ICB and CCB are reagent blanks, prepared similarly to the standards, but not subjected to preliminary sample preparation except for techniques in which the preparation is an integral part of the analysis. In these cases, the PB or method blank can be considered the equivalent of the ICB or CCB. The generally accepted criteria for these blanks are that they are below the EQL for each analyte of interest.

For inorganic compounds, each ICV shall be followed by an ICB, and each subsequent CCV shall be followed by a CCB. This protocol indicates potential carry-over effects (carry over of residual material from one sample to the next in the sequence).

\subsubsection{Internal Standards}

An internal standard, which is used in inorganic analysis, is an analyte that is similar to the analyte(s) of interest in terms of its analytical response, but which is not normally expected in the sample. Internal standards are added to every standard, blank, matrix spike, matrix spike duplicate, and sample before analysis. Internal standards are used as the basis for quantitation of the target analytes of interest.

Internal standards are routinely used in inductively coupled plasma/atomic emission spectrometry (ICP/AES) and inductively coupled plasma/mass spectroscopy (ICP/MS) analysis, although they may be appropriate to other types of analysis. 


\subsubsection{Low-Level Standard}

The low-level standard (LLS) is used to monitor instrument performance in the region at or near the EQL and is routinely applied to inorganic systems to monitor sensitivity in the EQL region.

For inductively coupled plasma (ICP) spectrometry systems, the LLS should be prepared at approximately two times the EQL. The majority of other inorganic techniques employ an LLS that is at or near the EQL. In those cases where it is used as part of instrument calibration, a separate LLS is not required.

\subsubsection{Interference Check Standards}

Interference check standards are typically applied in ICP systems (e.g., ICP and ICP/MS). Section 5.1.7 further discusses interferences in ICP systems. The interference check normally consists of two standards. The first standard contains known concentrations of the major interfering elements that will provide an adequate test of inter-element correction factors. The second standard contains both the major interferents and the majority of other analytes tested. The major interferents are spiked into the standards at concentrations that are expected to produce an interference effect. All other analytes are spiked at relatively low levels. Data from both standards, when corrected, should recover between $80 \%$ and $120 \%$ for all analytes tested or the inter-element correction is considered inadequate. The first standard, containing only the major interferents of concern, should produce no analyte concentration whose absolute value is in excess of the EQL. Instruments capable of showing negative results do not require the second standard that contains both interferents and additional analytes tested.

\subsubsection{Analytical Spike}

An analytical spike is a spike that is added to the sample just before analysis (i.e., after preparation). It differs from the MS where the spike is added to the sample before preparing the sample. The analytical spike is used to gauge instrument and sample-matrix performance during the measurement process. Typically, a very small quantity of spike is added, so no significant change occurs in sample volume or matrix effects. The concentration spiked should equal $50 \%$ to $100 \%$ of the sample analyte concentration or approximately two times the EQL if no analyte is expected or the concentration is unknown.

Analytical spikes are required for graphite furnace atomic absorption analysis. They are also used for other analysis, such as uranium by laser fluorimetry, to help determine potential interference effects. The analytical spike is essentially the same as a post digestion spike (PDS). However, because the analytical spike is applied to all samples whereas the PDS is applied exclusively to the MS sample, different nomenclature is applied.

\subsubsection{Post Digestion Spike}

For inorganic analytes of interest, a PDS is a spike added to the sample after preliminary preparation, usually just before analysis. The PDS is used to indicate matrix-related interference on the analytical system that may still be present in the sample following digestion. The PDS is normally used when an MS failure occurs. This technique is typically used for ICP analysis, but is appropriate to other analyses as well.

The PDS performance can be used to identify problems caused by sample-matrix effects during preparation and/or measurement. In the case of unusual matrix effects only during the preparation step, the MS will fail, but the PDS will pass. If both the MS and PDS fail, the failure is due to matrix effects in both the preparation and measurement steps. 


\subsubsection{Serial Dilution}

Serial dilution is used when new or unusual matrices are encountered as an indicator of potential matrixrelated interference associated with analysis. It is simply a five-fold dilution of a sample (after all preparation steps are complete) followed by analysis. Serial dilution is only performed when a sufficient number of target analyte concentrations exceed 50 times the IDL in the sample. When sample analyte concentration is less than 50 times the IDL, an analytical spike should be performed.

The serial dilution is designed to indicate potential problems, such as high solids effects, that can impact sample uptake, resulting in analyte-measurement differences. For Hanford tank waste, serial dilution may be used as a means of ensuring that the dose to the analyst is ALARA. In such cases, serial dilution alone may not be a sufficient indicator of matrix interferences (e.g., target analyte concentrations might not exceed 50 times the IDL). Additional sample preparation to remove the interfering compounds may be required. This is discussed in more detail in subsequent sections of this plan.

\subsubsection{Method of Standard Additions}

The method of standard additions consists of a blank and at least three standards to which aliquots of the sample are added. The standards used should be approximately $50 \%, 100 \%$, and $150 \%$ of the expected sample concentration. The method of standard additions can be used in lieu of instrument calibration because each sample essentially has its own calibration. The method of standard additions is meant to compensate for a sample-matrix effect that enhances or depresses analyte signals.

\subsubsection{Surrogates - Organic Analyses}

A surrogate, which is used in organic analyses, is a compound that is expected to respond to the preparation and measurement system in a manner similar to the analyte that it is representing. Surrogates are added to all samples (both waste samples and QC samples) before preparation. The surrogate is typically similar in chemical composition to the compound or analyte being determined, yet not normally encountered in most samples.

\subsection{Control Limits}

Control limits define acceptable performance of the QC samples. They are used with control charts, which provide a means to trend laboratory performance over time. The MS and LCS recoveries are usually monitored via control charts. For organic analysis, surrogate recoveries can also be tracked with control charts. SW-846 recommends the use of control charts, but does not require them.

For new analysis methods, the following steps can establish control limits for the QA sample recoveries:

1. Obtain a group of repeated measurements from analyzing an MS, a surrogate, or an LCS for which control limits are to be prepared. A group of no less than 7 and preferably 15 measurements is needed to obtain initial estimates for control statistics. These measurements shall be performed on different days and at a minimum of half-day intervals.

2. Calculate the average $(\overline{\mathrm{x}})$ recoveries for the group.

3. Calculate the standard deviation(s) for the series.

4. Calculate the upper and lower warning and control limits as follows: 


$$
\begin{aligned}
& \text { Warning Limits }=\overline{\mathrm{x}} \pm 2 \mathrm{~s} \\
& \text { Control Limits }=\overline{\mathrm{x}} \pm 3 \mathrm{~s}
\end{aligned}
$$

Using the limits calculated above, a control chart can be prepared with control lines corresponding to the average and the upper and lower warning and control limits. Each measurement of recovery is plotted on the chart in the order obtained, beginning with the original measurements used to calculate the controlchart limits. The control-chart limits shall be recalculated when major system changes occur.

For these control charts, there is a chance that 1 result out of 20 will exceed the warning limits and only 3 results out of 1000 will randomly exceed the control limits. If results exceed the warning limits more frequently than 1 in 20, then a systematic error exists (provided only the upper or lower limit has been crossed), or the random error has increased if both warning limits have been exceeded haphazardly.

\subsection{Method-Specific QC}

Tables 3-1 through 3-4 describe the typical QC samples used for each analytical method. Both preparative and analytical QC samples are described and include the frequency, acceptance criteria, and action to be taken in the event of failure. These criteria agree with the criteria published in the individual $\mathrm{SW}-846$ methods when criteria are provided. When criteria are not provided specifically in an SW-846 method, they are adapted from other methods because many of the criteria are the same from method to method.

New methods would employ the same QC samples and similar target levels. The capability to meet the QC criteria would need to be determined statistically. The method for determining the acceptance criteria would be similar to determining a control limit (see "Control Limits" above).

Table 3-1. Inorganic Preparative QC - All Inorganic Analytical Techniques (except pH)

\begin{tabular}{|l|l|l|l||}
\hline \multicolumn{1}{|c|}{ QC Samples } & \multicolumn{1}{|c|}{ Frequency } & \multicolumn{1}{c|}{ Acceptance Criteria } & \multicolumn{1}{c|}{ Failure Action } \\
\hline PB & 1 per batch & <EL & $\begin{array}{l}\text { Investigate. Determine usability } \\
\text { by evaluating against analyte } \\
\text { concentration in sample. Re- } \\
\text { prepare, as appropriate. }\end{array}$ \\
\hline BS $^{(\text {a) }}$ & 1 per batch & $80 \%$ to $120 \%$ & $\begin{array}{l}\text { Investigate. Re-prepare for failed } \\
\text { analytes. }\end{array}$ \\
\hline LCS & 1 per batch & $\begin{array}{l}\text { Vendor specs/regulatory } \\
\text { requirements/statistical }\end{array}$ & $\begin{array}{l}\text { Investigate. Re-prepare for failed } \\
\text { analytes. }\end{array}$ \\
\hline $\begin{array}{l}\text { Duplicate } \\
\text { (including MSD) }\end{array}$ & 1 per batch & $\begin{array}{l} \pm 20 \% \text { RPD, when result } \\
10 \text { times IDL }\end{array}$ & Investigate. Discuss in narrative. \\
\hline MS & 1 per batch & $75 \%$ to $125 \%$ recovery & $\begin{array}{l}\text { Investigate. Post spike for ICP and } \\
\text { Spectroscopy (FLAA) for failed } \\
\text { analyte. Discuss in narrative. }\end{array}$ \\
\hline
\end{tabular}

(a) Techniques where the ICV analytical standard (ICV) is prepared with the samples; the ICV can serve as the blank spike. 
Table 3-2. Inorganic Analytical QC - All Inorganic Analytical Techniques (except pH)

\begin{tabular}{|c|c|c|c|}
\hline QQC Samples & Frequency & Acceptance Criteria & Failure Action \\
\hline \multicolumn{4}{|c|}{ Inductively Coupled Plasma Spectrometer and Flame Atomic Absorption (FLAA) } \\
\hline $\mathrm{ICV}$ & $\begin{array}{l}\text { Immediately after } \\
\text { calibration } \\
\text { (typically mid- } \\
\text { range) }\end{array}$ & $90 \%$ to $110 \%$ & $\begin{array}{l}\text { Investigate failure for analytes of } \\
\text { interest. Recalibrate for analytes } \\
\text { of interest. }\end{array}$ \\
\hline ICB & After ICV & $<$ EQL & $\begin{array}{l}\text { Investigate failure for analytes of } \\
\text { interest. Recalibrate for analytes } \\
\text { of interest. }\end{array}$ \\
\hline $\mathrm{CCV}$ & $\begin{array}{l}\text { After every } 10 \\
\text { samples and at the } \\
\text { end of analytical } \\
\text { run }\end{array}$ & $90 \%$ to $110 \%$ & $\begin{array}{l}\text { Investigate failure for analytes of } \\
\text { interest. Recalibrate for analytes of } \\
\text { interest. Reanalyze samples, as } \\
\text { appropriate. }\end{array}$ \\
\hline $\mathrm{CCB}$ & After every CCV & $<\mathrm{EQL}$ & $\begin{array}{l}\text { Investigate failure for analytes of } \\
\text { interest. Recalibrate for analytes } \\
\text { of interest. Reanalyze samples, as } \\
\text { appropriate. }\end{array}$ \\
\hline LLS & $\begin{array}{l}\text { Immediately after } \\
\text { ICB }\end{array}$ & $75 \%$ to $125 \%$ & Investigate. Discuss in narrative. \\
\hline $\begin{array}{l}\text { Interference } \\
\text { check standard } \\
\text { (ICP only) }\end{array}$ & $\begin{array}{l}\text { After ICB and just } \\
\text { before last CCV }\end{array}$ & $80 \%$ to $120 \%$ & Investigate. Reanalyze all samples. \\
\hline Serial dilution & $\begin{array}{l}\text { One per batch as } \\
\text { required or needed }\end{array}$ & $\begin{array}{c}=10 \% \text { difference, when } \\
\text { analyte } 10 \text { times EQL after } \\
5 \text {-fold dilution }\end{array}$ & Investigate. Discuss in narrative. \\
\hline Post spike & $\begin{array}{l}\text { MS fails or new } \\
\text { and/or unusual } \\
\text { matrix is being } \\
\text { analyzed }\end{array}$ & $75 \%$ to $125 \%$ & Investigate. Discuss in narrative. \\
\hline \multicolumn{4}{|c|}{ ICP/MS } \\
\hline $\mathrm{ICV}$ & $\begin{array}{l}\text { Immediately after } \\
\text { calibration } \\
\text { (typically mid- } \\
\text { point region) }\end{array}$ & $90 \%$ to $110 \%$ & $\begin{array}{l}\text { Investigate failure for analytes of } \\
\text { interest. Correct. Recalibrate for } \\
\text { analytes of interest. }\end{array}$ \\
\hline $\mathrm{CCV}$ & $\begin{array}{l}\text { Every } 10 \text { samples } \\
\text { and at the end of } \\
\text { the run }\end{array}$ & $90 \%$ to $110 \%$ & $\begin{array}{l}\text { Investigate failure for analytes of } \\
\text { interest. Correct. Recalibrate for } \\
\text { analytes of interest. }\end{array}$ \\
\hline ICB & After ICV & $<\mathrm{EQL}$ & $\begin{array}{l}\text { Investigate failure for analytes of } \\
\text { interest. Correct. Recalibrate for } \\
\text { analytes of interest. }\end{array}$ \\
\hline $\mathrm{CCB}$ & After each CCV & $<\mathrm{EQL}$ & $\begin{array}{l}\text { Investigate failure for analytes of } \\
\text { interest. Correct. Recalibrate for } \\
\text { analytes of interest. }\end{array}$ \\
\hline $\begin{array}{l}\text { Interference } \\
\text { check standard }\end{array}$ & $\begin{array}{l}\text { After ICV and ICB } \\
\text { and every } 12 \mathrm{~h}\end{array}$ & $\begin{array}{c}\text { Monitor for interference that } \\
\text { will impact samples }\end{array}$ & $\begin{array}{l}\text { Investigate. } \\
\text { Correct/Reanalyze/Flag. }\end{array}$ \\
\hline
\end{tabular}




\begin{tabular}{|c|c|c|c|}
\hline QC Samples & Frequency & Acceptance Criteria & Failure Action \\
\hline Serial dilution & $\begin{array}{l}\text { One per batch of } \\
\text { samples prepared } \\
\text { or when internal } \\
\text { standard criteria } \\
\text { failure occurs }\end{array}$ & $\begin{array}{l} \pm 10 \% \text { difference when } \\
\text { analyte } 100 \text { times IDL }\end{array}$ & $\begin{array}{l}\text { Investigate for analyst error. } \\
\text { Discuss performance in narrative. }\end{array}$ \\
\hline Post spike & $\begin{array}{l}\text { When MS fails or } \\
\text { when new or } \\
\text { unusual matrix is } \\
\text { encountered }\end{array}$ & $75 \%$ to $125 \%$ & $\begin{array}{l}\text { Investigate for analyst error. } \\
\text { Discuss performance in narrative. }\end{array}$ \\
\hline Internal standard & $\begin{array}{l}\text { Every sample, QC } \\
\text { sample, blank, and } \\
\text { standard }\end{array}$ & $30 \%$ to $120 \%$ & $\begin{array}{l}\text { Perform serial dilution. Evaluate. } \\
\text { Correct/Report. }\end{array}$ \\
\hline \multicolumn{4}{|c|}{ Ion Chromatography (IC) for Anions } \\
\hline $\mathrm{ICV}^{(\mathrm{a})}$ & $\begin{array}{l}\text { Immediately after } \\
\text { calibration (typically } \\
\text { mid-range) }\end{array}$ & $95 \%$ to $105 \%$ & Investigate. Recalibrate. \\
\hline ICB & After ICV & $<\mathrm{EQL}$ & Investigate. Recalibrate. \\
\hline $\mathrm{CCV}$ & $\begin{array}{l}\text { After every } 10 \\
\text { samples and at the } \\
\text { end of analytical run }\end{array}$ & $95 \%$ to $105 \%$ & $\begin{array}{l}\text { Investigate. Recalibrate. Re- } \\
\text { prepare and reanalyze samples, as } \\
\text { appropriate. }\end{array}$ \\
\hline $\mathrm{CCB}$ & After every CCV & $<\mathrm{EQL}$ & $\begin{array}{l}\text { Investigate. Recalibrate. } \mathrm{Re}- \\
\text { prepare and reanalyze samples, as } \\
\text { appropriate. }\end{array}$ \\
\hline \multicolumn{4}{|c|}{ Mercury, Cold Vapor Atomic Absorption (CVAA) } \\
\hline $\mathrm{ICV}^{(\mathrm{a})}$ & $\begin{array}{l}\text { Immediately after } \\
\text { calibration (typically } \\
\text { mid-range) }\end{array}$ & $90 \%$ to $110 \%$ & Investigate. Recalibrate. \\
\hline ICB & After ICV & $<\mathrm{EQL}$ & Investigate. Recalibrate. \\
\hline $\mathrm{CCV}$ & $\begin{array}{l}\text { After every } 10 \\
\text { samples and at the } \\
\text { end of analytical run }\end{array}$ & $90 \%$ to $110 \%$ & $\begin{array}{l}\text { Investigate. Recalibrate. Re- } \\
\text { prepare and reanalyze samples, as } \\
\text { appropriate. }\end{array}$ \\
\hline $\mathrm{CCB}$ & After every CCV & $<\mathrm{EQL}$ & $\begin{array}{l}\text { Investigate. Recalibrate. Re- } \\
\text { prepare and reanalyze samples, as } \\
\text { appropriate. }\end{array}$ \\
\hline LLS & After ICV and ICB & $75 \%$ to $125 \%$ & Investigate. Discuss in narrative. \\
\hline \multicolumn{4}{|c|}{$\begin{array}{l}\text { Cyanide (CN) (All techniques) } \\
\end{array}$} \\
\hline $\mathrm{ICV}^{(\mathrm{a})}$ & $\begin{array}{l}\text { Immediately after } \\
\text { calibration (typically } \\
\text { mid-range) }\end{array}$ & $85 \%$ to $115 \%$ & Investigate. Recalibrate. \\
\hline ICB & After ICV & $<\mathrm{EQL}$ & Investigate. Recalibrate. \\
\hline $\mathrm{CCV}$ & $\begin{array}{l}\text { After every } 10 \\
\text { samples and at end } \\
\text { of analytical run }\end{array}$ & $85 \%$ to $115 \%$ & $\begin{array}{l}\text { Investigate. Recalibrate. Reanalyze } \\
\text { samples, as appropriate. }\end{array}$ \\
\hline $\mathrm{CCB}$ & After every CCV & $<\mathrm{EQL}$ & $\begin{array}{l}\text { Investigate. Recalibrate. Reanalyze } \\
\text { samples, as appropriate. }\end{array}$ \\
\hline LLS & After ICB & $90 \%$ to $110 \%$ & Investigate. Discuss in narrative. \\
\hline
\end{tabular}




\begin{tabular}{|c|c|c|c|}
\hline QQC Samples & Frequency & Acceptance Criteria & Failure Action \\
\hline \multicolumn{4}{|c|}{ Ion Specific Electrode, Spectrophotometric, and Titrimetric (e.g., Ammonia Hexavalent Chromium) } \\
\hline $\mathrm{ICV}$ & $\begin{array}{l}\text { Immediately after } \\
\text { calibration }\end{array}$ & $90 \%$ to $110 \%$ & Investigate. Recalibrate. \\
\hline ICB & After ICV & $<\mathrm{EQL}$ & Investigate. Recalibrate. \\
\hline $\mathrm{CCV}$ & $\begin{array}{l}\text { After every } 10 \\
\text { Samples for } \\
\text { working-curve } \\
\text { technique; at the end } \\
\text { of the run for all } \\
\text { other techniques }\end{array}$ & $\begin{array}{c}\text { Based on long-term } \\
\text { statistical performance }\end{array}$ & Rerun all samples since last valid. \\
\hline $\mathrm{CCB}$ & After each CCV & $<\mathrm{EQL}$ & Rerun all samples since last valid. \\
\hline
\end{tabular}

(a) If the ICV is representative of the sample matrix and prepared with the samples, then the ICV may be used as both the BS and ICV.

Table 3-3. Preparative Requirements for Volatile, Semivolatile, and Gas Chromatography (GC) QC

\begin{tabular}{||l|l|l|l||}
\hline \multicolumn{1}{|c|}{$\begin{array}{c}\text { QC } \\
\text { Requirements }\end{array}$} & \multicolumn{1}{|c|}{ Frequency } & \multicolumn{1}{c||}{ Acceptance Criteria } & \multicolumn{1}{c||}{ Failure Action } \\
\hline PB & One per batch of 20 & <QL & $\begin{array}{l}\text { Investigate. Correct. Reprepare } \\
\text { as required. }\end{array}$ \\
\hline $\begin{array}{l}\text { BS } \\
\text { or } \\
\text { LCS }\end{array}$ & $\begin{array}{l}\text { One per batch } \\
\text { (Blank, spiked with } \\
\text { surrogate) }\end{array}$ & $\begin{array}{l}70-130 \% \text { recovery (initial } \\
\text { target). } \\
\text { Develop control limits using } \\
15-20 \text { samples. }\end{array}$ & $\begin{array}{l}\text { Investigate. Correct. Reprepare } \\
\text { as required. }\end{array}$ \\
\hline $\begin{array}{l}\text { MS and MSD } \\
\text { (Pccuracy) }\end{array}$ & One set per batch & $\begin{array}{l}70-130 \% \text { recovery (initial } \\
\text { target) } \\
\text { Develop control limits using } \\
15-20 \text { samples. }\end{array}$ & $\begin{array}{l}\text { Investigate. Confirm matrix } \\
\text { effect. Discuss in narrative. }\end{array}$ \\
\hline Surrogate & Each sample, QC & $\begin{array}{l}\text { Analytes are within } \\
\text { established control limits. } \\
\text { Control limits are established } \\
\text { by one of the following: } \\
\text {-specified by regulatory } \\
\text { requirement } \\
\text {-statistically determined by } \\
\text { multiple analyses (15-20) } \\
\text { over time. }\end{array}$ & $\begin{array}{l}\text { Investigate. Correct. Reprepare } \\
\text { as required. }\end{array}$ \\
\hline
\end{tabular}


Table 3-4. Analytical Requirements for Volatile, Semivolatile, and GC QC

\begin{tabular}{|c|c|c|c|}
\hline $\begin{array}{c}\text { QC } \\
\text { Requirements } \\
\end{array}$ & Frequency & Criteria & Failure Action \\
\hline \multicolumn{4}{|c|}{ Volatile (Gas Chromatography/Mass Spectrometry [GC/MS]) } \\
\hline Tune & $\begin{array}{l}\text { Once on a 12-h } \\
\text { clock }\end{array}$ & $\begin{array}{l}\text { Decafluorotriphenylphos- } \\
\text { phine (DFTPP) }{ }^{(\text {a) }} \text { mass } \\
\text { intensity criteria or } \\
\text { manufacturer's instructions }\end{array}$ & Investigate. Correct. \\
\hline $\mathrm{CCV}$ & $\begin{array}{l}\text { Once on a 12-h } \\
\text { clock }\end{array}$ & $\begin{array}{l} \pm 15 \% \text { of initial calibration } \\
\text { response }\end{array}$ & Investigate. Correct. Reanalyze. \\
\hline Internal standard & $\begin{array}{l}\text { Each sample, QC } \\
\text { sample, blank, and } \\
\text { standard }\end{array}$ & $\begin{array}{l}\text { Generally, area counts } \\
\text { falling }<50 \% \text { or }>150 \% \text { of } \\
\text { original area counts in the } \\
\text { continuing calibration } \\
\text { standard are considered } \\
\text { unacceptable. }\end{array}$ & $\begin{array}{l}\text { Investigate. Reanalyze or } \\
\text { reprepare as appropriate. }\end{array}$ \\
\hline $\begin{array}{l}\text { Qualitative } \\
\text { identification }\end{array}$ & Each sample & $\begin{array}{l}\text { Compare to spectra } \\
\text { generated and retention } \\
\text { times }\end{array}$ & $\begin{array}{l}\text { Report any unusual circumstance } \\
\text { in narrative. }\end{array}$ \\
\hline Quantitation & $\begin{array}{l}\text { Each sample. See } \\
\text { also Section } 3.1 \text { for } \\
\text { surrogate and } \\
\text { internal standard. }\end{array}$ & $\begin{array}{l}\text { Calculate off continuing } \\
\text { calibration }\end{array}$ & $\begin{array}{l}\text { Report any unusual circumstance } \\
\text { in narrative. }\end{array}$ \\
\hline \multicolumn{4}{|c|}{ Semivolatile (GC/MS) } \\
\hline Tune & $\begin{array}{l}\text { Once on a 12-h } \\
\text { clock }\end{array}$ & $\begin{array}{l}\text { DFTPP mass intensity } \\
\text { criteria or manufacturer's } \\
\text { instructions. }\end{array}$ & Investigate. Correct. \\
\hline $\mathrm{CCV}$ & $\begin{array}{l}\text { Once on a 12-h } \\
\text { clock }\end{array}$ & $\begin{array}{l} \pm 15 \% \text { of initial calibration } \\
\text { response }\end{array}$ & Investigate. Correct. Reanalyze. \\
\hline Internal standard & $\begin{array}{l}\text { Each sample, QC } \\
\text { sample, blank, and } \\
\text { standard }\end{array}$ & $\begin{array}{l}\text { Generally, area counts } \\
\text { falling }<50 \% \text { or } 150 \% \text { of } \\
\text { original area counts in the } \\
\text { continuing calibration } \\
\text { standard are considered } \\
\text { unacceptable. }\end{array}$ & $\begin{array}{l}\text { Investigate. Reanalyze or } \\
\text { reprepare as appropriate. }\end{array}$ \\
\hline $\begin{array}{l}\text { Qualitative } \\
\text { identification }\end{array}$ & Each sample & $\begin{array}{l}\text { Compare to spectra } \\
\text { generated and retention } \\
\text { times }\end{array}$ & $\begin{array}{l}\text { Report any unusual circumstance } \\
\text { in narrative. }\end{array}$ \\
\hline Quantitation & $\begin{array}{l}\text { Each sample. See } \\
\text { also Calibration } \\
\text { Requirements for } \\
\text { Organic Analyses } \\
\text { for surrogate and } \\
\text { internal standard. }\end{array}$ & $\begin{array}{l}\text { Calculate off continuing } \\
\text { calibration }\end{array}$ & $\begin{array}{l}\text { Report any unusual circumstance } \\
\text { in narrative. }\end{array}$ \\
\hline \multicolumn{4}{|c|}{ Method 8081A - Pesticides by GC } \\
\hline ICV & $\begin{array}{l}\text { Before beginning } \\
\text { 12-h shift }\end{array}$ & $\begin{array}{l} \pm 15 \% \text { of initial calibration } \\
\text { response }\end{array}$ & Investigate. Correct. Reanalyze \\
\hline
\end{tabular}




\begin{tabular}{|c|c|c|c|}
\hline $\begin{array}{c}\text { QC } \\
\text { Requirements }\end{array}$ & Frequency & Criteria & Failure Action \\
\hline $\mathrm{CCV}$ & $\begin{array}{l}\text { Following } \\
\text { calibration and } \\
\text { routinely during run } \\
\text { (at least every } 20 \\
\text { samples) }\end{array}$ & $\begin{array}{l} \pm 15 \% \text { of initial calibration } \\
\text { response }\end{array}$ & Investigate. Correct. Reanalyze \\
\hline $\mathrm{CCB}$ & \begin{tabular}{l|} 
Periodically, \\
following \\
continuing \\
calibration blank
\end{tabular} & $\begin{array}{l}\text { Evaluate for carry-over and } \\
\text { contamination }\end{array}$ & Investigate. Correct. Reanalyze \\
\hline Internal standard & $\begin{array}{l}\text { Each sample, QC } \\
\text { sample, blank, and } \\
\text { standard }\end{array}$ & $\begin{array}{l}\text { Generally, area counts } \\
\text { falling }<50 \% \text { or }>150 \% \text { of } \\
\text { original area counts in the } \\
\text { continuing calibration } \\
\text { standard are considered } \\
\text { unacceptable. } \\
\end{array}$ & $\begin{array}{l}\text { Investigate. Reanalyze or } \\
\text { reprepare as appropriate. }\end{array}$ \\
\hline \multicolumn{4}{|c|}{ Method 8082 - Polychlorinated Biphenyls (PCBs) by GC } \\
\hline $\mathrm{ICV}$ & $\begin{array}{l}\text { Before beginning } \\
\text { 12-h shift }\end{array}$ & $\begin{array}{l} \pm 15 \% \text { of initial calibration } \\
\text { response }\end{array}$ & \\
\hline $\mathrm{CCV}$ & $\begin{array}{l}\text { Following } \\
\text { calibration and } \\
\text { routinely during run } \\
\text { (at least every } 20 \\
\text { samples) } \\
\end{array}$ & $\begin{array}{l} \pm 15 \% \text { of initial calibration } \\
\text { response }\end{array}$ & Investigate. Correct. Reanalyze \\
\hline $\mathrm{CCB}$ & \begin{tabular}{l|} 
Periodically, \\
following \\
continuing \\
calibration blank
\end{tabular} & $\begin{array}{l}\text { Evaluate for carryover and } \\
\text { contamination }\end{array}$ & Investigate. Correct. Reanalyze \\
\hline Internal standard & $\begin{array}{l}\text { Each sample, QC } \\
\text { sample, blank, and } \\
\text { standard }\end{array}$ & $\begin{array}{l}\text { Generally, area counts } \\
\text { falling }<50 \% \text { or }>150 \% \text { of } \\
\text { original area counts in the } \\
\text { continuing calibration } \\
\text { standard are considered } \\
\text { unacceptable. }\end{array}$ & $\begin{array}{l}\text { Investigate. Reanalyze or } \\
\text { reprepare as appropriate. }\end{array}$ \\
\hline $\begin{array}{l}\text { QC Reference } \\
\text { samples }\end{array}$ & $\begin{array}{l}\text { Every } 20 \text { samples } \\
\text { or once per batch is } \\
\text { less than } 20 \\
\text { samples }\end{array}$ & $80-120 \%$ recovery & $\begin{array}{l}\text { Investigate. Reanalyze or } \\
\text { reprepare as appropriate. }\end{array}$ \\
\hline
\end{tabular}

(a) DFTTP is a compound used for tuning GC/MS 


\subsection{Organic Analysis}

In this section, six individual organic analysis methods and their respective preparatory methods are described. Each section provides a summary of the SW-846 method and minor modifications that will be made to the methods to accommodate the tank waste matrix. Also included is a list of the compounds that will be analyzed by the specified method. A number provided in parenthesis after the subsection title indicates the number of Regulatory DQO priority compounds that will be determined by the method. Experience with tank waste analysis is also described.

Two compounds, ammonium perfluorooctanoate, and methyl isocyanate, on the Regulatory DQO priority compounds list are not addressed by this test plan because they would require major methods modification or methods development, which is outside the scope of this test plan. For these compounds and others identified through the work defined by this test plan, methods development will be conducted under a separate approved test plan. Additional information on ammonium perfluorooctanoate and methyl isocyanate is provided in Section 4.7.

\subsection{Volatile Organics Analysis (79)}

\subsubsection{Regulatory DQO Recommended Method}

The Regulatory DQO suggests Method 8260B "Volatile Organic Compounds By Gas Chromatography/Mass Spectrometry (GC/MS)," for analysis of the volatile compounds (see Table 4-1). Method $8260 \mathrm{~B}$ is used to analyze volatile organic compounds that have boiling points below $200^{\circ} \mathrm{C}$. The volatile compounds are prepared for injection into the gas chromatograph by one of six preparation methods listed in Method 8260B or by direct injection. The compounds are introduced to a wide-bore capillary column or cryofocussed on a capillary pre-column before being flash evaporated to a narrowbore capillary for analysis. The column temperature dictates separation of compounds in the column. From the column, the compounds are introduced to the MS by a jet separator or direct connection. Compounds are identified by comparing their mass spectra with the electron ionization spectra of authentic standards. Compounds are quantified by comparing the response of a major ion relative to an internal standard using a five-point calibration curve.

Of the 79 volatile compounds listed in the Regulatory DQO, 28 are not listed in Method 8260B. For these, Method $8260 \mathrm{~B}$ can be adapted for their analysis. The 28 volatile compounds are indicated in Table 4-1. For five compounds listed in Table 4-1 (1,4-dichlorobenzene, 1,3-dichlorobenzene, o-dichlorobenzene, 1,2,4-trichlorobenzene, and hexachlorobutadiene), Method 8270C, the method for measurement of semivolatiles, is the Regulatory DQO recommended technique. SW-846 lists these compounds in both Method 8260B and 8270C. Another five compounds-tetrahydrofuran; cyclopentane; nitric acid, propyl ester; 1,1-dimethylhydrazine; and methylhydrazine- have Method 8270C as their recommended method in the Regulatory DQO; however, these compounds are not listed in either SW-846 method. Method 8260B will be used for all of these compounds because it produces lower MDLs and EQLs and because the analysis experience with Method 8260B for analyzing these compounds has produced encouraging purge efficiencies (Klinger et al. 2000, Lucke et al. 1993, Hoppe et al. 1992). Triethylamine, for which the Regulatory DQO recommends Method 8260B, will be measured with the polar volatile organic compounds (Section 4.4). 


\subsubsection{Target MDLs and EQLs for Volatiles}

Table 4-1 presents the target MDLs for the volatile organic compounds as listed in SW-846 Method $8260 \mathrm{~B}$ for a $25-\mathrm{mL}$ sample. The sample matrix (liquid or solids) was not specified in the method. The method provides values for analysis on wide- and narrow-bore capillary columns. The EQL for 5-mL groundwater samples is expected to be $5 \mu \mathrm{g} / \mathrm{L}$ when using the purge and trap method and $5 \mu \mathrm{g} / \mathrm{kg}$ for soils. The matrix factor for waste samples is estimated by the method to be 50 for a liquid waste matrix and 125 for a solid waste matrix. For compounds in which Method 8260B does not provide an MDL, it is assumed that acceptable MDLs for the sand or water matrix will be on the same order of magnitudes as those in Table 4-1.

Table 4-1. Target MDLs for Volatile Compounds as Published in SW-846 Method 8260B

\begin{tabular}{|c|c|c|c|}
\hline & & Wide-Bore $^{(\mathbf{a})}$ & Narrow-Bore ${ }^{(a)}$ \\
\hline $\begin{array}{l}\text { CAS } \\
\text { Registry } \\
\text { Number }\end{array}$ & Compound & $\begin{array}{l}\text { Target MDL } \\
(\mu \mathrm{g} / \mathrm{L})\end{array}$ & $\begin{array}{l}\text { Target MDL } \\
(\mu \mathrm{g} / \mathrm{L})\end{array}$ \\
\hline \multicolumn{4}{|c|}{ Compounds Listed in SW-846, Method 8260B } \\
\hline $100-41-4$ & Ethyl benzene (F003) & 0.06 & 0.03 \\
\hline $100-42-5$ & Styrene & 0.04 & 0.27 \\
\hline 10061-01-5 & cis-1,3-Dichloropropene & N/A & N/A \\
\hline $10061-02-6$ & trans-1,3-Dichloropropene & N/A & N/A \\
\hline $106-42-3$ & p-Xylene (Dimethyl benzene) (F003) & 0.13 & 0.06 \\
\hline $106-46-7$ & 1,4-Dichlorobenzene (D027) & 0.03 & 0.04 \\
\hline $106-93-4$ & Ethylene dibromide (Dibromoethane) & 0.06 & 0.10 \\
\hline $107-02-8$ & Acrolein & N/A & N/A \\
\hline $107-05-1$ & 3-Chloropropene (Allyl chloride) & N/A & N/A \\
\hline $107-06-2$ & $\begin{array}{l}\text { 1,2-Dichloroethane (Ethylene } \\
\text { chloride) (D028) }\end{array}$ & 0.06 & 0.02 \\
\hline $107-12-0$ & Propionitrile & N/A & N/A \\
\hline $107-13-1$ & Acrylonitrile & N/A & N/A \\
\hline $107-87-9$ & 2-Pentanone & N/A & N/A \\
\hline $108-10-1$ & $\begin{array}{l}\text { Hexone (4-Methyl-2-pentanone or } \\
\left.\text { MIBK }^{(b)}\right)(\text { F003) }\end{array}$ & N/A & N/A \\
\hline $108-38-3$ & m-Xylene (Dimethyl benzene) (F003) & 0.05 & 0.03 \\
\hline $108-88-3$ & Toluene (F005) & 0.11 & 0.08 \\
\hline $108-90-7$ & Chlorobenzene (D021, F002) & 0.04 & 0.03 \\
\hline $120-82-1$ & 1,2,4-Trichlorobenzene & 0.04 & 0.20 \\
\hline 123-91-1 & 1,4-Dioxane & N/A & N/A \\
\hline $126-98-7$ & $\begin{array}{l}\text { 2-Methyl-2-propenenitrile } \\
\text { (Methacrylonitrile) }\end{array}$ & N/A & N/A \\
\hline $127-18-4$ & $\begin{array}{l}\text { Perchloroethylene } \\
\text { (tetrachloroethylene) (D039, F001, } \\
\text { F002) }\end{array}$ & N/A & N/A \\
\hline
\end{tabular}




\begin{tabular}{|c|c|c|c|}
\hline & & Wide-Bore $^{(\mathbf{a})}$ & Narrow-Bore (a) $^{(a)}$ \\
\hline $\begin{array}{c}\text { CAS } \\
\text { Registry } \\
\text { Number }\end{array}$ & Compound & $\begin{array}{l}\text { Target MDL } \\
(\mu \mathrm{g} / \mathrm{L})\end{array}$ & $\begin{array}{l}\text { Target MDL } \\
(\mu \mathrm{g} / \mathrm{L})\end{array}$ \\
\hline $141-78-6$ & $\begin{array}{l}\text { Acetic acid ethyl ester (Ethyl acetate) } \\
\text { (F003) }\end{array}$ & N/A & N/A \\
\hline $4170-30-3$ & $\begin{array}{l}\text { 2-Butenaldehyde (2-Butenal or } \\
\text { Crotonaldehyde) }\end{array}$ & N/A & N/A \\
\hline $541-73-1$ & 1,3-Dichlorobenzene & 0.12 & 0.05 \\
\hline $56-23-5$ & Carbon tetrachloride (D019, F001) & 0.21 & 0.02 \\
\hline $591-78-6$ & 2-Hexanone & N/A & N/A \\
\hline 67-64-1 & 2-Propanone (Acetone) (F003) & N/A & N/A \\
\hline $67-66-3$ & Chloroform (D022) & 0.03 & 0.04 \\
\hline $71-43-2$ & Benzene (D018, F005) & 0.04 & 0.03 \\
\hline $71-55-6$ & $\begin{array}{l}\text { Methyl chloroform }(1,1,1- \\
\text { Trichloroethane) (F001, F002) }\end{array}$ & 0.08 & 0.04 \\
\hline 74-83-9 & Bromomethane (Methyl bromide) & 0.11 & 0.03 \\
\hline $74-87-3$ & Chloromethane (Methyl chloride) & 0.13 & 0.05 \\
\hline $75-00-3$ & Chloroethane & 0.10 & N/A \\
\hline $75-01-4$ & $\begin{array}{l}\text { Vinyl chloride (1-Chloroethene) } \\
\text { (D043) }\end{array}$ & 0.17 & 0.04 \\
\hline $75-05-8$ & Acetonitrile & N/A & N/A \\
\hline $75-09-2$ & $\begin{array}{l}\text { Dichloromethane (Methylene } \\
\text { chloride) (F001, F002) }\end{array}$ & 0.03 & N/A \\
\hline $75-15-0$ & Carbon disulfide (F005) & N/A & N/A \\
\hline $75-21-8$ & Ethylene oxide (Oxirane) & N/A & N/A \\
\hline $75-34-3$ & 1,1-Dichloroethane & 0.04 & 0.03 \\
\hline $75-35-4$ & $\begin{array}{l}\text { 1,1-Dichloroethene (Vinylidene } \\
\text { chloride) (D029) }\end{array}$ & 0.12 & N/A \\
\hline $75-69-4$ & Trichlorofluoromethane (F001, F002) & 0.08 & N/A \\
\hline $75-71-8$ & Dichlorodifluoromethane & 0.10 & 0.11 \\
\hline $78-87-5$ & 1,2-Dichloropropane & 0.04 & 0.02 \\
\hline $78-93-3$ & $\begin{array}{l}\text { Methyl ethyl ketone (MEK, 2- } \\
\text { Butanone) (D035, F005) }\end{array}$ & N/A & N/A \\
\hline $79-00-5$ & 1,1,2-Trichloroethane (F002) & 0.01 & 0.08 \\
\hline $79-01-6$ & $\begin{array}{l}\text { Trichloroethylene (D040, F001, } \\
\text { F002) }\end{array}$ & N/A & N/A \\
\hline $79-34-5$ & 1,1,2,2-Tetrachloroethane & 0.04 & 0.20 \\
\hline $87-68-3$ & Hexachlorobutadiene (D033) & 0.11 & 0.10 \\
\hline $95-47-6$ & o-Xylene (F003) & 0.11 & 0.06 \\
\hline $95-50-1$ & $\begin{array}{l}\text { o-Dichlorobenzene }(1,2- \\
\text { Dichlorobenzene) (F002) }\end{array}$ & 0.03 & 0.05 \\
\hline \multicolumn{4}{|c|}{ Compounds not listed in SW-846 Method 8260B } \\
\hline $106-35-4$ & 3-Heptanone & N/A & N/A \\
\hline $106-97-8$ & Butane & N/A & N/A \\
\hline
\end{tabular}




\begin{tabular}{|c|c|c|c|}
\hline & & Wide-Bore $^{(a)}$ & Narrow-Bore $^{(a)}$ \\
\hline $\begin{array}{c}\text { CAS } \\
\text { Registry } \\
\text { Number }\end{array}$ & Compound & $\begin{array}{l}\text { Target MDL } \\
(\mu \mathrm{g} / \mathrm{L})\end{array}$ & $\begin{array}{l}\text { Target MDL } \\
(\mu \mathrm{g} / \mathrm{L})\end{array}$ \\
\hline $106-99-0$ & 1,3-Butadiene & N/A & N/A \\
\hline $108-87-2$ & Methylcyclohexane & N/A & N/A \\
\hline 108-94-1 & Cyclohexanone (F003) & N/A & N/A \\
\hline $109-66-0$ & n-Pentane & N/A & N/A \\
\hline $109-99-9$ & Tetrahydrofuran & N/A & N/A \\
\hline $110-12-3$ & 5-Methyl-2-hexanone & N/A & N/A \\
\hline $110-43-0$ & 2-Heptanone & N/A & N/A \\
\hline $110-54-3$ & n-Hexane & N/A & N/A \\
\hline $110-82-7$ & Cyclohexane & N/A & N/A \\
\hline $110-83-8$ & Cyclohexene & N/A & N/A \\
\hline $111-65-9$ & n-Octane & N/A & N/A \\
\hline $111-84-2$ & n-Nonane & N/A & N/A \\
\hline $123-19-3$ & 4-Heptanone & N/A & N/A \\
\hline $123-38-6$ & n-Propionaldehyde & N/A & N/A \\
\hline $123-86-4$ & Acetic acid n-butyl ester & N/A & N/A \\
\hline $142-82-5$ & n-Heptane & N/A & N/A \\
\hline $287-92-3$ & Cyclopentane & N/A & N/A \\
\hline $563-80-4$ & 3-Methyl-2-butanone & N/A & N/A \\
\hline $57-14-7$ & 1,1-Dimethylhydrazine & N/A & N/A \\
\hline $60-34-4$ & Methylhydrazine & N/A & N/A \\
\hline $627-13-4$ & Nitric acid, propyl ester & N/A & N/A \\
\hline $684-16-2$ & Hexafluoroacetone & N/A & N/A \\
\hline $75-43-4$ & Dichlorofluoromethane & N/A & N/A \\
\hline $75-45-6$ & Chlorodifluoromethane & N/A & N/A \\
\hline 76-13-1 & $\begin{array}{l}\text { 1,2,2-Trichloro-1,1,2-trifluoroethane } \\
\text { (Freon 113) (F002) }\end{array}$ & N/A & N/A \\
\hline $76-14-2$ & $\begin{array}{l}\text { 1,2-Dichloro-1,1,2,2- } \\
\text { tetrafluoroethane }\end{array}$ & N/A & N/A \\
\hline $96-22-0$ & 3-Pentanone & N/A & N/A \\
\hline
\end{tabular}

(a) Wide and Narrow Bore refer to the type of capillary used to introduce the sample into the equipment.

(b) MIBK = methyl isobutyl ketone

$\mathrm{N} / \mathrm{A}=$ Not available. Method 8260B does not provide an MDL for this compound.

\subsubsection{Preparative Methods for Liquids and Solids}

The samples, both supernatants and solids, are diluted with organic-free water from 3-fold to 10-fold to a final volume of approximately $5 \mathrm{~mL}$ in special disposable dual septa-sealed purge vessels that are used to avoid sample loss. The volatile compounds are purged from the samples with helium onto a multi-bed 
absorbent trap using a commercial purge-and-trap sample concentrator and autosampler. The trapped volatiles are then thermally desorbed onto a $75-\mathrm{m}$ by $0.45-\mathrm{mm}$ DB-624 column $(2.55$-micron film) that is directly interfaced to the mass spectrometer. With the exception of flow path and headspace restrictions, this preparation method is analogous to SW-846 Method 5030B, "Purge-and-Trap for Aqueous Samples" for liquids and Method 5035 "Closed System Purge-and-Trap and Extraction For Volatile Organics In Solid and Waste Samples" for solids. A minor modification in the method is smaller sample sizes for ALARA. Maintaining sealed vials and ensuring sufficient purge volumes compensates for the increased headspace.

\subsubsection{Analysis Methods}

The samples will be analyzed using SW-846 Method 8260B. The analysis system for volatiles includes the equipment used for the sample preparation that is described above (i.e., autosampler, purge-and-trap system, and GC/MS system).

If chromatographic peaks, which are not target analytes, are present and are sufficiently abundant (10\% or greater of the total ion response of the nearest internal standard), then the peak is tentatively identified and the results reported based on the guidance provided in Method 8260B, Section 7.6.2. Requirements of the project QA plan will also be followed regarding the reporting of this data (i.e. caveats are placed on the data using flags including the uncertainty associated with the data).

It is anticipated that the target MDLs and EQLs published in Method 8260B can be met for the sand and water matrix.

\subsubsection{Modification to Regulatory DQO Recommended Method}

Minor modifications will be made to the SW-846 preparative methods (SW-846 Methods 5030B and 5035) used for the liquid and the solid samples. These modifications include use of smaller sample sizes because of ALARA concerns, temperature of sample during purge, $\mathrm{pH}$, flowpath, headspace restrictions, or other minor changes to enhance or render the method practical for radioactive samples. There are no major modifications to the preparative or analytical method (Method 8260B) anticipated.

\subsubsection{Experience with Analysis of Tank Waste Matrices}

Volatile compounds have been analyzed in samples from waste in tanks AW101, AN107, C104, and other tanks (Klinger et al. 2000; Lucke et al. 1993; Hoppe et al. 1992). The procedures discussed above have proven to be relatively reliable for analyzing volatiles. However, the focus of this work was not the determination of MDLs or EQLs.

\subsubsection{Limitations}

Triethylamine can be analyzed by Method 8260B; however, better results are obtained if Method 8075 is used. Limitations of Method 8260B include problems with chromatography and carryover of this compound due to polarity, relatively high boiling point, and other unknown factors. Triethylamine should be analyzed as a polar volatile by SW-846 Method 8075, 5031, or 5032 (to be determined, refer to Polar Volatiles (Section 4.4) discussion). 


\subsubsection{Summary}

The method for analyzing and preparing samples may require minor modifications, such as reducing the sample size for ALARA. The target MDLs listed in Table 4-1 are achievable in the sand and water matrix. Quality control criteria listed in Tables 3-3 and 3-4 should be met.

\subsection{Semi-Volatile Organics Analysis (19)}

\subsubsection{Regulatory DQO Recommended Method}

The Regulatory DQO suggests Method 8270C, "Semivolatile Organic Compounds By Gas Chromatography/Mass Spectrometry," for analysis of the semivolatile compounds (see Table 4-2) with the exception of 2-sec-butyl-4,6-dinitrophenol (Dinoseb). While Dinoseb is listed in the 8270C compound list, the Regulatory DQO recommends Method 8151A. For Method 8270C, the semivolatile compounds are prepared to be injected into the GC by one of six preparation methods listed in Method $8270 \mathrm{C}$ or by direct injection. The compounds are introduced to a narrow-bore fused-silica capillary column. The column temperature dictates separation of compounds in the column. From the column, the compounds are introduced to the mass spectrometer by a jet separator or direct connection. Compounds are identified by comparing their mass spectra with the electron ionization spectra of authentic standards. Compounds are quantified by comparing the response of a major ion relative to an internal standard using a five-point calibration curve.

Method 8151A is a GC method for determining chlorinated acid herbicides in aqueous, soil, and waste matrices. This method provides instruction for extracting and derivatizing the chlorinated acid herbicides before injecting them into a GC. Samples are extracted and esterified with either diazomethane or pentafluorobenzyl bromide before being injected into the gas chromatograph. The method contains provisions for using a GC/MS as well.

Of the 19 semivolatile compounds listed in the Regulatory DQO, 7 are not listed in Method 8270C. For these, the Regulatory DQO suggests Method $8270 \mathrm{C}$ as a method that can be adapted for their analysis. These compounds are indicated in Table 4-2.

\subsubsection{Target MDLs and EQLs for Semivolatiles}

Table 4-2 presents the target EQLs for the semivolatile organic compounds as published in SW-846 Method 8270C. The soil/sediment EQLs are based on 30-g samples. The volume of sample for the groundwater EQLs is not specifically stated; however, it is assumed to be $1 \mathrm{~L}$, based on the quantity of sample needed for the preparatory procedures. Method 8270C states that typical EQLs are $660 \mu \mathrm{g} / \mathrm{kg}$ for wet soil/sediment samples, $10 \mu \mathrm{L}$ for groundwater, and 1 to $100 \mathrm{mg} / \mathrm{Kg}(1,000$ to $10,000 \mu \mathrm{g} / \mathrm{kg})$ for wastes. These values will be used for target EQLs if none are specifically provided in Method 8270C. Method 8270C does not provide target MDLs. 
Table 4-2. Target EQLs for Semivolatile Compounds in Groundwater and Soil as Published in SW-846, Method 8270C

\begin{tabular}{|c|c|c|c|}
\hline \multirow{2}{*}{\multicolumn{2}{|c|}{$\begin{array}{c}\text { CAS } \\
\text { Registry } \\
\text { Number }\end{array}$}} & Groundwater & Soil/Sediment \\
\hline & & $\begin{array}{l}\text { Target EQL } \\
(\mu \mathrm{g} / \mathrm{L})\end{array}$ & $\begin{array}{c}\text { Target EQL } \\
(\mu \mathrm{g} / \mathrm{kg})\end{array}$ \\
\hline \multicolumn{4}{|c|}{ Compounds Listed in SW-846, Method 8270C } \\
\hline $100-25-4$ & 1,4-Dinitrobenzene & 40 & N/A \\
\hline $108-95-2$ & Phenol & 10 & 660 \\
\hline $110-86-1$ & Pyridine (D038, F005) & N/A & N/A \\
\hline $122-39-4$ & N,N-Diphenylamine & N/A & N/A \\
\hline $50-32-8$ & Benzo(a)pyrene & 10 & 660 \\
\hline $53-70-3$ & Dibenzo(a,h)anthracene & 10 & 660 \\
\hline $62-75-9$ & $\begin{array}{l}\text { N-Nitroso-N,N-dimethylamine } \\
\text { (Dimethylnitrosamine) }\end{array}$ & N/A & N/A \\
\hline $82-68-8$ & $\begin{array}{l}\text { Pentachloronitrobenzene (PCBN or } \\
\text { quintobenzene) }\end{array}$ & 20 & N/A \\
\hline $87-86-5$ & Pentachlorophenol (D037) & 50 & 3300 \\
\hline $88-85-7$ & $\begin{array}{l}\text { 2-sec-Butyl-4,6-dinitrophenol } \\
\text { (Dinoseb) }\end{array}$ & 20 & N/A \\
\hline $98-86-2$ & Acetophenone & 10 & N/A \\
\hline $98-95-3$ & Nitrobenzene (D036, F004) & 10 & 660 \\
\hline \multicolumn{4}{|c|}{ Compounds not listed in SW-846 Method 8270C } \\
\hline $100-00-5$ & p-Nitrochlorobenzene & N/A & N/A \\
\hline $126-73-8$ & Tributyl phosphate & N/A & N/A \\
\hline $128-37-0$ & 2,6-Bis(tert-butyl)-4-methylphenol & N/A & N/A \\
\hline $1321-64-8$ & Pentachloronaphthalene & N/A & N/A \\
\hline $1335-87-1$ & Hexachloronaphthalene & N/A & N/A \\
\hline $1335-88-2$ & Tetrachloronaphthalene & N/A & N/A \\
\hline $92-52-4$ & 1,1`-Biphenyl & N/A & N/A \\
\hline
\end{tabular}

N/A = Not available. Method 8270C does not provide an MDL for this compound.

\subsubsection{Preparative Methods for Liquids and Solids}

The preparative method used for liquid samples is SW-846 Method 3510C, "Separatory Funnel LiquidLiquid Extraction," with minor modifications. The preparative method for solid samples is SW-846 Method 3550B, "Ultrasonic Extraction," with minor modifications. Before performing the single extraction process for the semivolatile compounds, aliquots of the supernatants and the solids (mixed with DI water) are titrated with phosphoric acid. The resulting titration curves are used to establish the quantity of phosphoric acid required to adjust the extracting $\mathrm{pH}$ to the level defined by the procedure (approximately 6.5) (Stromatt et al. 1993).

For each supernatant sample extracted, a known quantity of sample is transferred into a Teflon separatory funnel. Appropriate spikes, internal standards, and surrogates are added to the samples before subjecting the samples to the extraction process. Each supernatant sample is extracted with three portions of 
methylene chloride by subjecting the separatory funnel to mechanical shaking. The sample quantity used is dependent on ALARA concerns, and will be smaller than the quantities specified in the SW-846 methods. The amount of extraction solvent used will be proportionally equivalent to the quantity specified in the SW-846 method. Following this initial extraction, the supernatant is chilled in ice and stirred while the $\mathrm{pH}$ is adjusted with a predetermined quantity of phosphoric acid determined from the titration curve developed for the sample. If significant precipitates form, they are separated from the supernatant by centrifuging and decanting. The extraction process is repeated on the $\mathrm{pH}$-adjusted supernatant. The precipitated solids are further extracted using three portions of methylene chloride. All extracts from the supernatant sample (including extracts from any precipitated solids) are combined and passed through a column containing an anhydrous sodium sulfate desiccant to complete the supernatant extraction process.

For each solids sample extracted, a known quantity of sample is transferred to small Teflon bottle, and anhydrous sodium sulfate (pre-dried in a muffle furnace) desiccant is added. Appropriate spikes, internal standards, and surrogates are added to the samples before subjecting the samples to the ultra-sonication extraction process. Each sample is ultra-sonicated with three portions of a 1:1 methylene chloride:acetone mixture. The sample quantity used is dependant on ALARA concerns, and will be smaller than the quantities specified in the SW-846 methods. The amount of extraction solvent used will be proportionally equivalent to the quantity specified in the SW-846 method. Following this initial extraction, the $\mathrm{pH}$ of the solids is adjusted with a predetermined quantity of phosphoric acid (determined from the titration curve developed for the sample), and the ultra-sonication extraction process is repeated. All extracts from the solids sample are combined and passed through a column containing an anhydrous sodium sulfate desiccant to complete the solids extraction process.

Once the extraction processes are completed, the supernatant extracts and the solids extracts are transferred to the analytical laboratories and refrigerated before subsequent volume-reduction processing. During the volume-reduction processing using a Kuderna-Danish concentrator, each extract is reduced in volume to $1 \mathrm{~mL}$ and refrigerated to prevent loss of sample until it is analyzed. The volume-reduction procedure using the Kuderna-Danish concentration follows the steps from either Method 3510C or Method 3550B.

\subsubsection{Analysis Methods}

An aliquot of the concentrated extract is prepared and analyzed for semivolatiles by method PNLALO-345 ${ }^{\text {(a) }}$, which is equivalent to SW-846 Method $8270 \mathrm{C}$ with no major modifications. Target EQLs provided in Table 4-2 can be met for the sand and water matrices.

If chromatographic peaks, which are not target analytes, are present and are sufficiently abundant (10\% or greater of the total ion response of the nearest internal standard), then the peak is tentatively identified and the results reported based on the guidance provided in Method 8270C, Section 7.6.2. Requirements of the project QA plan will also be followed regarding the reporting of this data (i.e. caveats are placed on the data using flags including the uncertainty associated with the data).

\subsubsection{Modification to Regulatory DQO Recommended Method}

Minor modifications will be made to the SW-846 preparative methods used for the liquid and the solid samples. For SW-846 Method 3510C, "Separatory Funnel Liquid-Liquid Extraction," the modifications include using smaller volumes of sample and methylene chloride for extraction. Phosphoric acid is used

(a) Battelle-PNL Technical Procedure. 1991. GC/MS Analysis of Semivolatile Organic Compounds, PNL-ALO345, Rev. 0, Pacific Northwest National Laboratory, Richland, Washington. 
for $\mathrm{pH}$ adjustment instead of a sulfuric acid solution. For SW-846 Method 3550B, "Ultrasonic Extraction," the modifications include using smaller amounts of sample, methylene chloride for extraction, and the addition of a $\mathrm{pH}$ adjustment. Phosphoric acid is used for the $\mathrm{pH}$ adjustment instead of sulfuric acid because it is a weaker acid than sulfuric acid and allows for more control over the $\mathrm{pH}$ adjustment step. Smaller sample sizes and volumes of methylene chloride are based on ALARA concerns. The amount of extraction solvent used will be proportionally equivalent to the quantity used in the SW-846 method. These modified methods are currently used during tank waste characterization.

No major modifications are proposed for analyzing semivolatiles by SW-846 Method 8270C.

\subsubsection{Experience with Analysis of Tank Waste Matrices}

Semivolatile compounds have been analyzed in samples from waste in tanks AW101, AN107 (Campbell et al. 2000; Klinger et al. 2000; Campbell et al. 1996), and C104. Through these analyses, experience has been gained on performing extraction procedures on tank waste samples. The procedures discussed above have proven to be relatively reliable for analyzing semivolatiles. However, the previous work did not focus on determination of EQLs.

\subsubsection{Limitations}

Several N-nitrosoamines have been reported (e.g., in the AN107 supernatant and solids data), such as $\mathrm{N}$-nitrosodimethylamine, N-nitrosomethylethylamine, N-nitrosodiethylamine, 1,4-dinitrosopiperazine, etc. and may be artifacts of the extraction procedure. This is a concern because N-nitrosodimethylamine is a driver from a risk-assessment perspective. Most tank waste samples contain large quantities of nitrite. The sample $\mathrm{pH}$ is adjusted to 6.4 with phosphoric acid in the second part of the extraction procedure to protonate phenolic compounds so they are extracted in the solvent. This $\mathrm{pH}$ adjustment may produce nitrous acid, particularly in isolated regions when the addition of acid is first made and is mixed into the sample. Secondary amines, both aliphatic and aromatic, react with nitrous acid to produce Nnitrosoamines:

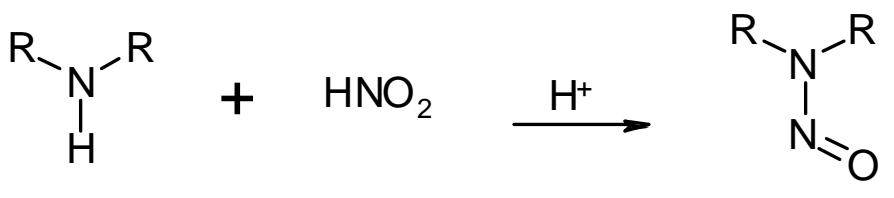

Primary amines react with $\mathrm{HNO}_{2}$ to form diazonium salts; however, these tend to be unstable and produce alkenes, alcohols, and nitrogen gas. It is not entirely clear as how to interpret the presence of N-nitrosocompounds in the samples; it is conceivable they could be present in the native tank material. However, studies performed, which established the $\mathrm{pH}$ adjustment (Stromatt et al. 1993) on Hanford single-shell tank matrices, did not observe the formation of nitration products.

Nitroso-compounds were also observed as artifacts in the derivatization procedure for analyzing chelators and chelator fragments (Grant et al. 1996a; Grant et al. 1996b). The reaction of boron trifluoride (Lewis acid) in the presence of high concentrations of nitrate and nitrite produced nitroso-compounds.

Subsequent analysis using thermospray liquid chromatography/mass spectrometry under basic conditions proved that the nitroso-compounds were not in the tank waste, but artifacts of the derivatization procedure. Therefore, it is possible that the nitroso-compounds are formed during the $\mathrm{pH}$ adjustment. Further investigation into N-nitroso- compounds is warranted. 


\subsubsection{Proposed Alternative Techniques}

A modified preparation procedure will be used for determining MDLs and EQLs of nitroso compounds. A sample will be extracted under basic conditions before analysis to avoid creation of nitroso compounds during acidification with a derivatizing reagent. Spiked samples and spiked blanks will be prepared and analyzed with the samples. Recoveries for the spike samples will be evaluated against the appropriate QC criteria to determine the success of the extraction under basic conditions. This approach will only determine the concentration of nitrosoamine compounds in the waste.

If a need is identified for a complete understanding of the conditions under which nitroso compounds form during acidification with a derivatizing reagent, additional scientific investigation is required. A study would be conducted with spiked simulants and would investigate a range of acid conditions that may result in the formation of nitroso compounds. The understanding of this phenomenon may be important if there is a concern with the formation of nitroso compounds in the waste-treatment plant. This activity is currently outside the scope of the Regulatory DQO.

\subsubsection{Summary}

Minor modifications are planned for preparatory methods. These include alternative acids and smaller sample sizes. Details based on each preparatory technique are provided in Section 4.2.3. Also, a modified preparation will be used to extract $\mathrm{N}$-nitroso compounds under basic conditions instead of acidic conditions. This extraction will also be performed on spiked samples and blanks to determine successful recovery of the N-nitroso compounds. No modifications will be made to the analysis method.

The target EQLs provided in Table 4-2 are achievable for the sand and water matrics. The QC criteria listed in Tables 3-3 and 3-4 should be met.

\subsection{Pesticides Analysis and PCBs (12)}

\subsubsection{Regulatory DQO Recommended Method}

The Regulatory DQO suggests Method 8081A, "Organochlorine Pesticides by Gas Chromatography," to analyze the pesticides (see Table 4-3) and Method 8082, "Polychorinated Biphenyls (PCBs) by Gas Chromatography," for PCBs. In Method 8081A, samples are first extracted, depending on the sample matrix. For liquid matrices, samples are extracted at neutral $\mathrm{pH}$ with methylene chloride using a separatory funnel (Method 3510), a continuous liquid-liquid extractor (Method 3520), or other appropriate method. For a solid matrix, samples are extracted with 1:1 hexane-acetone or 1:1 methylene chloride-acetone using a Soxhlet (Method 3540), an automated Soxhlet (Method 3541), pressurized fluid extraction (Method 3545), ultrasonic extraction (Method 3550B), or other appropriate extraction method. After extraction, cleanup methods may be applied to the sample as necessary, depending on the nature of the matrix interferences and the compounds of interest. These techniques are listed in Method 8081A. The samples are then introduced to a narrow- or wide-bore fused-silica capillary column of a GC with an electron-capture detector or electrolytic-conductivity detector.

Method 8082 for PCBs is the same as Method 8081A for pesticides, except that a cleanup procedure that destroys the pesticides is applied following extraction. This avoids interferences from the pesticides in the PCB analysis. SW-846 Method 8081A suggests that extracted samples can be split after extraction and before clean up for pesticides and PCB analysis. 
All of the pesticides listed for analysis in the Regulatory DQO are listed in Method 8081A. Using Method 8082, seven aroclors, individual PCB congeners, or total PCBs may be determined. The Regulatory DQO only requires total PCBs.

\subsubsection{Target MDLs and EQLs for Pesticides and PCBs}

Table 4-3 presents a list of pesticides that are on the Regulatory DQO priority compound list. Total PCB is also included. Method 8081A for pesticides does not provide target MDLs; however, it recommends that individual laboratories determine MDLs. Therefore, there are no target MDLs for the sand and water matrixes. Method 8081A does provide various factors for determining EQLs from water MDLs. The factors are 10 for groundwater (liquid matrix), 670 for low-concentration soil by sonication with GPC cleanup, 10,000 for high-concentration soil and sludges by sonications, and 100,000 for non-water miscible waste. The target EQLs, therefore, will be based on the water MDL multiplied by the appropriate matrix factor.

Method 8082 for PCBs provides the following guidance for target MDLs: for Aroclors, MDLs range from 0.054 to $0.90 \mu \mathrm{g} / \mathrm{L}$ in water to 57 to $70 \mu \mathrm{g} / \mathrm{kg}$ in soils. Matrix factors for calculating EQLs are the same as those provided for pesticides.

Table 4-3. Pesticides and PCBs on the Regulatory DQO Priority Compound List

\begin{tabular}{|l|l|}
\hline $\begin{array}{c}\text { CAS } \\
\text { Registry } \\
\text { Number }\end{array}$ & \multicolumn{1}{c|}{ Compound } \\
\hline $118-74-1$ & Hexachlorobenzene (D032) \\
\hline $2234-13-1$ & Octachloronaphthalene \\
\hline $309-00-2$ & Aldrin \\
\hline $319-84-6$ & Hexachlorocyclohexane, Alpha BHC \\
\hline $319-85-7$ & Hexachlorocyclohexane, Beta BHC \\
\hline $465-73-6$ & Isodrin \\
\hline $58-89-9$ & gamma-BHC (Lindane) (D013) \\
\hline $60-57-1$ & Dieldrin \\
\hline $72-20-8$ & Endrin (D012) \\
\hline $76-44-8$ & Heptachlor (D031) \\
\hline $8001-35-2$ & Toxaphene (D015) \\
\hline $1336-36-3$ & PCBs \\
\hline
\end{tabular}

\subsubsection{Preparative Methods for Liquids and Solids}

\subsubsection{Extraction of Liquid/Water Samples}

SW-846 Method 3510C, "Separatory Funnel Liquid-Liquid Extraction," begins with a nominal 1-L sample added to a separatory funnel or continuous liquid-liquid extractor. This is followed by the addition of surrogates, tetrachloro-m-xylene (TCX) and decachlorobiphenyl (DCB). Spike compounds are also added if the sample is designated for QC. The surrogates are added to achieve a concentration in the sample of 0.2 to $5.0 \mu \mathrm{g} / \mathrm{L}$ for analysis by gas chromatograph/electron capture detection (GC/ECD). 
Following sample extraction, the residue is exchanged into hexane and reduced to a $10.0-\mathrm{mL}$ final volume.

Because of lowered regulatory detection limits, environmental samples analyzed at Pacific Northwest National Laboratory (PNNL) employ a liter of sample as described above; however, the final residue volume is 1 to $2 \mathrm{~mL}$. Surrogates are added to provide a concentration in the final residue of $20 \mathrm{ng} / \mathrm{mL}$. Typically, this means a sample is spiked with the surrogates at $0.02 \mu \mathrm{g} / \mathrm{L}$, which is substantially below the EPA method. However, this is a good practice with lower detection limits.

In most cases, a full liter of radioactive sample should not be used due to ALARA concerns. In those cases, a minimum of 100-mL liquid or water sample is used. The procedure can be proportionately scaled down. If analysis is performed using electron ionization low resolution mass spectrometric detection (GC/MS), the surrogate and spike levels will need to be about 1000 times greater than for GC/ECD because the technique is less sensitive than GC/ECD.

It is also critical that the entire sample bottle contents are used for the extraction. Sub-sampling of aqueous samples, particularly high salt samples such as tank wastes, will result in analyte loss. The sample bottle must be rinsed with the extraction solvent and combined with the other extractants for that sample.

Methylene chloride is used as the partitioning solvent for three extractions. The methylene chloride extracts are combined, concentrated, and exchanged into hexane. The final volume of the residue is reduced from $10 \mathrm{~mL}$ to 0.1 to $2 \mathrm{~mL}$ for most samples. This results in approximately the same concentration factor as when a reduced sample quantity is used. If the sample quantity has not been reduced, this results in an improved concentration by a factor of 5 to 10 times as compared to the SW-846 method. Residues may be placed in storage for up to 40 days at $4^{\circ} \mathrm{C}$. Residues chilled in storage must be allowed to completely warm to room temperature before use.

Continuous liquid-liquid extraction is not recommended for samples less than $1 \mathrm{~L}$, as the required dilution to make the proper volume to conduct the procedure is contrary to waste-reduction practices (i.e., water added to samples results in a larger volume of laboratory waste that requires disposal.)

\subsubsection{Extraction of Solid/Sludge Samples}

For solid samples, sample heterogeneity is generally the greatest source of variability in analytical results. Although dependent on particle size and the distribution of analyte, extractions performed on less than approximately 0.5 - to $1-\mathrm{g}$ samples are generally subject to substantially increasing variations of the results. It is planned to use 1-g solid samples for analysis. If, because of ALARA concerns, sample size is less than $0.5 \mathrm{~g}$, then homogenization of the centrifuged solids before extraction is critical. Extractions should be accomplished in radiological fume hoods to the extent possible to reduce the complications associated with performing these procedures in a glove box or remote-handling facilities. Extracts obtained from remote handling can usually undergo further treatment and concentration in a radiological fume hood.

Ultrasonic extraction (Method 3550B) is recommended as the method for performing sludge or soil sample extractions. It is known that very non-polar species, such as pesticides or PCBs, can be difficult to extract from materials with a great deal of surface area, particularly when they are comprised of insoluble organic materials. While most tank materials do not contain an appreciable quantity of insoluble organic material, they do contain small particle sizes and offer a substantial surface area. To minimize this potential problem, the sample is solvent contacted and sonicated three times rather than 
once as is done in SW-846 Method 3550B. The samples are extracted employing as much sample material as possible, although this is usually $5 \mathrm{~g}$ or less for tank material.

An alternate to sonication extraction is to employ Soxhlet extraction (Method 3540). The Soxhlet method is time consuming and is not conducive to work in remote-handling facilities. If sample radiation doses allow, Soxhlet extraction can be performed in a radiological fume hood. Historically, sample dose levels have been prohibitively high, and in these cases Soxhlet extractions are not recommended.

The samples can be extracted using methylene chloride/acetone (1:1) or hexane/acetone (1:1) solvent mixtures. The methylene chloride mixture is recommended to reduce the amount of flammable solvent usage when working with radioactive materials. The samples are subjected to high-intensity sonication for approximately 1 to 3 min using a 400-watt transducer. The length of time is dependent on sample and probe size. The resulting extracts are combined and concentrated. They are then exchanged into hexane and reduced to a final volume of 1 to $2 \mathrm{~mL}$. Residues may be placed in storage for up to 40 days at $4^{\circ} \mathrm{C}$. Residues chilled in storage must be allowed to completely warm to room temperature before use.

\subsubsection{Sample Residue Cleanup}

When residues to be analyzed by this method are split from semivolatile extractions or samples are suspected of containing substantial interferences, then additional cleanup should be performed. These are typically acid washes (when PCB-only analysis is performed) or columns employing silica gel or Florisil. The acid wash by Method 3665 employs sulfuric acid and potassium permanganate to remove pesticides.

Whenever silica gel or Florisil (SW-846 Method 3630 or 3620) cleanups are used, the analyst must demonstrate that the fractionation scheme is reproducible. Batch-to-batch variation in the composition of the silica gel or Florisil, or overloading the column, may cause a change in the fractionation of the organochlorine pesticides. When compounds are found in two fractions, the concentrations are added and corrected for additional dilution. Florisil cleanup is preferred because of the ease of use. However, experience in splitting extracts for both semivolatile and pesticide extracts (Klinger et al. 2000) has resulted in higher detection limits from additional interferences.

\subsubsection{Analysis Methods}

Analysis is performed using a dual capillary GC connected to electron capture detectors (ECDs). With dual columns, one column is connected to one ECD and the other column, usually of slightly different polarity, is connected to the other ECD. The second column is used for confirmation. For the individual pesticides (Method 8081A) or PCB congeners (Method 8082), identification is made by matching the retention time of a chromatographic peak on each column to those obtained for the standards. For multicomponent pesticides and Aroclors (PCB mixtures), the method identifies the pattern of the mixtures present by direct comparison to authentic reference standards in addition to retention time matching. Quantitation is performed following calibration of the instrument using authentic materials of known concentration.

If compound identification or quantitation is precluded due to interference, such as broad, rounded, or severely co-eluted peaks, then further cleanup of the sample residue may be required. In some instances, the confirmation column may not exhibit the same level of interference observed on the quantitation column. Quantitation may be performed using the confirmation column, provided it has met all of the calibration criteria.

Both SW-846 Method 8081A and 8082 allow for confirmation analysis by GC/MS if the analyte concentration is sufficient for detection by GC/MS. Confirmation may be used if false positives are 
suspected or multiple interferences exist in the GC/ECD data that limit quantitation. If confirmation is performed using low-resolution electron ionization GC/MS, each Aroclor usually must be present at $>10 \mathrm{mg} / \mathrm{L}$ in the final extract to perform quantitation. If the GC/MS is used for quantitation, a multi-point calibration of the GC/MS will be performed for the Aroclor(s) present. Since GC/MS is less susceptible to interferences, it is anticipated to provide results, which are more accurate than those produced from the $\mathrm{GC} / \mathrm{ECD}$ instrument for analysis performed in the concentration range of the GC/MS.

It is anticipated that target MDLs for PCBs will be met in the sand and water matrix. No target MDLs are available for pesticides. However, matrix factors for determining EQLs in various matrices are provided by the method. Therefore, success for pesticides will be determined by the capability to meet the matrix factors after the waste analysis.

\subsubsection{Modification to Regulatory DQO Recommended Method}

The analysis approach for pesticides and PCBs is based upon existing SW-846 Methods 8081A and 8082, preceded with sample preparation in accordance with the appropriate SW-846 method and cleanup when required. If necessary, modifications of the methods are primarily due to ALARA concerns, and consequently the procedure is scaled down. During solids sample preparation, three ultrasonic extractions will be used versus the one extraction described in SW-846 Method 3550B to ensure complete extraction from the solids. These sample-preparation modifications are considered to be minor.

Methods 8081A and 8082 specify the use of GC/ECD in either single- or dual-column mode. The methods also include using GC/MS if confirmatory analysis is necessary. Any method modifications will be minor and will be related to sample size or adjustment of equipment parameters to optimize the analysis.

\subsubsection{Experience with Analysis of Tank Waste Matrices}

Tank waste analyses for pesticides and PCBs (Klinger et al. 2000; Campbell et al. 2000) have generated extremely complex chromatograms because the ECD will respond to analytes other than chlorinated species such as PCBs and pesticides. As a result, additional cleanup procedures of these residues need to be investigated. A more specific detection method may reduce the need for cleanup. Analysis using the EPA SW-846 Method 8081A or 8082 may exhibit difficulties and present false-positive results, particularly for single-component analytes (most pesticides and PCB congeners). If false positives are suspected, GC/MS can be used to confirm the analysis when adequate concentrations are detected.

\subsubsection{Limitations}

Additional cleanup procedures of the Hanford tank waste sample residues need to be investigated if electron capture detection is employed. Pesticides analysis is limited by interferences, not by sensitivity. Although more robust cleanup methods can be employed for PCB analysis, analysis using the SW-846 Method 8082 for Aroclor or congener-specific quantitation will exhibit difficulties meeting new lower detection limits. In cases where samples contain single Aroclor or Aroclor mixtures without substantial degradation or "weathering," the Aroclor method performs best. In cases where severe degradation has occurred, the congener method will perform better than the Aroclor method. In many cases, even when substantial degradation has occurred, the congener method may actually have greater error associated with calculating the total PCBs and will be more susceptible to interferences than the Aroclor method without robust cleanup methods being applied. If aggressive cleanup treatments are employed, the congener method will perform better in an overall greater variety of instances. 


\subsubsection{Summary}

Only minor modifications to the preparatory and analysis method will be necessary. These modifications are primarily due to ALARA concerns and involve using smaller sample sizes. During solids sample preparation, three ultrasonic extractions will be used versus the one extraction described in SW-846 Method 3550B to ensure complete extraction from the solids. For the analysis methods, any method modifications will be minor and will be related to sample size or adjustment of equipment parameters to optimize the analysis.

Target MDLs for PCBs will be met in the sand and water matrix. No target MDLs are available for pesticides. However, matrix factors for determining EQLs in various matrices are provided by the method. Therefore, success for pesticides will be determined by the capability to meet the matrix factors after the waste analysis. The QC criteria listed in Tables 3-3 and 3-4 should also be met.

\subsection{Polar Volatiles Analysis (8)}

\subsubsection{Regulatory DQO Recommended Method}

The Regulatory DQO suggests Method 8260B, "Volatile Organic Compounds By Gas Chromatography/Mass Spectrometry," for analyzing the polar volatile compounds (see Table 4-4). Method $8260 \mathrm{~B}$ is used to analyze volatile organic compounds that have boiling points below $200^{\circ} \mathrm{C}$. The volatile compounds are prepared for injection into the gas chromatograph by one of six preparation methods listed in Method 8260B or by direct injection. The compounds are introduced to a wide-bore capillary column or cryofocussed on a capillary pre-column before being flash evaporated to a narrowbore capillary for analysis. The column temperature dictates separation of compounds in the column. From the column, the compounds are introduced to the mass spectrometer by a jet separator or direct connection. Compounds are identified by comparing their mass spectra with the electron impact spectra of authentic standards. Compounds are quantified by comparing the response of a major ion relative to an internal standard using a five-point calibration curve. With the exception of 1-methylpropyl alcohol, all of the polar volatile compounds are listed under the applicable compounds for Method 8260B.

\subsubsection{Target MDLs and EQLs for Polar Volatiles}

Table 4-4 lists the polar volatile compounds that are on the Regulatory DQO priority compound list. Method 8260B does not provide specific MDLs for the polar volatile compounds listed in Table 4-4. Therefore, it is assumed that acceptable MDLs for the sand or water matrix will be on the same order of magnitudes as those in Table 4-1. The EQL for 5-mL groundwater samples is expected to be $5 \mu \mathrm{g} / \mathrm{L}$ when using the purge-and-trap method and $5 \mu \mathrm{g} / \mathrm{kg}$ for soils. The matrix factor for waste samples is estimated by the method to be 50 for a liquid waste matrix and 125 for a solid waste matrix. 
Table 4-4. Polar Volatile Compounds on the Regulatory DQO Priority Compound List

\begin{tabular}{|c|l|}
\hline $\begin{array}{c}\text { CAS } \\
\text { Registry } \\
\text { Number }\end{array}$ & \multicolumn{1}{|c|}{ Compound } \\
\hline $64-17-5$ & Ethyl alcohol \\
\hline $67-56-1$ & Methyl alcohol (Methanol) \\
\hline $67-63-0$ & 2-Propyl alcohol (Isopropanol) \\
\hline $71-23-8$ & n-Propyl alcohol (1-propanol) \\
\hline $71-36-3$ & n-Butyl alcohol \\
\hline $75-65-0$ & 2-Methyl-2-propanol \\
\hline $78-92-2$ & 1-Methylpropyl alcohol(2-butanol) \\
\hline $121-44-8$ & Triethylamine \\
\hline
\end{tabular}

\subsubsection{Preparative Methods for Liquids and Solids}

The preparative method used is SW-846 Method 5021, for volatile organic compounds in soils and other matrices using equilibrium headspace analysis. Method 5021 is a recommended sample preparation method for SW-846 Method 8260B. Standards or samples are analyzed by weighing or measuring a volume aliquot of the matrix directly into a headspace vial. Unless the quantity of sample must be modified due to matrix or target compound behavior, $1 \mathrm{~g}$ or $\mathrm{mL}$ of either a liquid or solid sample is used in a 10-mL vial. If a different sample or vial size must be employed, as determined during analytical parameter development, this must be documented in the case narrative and the identical parameters used during calibration. The sample aliquot must have a final volume in the headspace vial within $15 \%$ of the volume used during calibration. After the aliquot is added to the vial, internal standards and surrogates are added to the sample, and the vial is immediately capped. In some cases, such as handling radioactive materials, the internal standards may be added after the vial is capped by injection through the septa. Ideally, the surrogates are added immediately following obtaining the sample aliquot if the sample is to be stored before analysis. This can aid in the assessment of sample storage conditions.

\subsubsection{Analysis Methods}

SW-846 Method 8260B for analyzing volatile compounds will be used. The sample is analyzed by placing the vial in the autosampler and subjecting it to the same heating and mechanical shaking as for calibration standards. Before analysis, the sample is moved to a heated zone and allowed to equilibrate. After a period of time, typically an hour, the vial is pressurized with helium, which forces a portion of the headspace gas mixture through a heated transfer line on the GC column. The GC column is then temperature programmed, and the components are analyzed by mass spectrometry. The temperature, duration, amount of agitation, and vial pressurization the sample is subjected to is determined by developing the method for a given analyte and matrix. The SW-846 method allows this latitude. However, these parameters cannot be varied after calibration, or a new calibration must be performed.

The advantage to the headspace method is primarily the lack of direct contact with the sample. This is of particular importance when dealing with high levels of radioactivity. Once the sample is contained in the headspace vial, the vial is sealed. The surrogate compounds can be added before sealing the vial (preferred) or later by injection with a syringe when internal standards are added. Even when the instrument obtains a sample of headspace vapor through the vial septa, no direct sample contact is made.

Most headspace analytical methods require the use of internal standards to achieve accurate quantitation by obtaining relative response factors (RRFs) (referred to as response factors in SW-846). 


$$
R R F=\frac{\text { Response of the analyte } \times \text { Amount of internal standard }}{\text { Response of the internal standard } \times \text { Concentration of analyte }}
$$

After an aliquot of the headspace gas is analyzed, quantitation is performed by comparing the RRF of the analyte to the internal standard.

$$
\text { Concentration of analyte }=\frac{\text { Response of the analyte } \times \text { Amount of internal standard } \times \text { Dilution factor }}{\text { Response of the internal standard } \times(R R F) \times \text { Volume or Mass of sample }}
$$

Without the use of an internal standard, the headspace method does not demonstrate adequate reproducibility for good quantitation. Quantitation of the analyte must not exceed the upper range of the calibration for that analyte. As with similar methods, the internal standard response during sample analysis cannot vary by more than -50 to $+100 \%$ of the internal standard response observed during the continuing calibration. Failures must be verified by reanalysis or comparison to sample duplicate results and noted in the report narrative citing the matrix-interference issue. Unlike purge and trap method, in the headspace method, the same vial may be reanalyzed multiple times. This is convenient if for some reason analysis was not successful on the first attempt. However, the detection limit will be adversely affected with each subsequent analytical attempt. Also, if an improper quantity of internal standard were inadvertently added to the sample, a new sample aliquot would need to be analyzed.

If chromatographic peaks, which are not target analytes, are present and are sufficiently abundant (10\% or greater of the total ion response of the nearest internal standard), then the peak is tentatively identified and the results reported based on the guidance provided in Method 8260B, Section 7.6.2. Requirements of the project QA plan will also be followed regarding the reporting of this data (i.e. caveats are placed on the data using flags including the uncertainty associated with the data).

The vial size, final volume in the headspace vial, heating conditions and duration, vial pressurization, and all introduction processes must be identical for sample and calibration standard analyses. Ideally, authentic sample material or a simulated matrix is used while establishing method parameters and during calibration. However, equivalency of standard-to-sample matrices may be demonstrated using spiking or standard additions also.

The desired MDLs and EQLs are attainable using this method. However, some development of the method is needed to improve the sensitivity with a high degree of confidence, particularly for triethylamine. However, the modifications needed are minor.

\subsubsection{Modification to Regulatory DQO Recommended Method}

The DQO method assumes all volatile compounds are to be analyzed using SW-846 Method 8260B. However, the Regulatory DQO does not specify the preparative methods to be used for these compounds. Some of the more polar compounds do not exhibit sufficient purging efficiencies to be analyzed using a purge-and-trap method that will be applied to the other volatile compounds. Therefore, it is proposed to use headspace sample introduction very similar to SW-846 Method 5021. Method 5021 uses a static headspace equilibration technique. This technique is more robust than sample purging. Other than using an alternate analyte-introduction technique, the methods are very similar. Modifications to Method 5021 would be minor and consist of adjusting sample size or equipment parameters such as equilibrium temperature or column-temperature programming. The same equipment parameters must be used throughout calibration and sample analysis. 


\subsubsection{Experience with Analysis of Tank Waste Matrices}

Polar volatile analytes in tank materials has been accurately quantified (Klinger et al. 2000; Campbell et al. 2000). Most commonly, n-butanol has been encountered. The primary interference has been normal paraffin hydrocarbons (NPH). In those cases where the NPH concentration is significantly high to present an interference problem, a closed-system, solid-phase extraction cleanup method for the removal of NPH before volatile analysis will be used (Lucke et al. 1993; Hoppe et al. 1992).

The headspace method lends itself well to analyzing radioactive samples because the sample is sealed within the headspace vial and reduces the opportunity for contamination. When the calibration is performed where tank waste samples are to be analyzed, a sodium hydroxide solution has been used for the matrix. This has demonstrated reasonable matrix equivalency. Analysis has been accomplished using GC/MS.

\subsubsection{Limitations}

Sensitivity using headspace is greatly dependent on the vial size chosen and the amount of sample. It is not as sensitive as purge-and-trap methods for compounds with reasonable purging efficiencies.

Therefore, this method should be limited for use on those constituents proven or otherwise known not to perform well using dynamic purge and trap. This method generally exhibits better performance than direct-injection methods and has a much lower risk of radiological contamination.

Another limitation of this technique involves the quantitation of triethylamine. Triethylamine may have poor recovery in the mass spectrometer because of poor elution from the chromatograph columns. This results in poor spike recoveries and carryover of triethylamine to subsequent blank samples. An adjustment of equipment parameters may solve this issue.

Another limitation is the presence of NPH. Samples with high concentrations of NPH can cause contamination throughout the chromatographic system, acting as a liquid stationary phase (Lucke et al. 1993; Hoppe et al. 1992). This may affect retention times of polar volatile components.

\subsubsection{Summary}

Preparation method SW-846 Method 5021 (with minor modifications) and subsequent analysis using SW-846 Method 8075, 5031, or 5032 (to be determined) should be used to analyze the polar volatile compounds. The target MDLs and EQLs are attainable using this method. Some development of the method is needed to improve the sensitivity with a high degree of confidence, particularly for triethylamine. However, the modifications needed are minor. An issue of carryover for triethylamine in the analytical system needs to be addressed. Carryover would result in the failure of the analysis of blanks and elevated detection limits. Equipment-parameter adjustment will be investigated to solve this issue. The convenience of the headspace method, particularly when applied to radioactive samples, makes it an ideal candidate for all volatile compounds. Sensitivity will determine if this can be achieved.

\subsection{Organic Acids Analysis (4)}

\subsubsection{Regulatory DQO Recommended Method}

The Regulatory DQO suggests Method 9056, which is an IC method for analyzing inorganic anions. In SW-846 Method 9056, a small volume of sample is injected into an ion chromatograph to flush and fill a 
constant-volume sample loop. The sample is then injected into a stream of carbonate-bicarbonate eluent of the same strength as the sample. The sample is then pumped through three different ion exchange columns and into a conductivity detector. The first two columns, a precolumn and a separator column, are packed with low-capacity, strongly basic anion exchanger. Ions are separated into discrete bands based on their affinity for the exchange sites of the resin. The last column is a suppressor column that reduces the background conductivity of the eluent to a low or negligible level and converts the anions in the sample to their corresponding acids. The separated anions in their acid form are measured using an electrical-conductivity cell. Anions are identified based on their retention times compared to known standards. Quantitation is accomplished by measuring the peak height or area and comparing it to a calibration curve generated from known standards.

An IC method has been developed to detect and quantify low molecular weight (LMW) organic acids in simulated tank waste and actual tank waste from a single sample injection in one gradient run using hydroxide eluant systems (Sharma et al. 1998). The LMW organic acids that can be determined by this method are listed in Table 4-5. In addition to the organic acids listed in Table 4-5, anions and inorganic anions, including nitrate, nitrite, $\mathrm{Cl}^{-}, \mathrm{F}^{-}$, sulfate and phosphate, can also be quantified by this method. However, this procedure focuses on LMW organic acids and/or their conjugate bases.

\subsubsection{Target MDLs and EQLs for Organic Acids}

Table 4-5 presents a list of organic acids that are on the Regulatory DQO priority compound list. The organic acids are not listed in Method 9056, and therefore, Method 9056 provides no MDLs or EQLs for these compounds. The MDLs for these compounds will be determined on a best-effort basis. Success will be based on currently undefined criteria.

Table 4-5. Organic Acids on the Regulatory DQO Priority Compound List

\begin{tabular}{|c|l|}
\hline $\begin{array}{c}\text { CAS } \\
\text { Registry } \\
\text { Number }\end{array}$ & \multicolumn{1}{|c|}{ Compound } \\
\hline $64-19-7$ & Acetic acid/acetate \\
\hline $64-18-6$ & Formic acid/formate \\
\hline $144-62-7$ & Oxalic acid/oxalate \\
\hline $79-10-7$ & 2-propenoic acid/acrylate \\
\hline
\end{tabular}

\subsubsection{Preparative Methods for Liquids and Solids}

Tank waste samples are highly radioactive. As a result, a sample preparation method was developed to reduce the radioactivity levels, according to the principles of ALARA, without introducing or removing any organic carbon (Mong et al. 1997). This method removes ${ }^{137} \mathrm{Cs}$ and ${ }^{90} \mathrm{Sr}$ in the waste sample by exchange with Na. During an experimental trial of the ion exchange process, the total organic carbon was measured before and after elution through the cation exchange column. Results indicate that the ion exchange medium did not reduce the concentration of the analytes significantly or augment the total organic carbon.

For this "cleanup method," Dowex 50W-X8 cation exchange resins in two mesh sizes are employed: 20:50 mesh and 100:200 mesh. A 500-g bottle of the commercial hydrogen form resin (in either of the mesh grades used) is placed in a 1-L beaker. Deionized water is added to slurry the resin. The mix is stirred with a mechanical stirrer for approximately $1 \mathrm{~h}$ (NOTE: magnetic stir bars tend to break up the 
resin beads and should not be used). Sodium hydroxide (6N) is added as a thin stream (about $50 \mathrm{~mL}$ ) over several minutes. The resin tends to darken as the neutralization reaction takes place. Sodium exchange is accomplished when the mixture will maintain a $\mathrm{pH}>11$ for $10 \mathrm{~min}$. Use of 0 - to 14-pH paper is convenient to monitor the exchange. Excess sodium hydroxide should not be employed; the goal is to add only enough caustic to exchange $\mathrm{H}^{+}$for $\mathrm{Na}^{+}$on the resin bead. The resin is allowed to stir for $1 \mathrm{~h}$ at $\mathrm{pH}>11$. The dark aqueous layer is filtered out, and the resin is washed with an equivalent amount of DI water and may be used immediately. However, when placed in storage, the resin may be stable indefinitely. Resin that has been stored for more than a month should be washed with an additional dilute solution of $\mathrm{NaOH}$ to ensure that the surface is still equilibrated with sodium.

An appropriate quantity of tank waste material ( $0.5 \mathrm{~g}$ for Poly-Prep columns, up to $3 \mathrm{~g}$ for Econo -Pak columns) is transferred into a tarred vessel. If the sample is solid, it is diluted with at least $2 \mathrm{~mL}$ DI water/gram sample. The $\mathrm{pH}$ is checked with wide range (0 to 14$) \mathrm{pH}$ paper. If the $\mathrm{pH}$ is not strongly alkaline (>12), up to $2 \mathrm{~mL} 6 \mathrm{~N} \mathrm{NaOH}$ is added to the sample. The samples are covered and stirred overnight to allow dissolution of precipitated oxalates and other slightly soluble carboxylates, which might be in the sample. Adjustment of the sample to $\mathrm{pH} 12$ to 13 after addition of sufficient water will decrease the possibility of low oxalate recovery. For the Regulatory DQO analysis, appropriate matrix spikes and other control samples will be processed with the sample through the procedure to assess recovery. In recent analytical work, spikes were added after the sample preparation, and therefore, recovery of oxalate during sample preparation was not assessed.

Following $\mathrm{pH}$ adjustment, the samples are removed from stirring, filtered with a $0.45-\mu \mathrm{m}$ in-line syringe filter (Gelman Acrodisc hydrophilic PVDF, Cellulose Acetate, or equivalent), and the filter medium is rinsed with $1 \mathrm{~mL}$ of water. The filter rinsate is combined with the filtered sample.

The flow rate from Econo-Pak or Poly-Prep disposable plastic columns is the principal limiting factor for contact time of the sample and the ion exchange resin. Two methods have been employed to increase the contact time of the sample with the resin bed: 1) a disposable plastic stopcock is placed on the end of the column after a full bed of 20- to 50-mesh resin has been placed in the column, and the drip rate is set to about 1 drop per 3 to $5 \mathrm{sec}$ and 2) a bed of 100- to 200-mesh sodium form 50W-X8 is placed in the bottom of either the Econo-Pak (ca. 2 to $3 \mathrm{~mL}$ depth) or Poly Prep column (ca. $1 \mathrm{~mL}$ depth), the excess water is allowed to drip away, and the larger 20- to 50-mesh resin is carefully decanted into the column on top of the smaller resin bed. The smaller particles limit the flow rate through the column, and the increased surface area of the smaller resin beads increases the exchange of sodium to the sample.

Two ion exchange columns per sample are treated with one column volume of $1 \mathrm{~N} \mathrm{NaOH}$, allowing enough liquid to drain from the column without allowing the resin bed to dry out. The columns are arranged in series so that the effluent from the top column drains into the bottom column. The sample filtrate is applied to the top column. After all of the sample has passed through both columns, a rinse of two column volumes ( $40 \mathrm{~mL}$ if two Econo Pak columns are used, $18 \mathrm{~mL}$ if Poly -Prep columns are used) of $1 \mathrm{~N} \mathrm{NaOH}$ is allowed to drip through the column beds as a rinse. At this point, it is assumed that the entire sample has been in contact with the ion exchange media for a sufficient time to allow exchange and that the sample is entirely washed from the ion exchange column. After sufficient dilution, the sample is ready for IC analysis.

\subsubsection{Analysis Methods}

A simple but robust IC gradient technique was developed to analyze LMW organic acids using conductivity detection. This technique is considered a minor modification to SW-846 Method 9056. The relevant deviations are in the columns and mobile phases. The developed IC gradient conditions were 1) $0.0 \mathrm{~min} 0 \% 100 \mathrm{mM} \mathrm{NaOH}, 98.1 \%$ DI water and 1.9\% $5 \mathrm{mM} \mathrm{NaOH}$, 2) $6.4 \mathrm{~min} 0 \% 100 \mathrm{mM} \mathrm{NaOH}, 0 \%$ 
DI water and $100 \% 5 \mathrm{mM} \mathrm{NaOH}$, and 3) $18.4 \mathrm{~min} 35 \% 100 \mathrm{mM} \mathrm{NaOH}, 0 \%$ DI water and $65 \% 5 \mathrm{mM}$ $\mathrm{NaOH}$. The mobile phase contained a gradient of DI water and a weak solution of $\mathrm{NaOH}$. This method required minimum sample preparation and was found to be effective for identifying and quantifying these acids.

The applicable QC criteria listed in Tables 3-3 and 3-4 should be met with the IC method. In terms of ALARA issues, if the cation-exchange column is employed, results have shown that radioactivity levels were reduced nearly 1000-fold. In addition, if the samples are then extracted with an organic solvent and derivatized, in most cases, it has been found that there is very little radioactivity extracted into the organic fraction. As a result, most of the radioactivity tends to be associated with the aqueous fraction.

\subsubsection{Modification to Regulatory DQO Recommended Method}

Method 9056 as written is applicable to inorganic anions. However, it can be applied to organic acids. Sample preparation as described above adds an ion exchange column to reduce radioactivity. Two additional columns follow this column. Method 9056 uses three columns before injection in the ion chromatograph electrical-conductivity cell. Method 9056 also describes the standard conditions for conducting the analysis on anions. Different conditions have been developed as described in Section 4.5.4 to optimally analyze the organic acids.

\subsubsection{Experience with Analysis of Tank Waste Matrices}

The IC method described in Sections 4.5.3 and 4.5.4 was developed to detect and analyze LMW organic acids in simulated tank waste and actual tank waste. The results show that IC can be effectively used to identify and quantify LMW organic acids in the presence of high nitrate and nitrite concentrations typically found in Hanford tank waste samples.

\subsubsection{Limitations}

While using the AS-11 column for analyzing LMW material, it was observed that the glycolate anion coelutes with the acetate anion. This interference can be readily resolved by using the AS- 6 column, which is capable of analyzing glycolate in the presence of acetate. The eluant and the conditions for analysis by the AS- 6 column are different from that of the AS-11 column. Another limitation of the IC analysis is the large dilution factors that have to be applied to the sample before analysis to prevent overloading of the column. As an example, for samples from C104 tank waste, the dilution factor was approximately 2000 to prevent overloading due to large concentrations of nitrate and nitrite present in the tank waste samples. In addition, other interferences, e.g. $\mathrm{F}^{-}$, have been encountered in $\mathrm{C} 104$ tank wastes. Fluoride elutes with a retention time similar to that of acetate/glycolate. Preliminary results indicate that $\mathrm{F}^{-}$could be removed with the addition of $\mathrm{Ca}(\mathrm{OH})_{2}$. The $\mathrm{F}^{-}$problem was not evaluated with the AS-6 column. Before adding $\mathrm{Ca}(\mathrm{OH})_{2}$, the sample would be analyzed for oxalate.

\subsubsection{Summary}

Method 9056 has been adapted for analyzing the organic acids. The modifications to the method can involve changes in ion exchange columns used before analysis and changes in operating conditions of the chromatograph to optimize the analysis of the organic acids. Method 9056 provides no MDLs or EQLs for the organic acids. Therefore, the MDLs for these compounds will be determined on a best-effort basis. Success will be based on currently undefined criteria. 


\subsection{Picric Acid Analysis}

\subsubsection{Regulatory DQO Recommended Method}

The Regulatory DQO suggests Method 8330, "Nitroaromatics and Nitramines by High Performance Liquid Chromatography (HPLC)" for picric acid analysis. Method 8330 was developed for analyzing part per billion concentrations of explosive residues in water, soil, and sediment. The method includes a low-level salting out extraction process for preparation of the sample for injection into the chromatagraph. Picric acid is not listed in the method's compound list. Analytes included in that method are the nitroamines and other explosives-related organic compounds. The method provides high performance liquid chromatographic (HPLC) conditions for the detection of nitroamines and other explosive-related organic residues in water, soil and sediment matrix by HPLC using an ultraviolet (UV) detector.

Prior to use of Method 8330, appropriate sample preparation techniques must be used. Aqueous samples of low concentration are extracted by a salting-out extraction procedure with acetonitrile and sodium chloride. The undissolved acetonitrile is drawn off and back-extracted by stirring with salt water. After equilibration and phase separation, the small volume of acetonitrile is removed and the concentrated extract is diluted, separated on a C-18 reverse phase column, determined at $254 \mathrm{~nm}$, and confirmed on a $\mathrm{CN}$ reverse phase column. Aqueous samples of higher concentration can be diluted with methanol or acetonitrile, filtered, separated on a C-18 reverse phase column, determined at $254 \mathrm{~nm}$, and confirmed on a CN reverse phase column. Soil and sediment samples are extracted using acetonitrile in an ultrasonic bath, filtered, separated on a C-18 reverse phase column, determined at $254 \mathrm{~nm}$, and confirmed on a CN reverse phase column.

\subsubsection{Target MDLs and EQLs for Picric Acid}

Method 8330 provides no MDLs or EQLs for picric acid. The MDLs for picric acid will be determined on a best-effort basis. Success will be based on currently undefined criteria.

\subsubsection{Preparative Methods for Liquids and Solids}

Tank waste has not been analyzed for picric acid. Therefore, there are no preparative methods that have been applied to tank wastes for this analyte. Method 8330 discusses a low-level salting-out method with no evaporation for the analysis of explosives-related compounds and a method for high-level analysis using direct injection. These methods may be applicable to tank wastes for the analysis of picric acid. Other preparation methods that may be applicable include Method 3510 or 3520, preparatory methods for phenols. Water samples are extracted at a $\mathrm{pH} \leq 2$ with methylene chloride. An extreme $\mathrm{pH}$ adjustment for the extraction of phenolic-type compounds may cause chemical changes and negate matrix homogeneity. In view of these possibilities and the fact that there is no experience with preparative methods for picric acid in tank waste, additional research will be required. For solid samples containing phenols, either Method 3540 or 3550 is recommended in SW-846. A literature search would be performed to obtain sample preparative methods for picric acid.

In terms of ALARA issues, if the cation exchange column is employed, results have shown that radioactivity levels were reduced nearly 1000 -fold. In addition, if the samples are extracted with organic solvents, in most cases, it has been found there is very little radioactivity extracted into the organic fraction. Therefore, most of the radioactivity is associated with the aqueous fraction. These methods will have to be tested with picric acid. 


\subsubsection{Analysis Methods}

Method 8330 provides high performance liquid chromatographic conditions for detecting explosivesrelated organic components. It recommends a C-18 (or equivalent) reversed-phase column with water/methanol as the mobile phase and UV detection. Minor modifications, including column and mobile phase choices, will be applied to Method 8330 for the analysis of picric acid.

\subsubsection{Modification to Regulatory DQO Recommended Method}

Minor modifications will be made to SW-846 preparative methods (e.g. sample size, $\mathrm{pH}$ for extraction) used for the liquid and solid samples. Minor modifications, column (e.g. Synergi $4 \mu \mathrm{m} \mathrm{C12}$, Phenomenex) and mobile phase composition (e.g. $10 \mathrm{mM}$ ammonium acetate in water and $10 \mathrm{mM}$ ammonium acetate in methanol), will be made to SW-846 Method 8330 for the analysis of picric acid.

\subsubsection{Experience with Analysis of Tank Waste Matrices}

Picric acid is expected to exist in its anionic form, picrate, in the alkaline tank waste. Method 8330 or a modified version has not yet been used for the analysis of picric acid in tank waste.

\subsubsection{Limitations}

Due to the lack of experience with analyzing picric acid in tank waste matrices, limitations of analysis methods cannot be described at this time.

\subsubsection{Summary}

There is no experience with the analysis of picric acid in a tank waste matrix. Minor modifications to Method 8330 that include changes to the column and mobile phase composition will be used for the analysis of picric acid in tank wastes. The MDLs for picric acid will be determined on a best-effort basis. Success will be based on currently undefined criteria. Depending on the chosen method for analyses, the QC criteria listed for mass spectrometry or a chromatography technique in Tables 3-3 and 3-4 should be met.

DOE-ORP and Ecology agreed on 10 Jan 01 that analysis of picric acid would be deferred. The need for characterization work on picric acid will be reevaluated by ORP and Ecology in light of questionable stability in the tank waste matrix, the anticipated cost for analyses and that a unique method will need to be developed. No analysis of picric acid will be initiated by the contractor without further direction from ORP.

\subsection{Ammonium Perfluorooctanoate and Methyl Isocyanate}

The Regulatory DQO suggests Method 8330, which is a high-performance liquid chromatographic (HPLC) technique, for ammonium perfluorooctanoate and methyl isocyanate analysis. Method 8330 was developed for analyzing part per billion concentrations of explosive residues is water, soil, and sediment. The method includes a low-level salting out extraction process for preparation of the sample for injection into the chromatograph. Ammonium perfluorooctanoate and methyl isocyanate are not listed in the method's compound list. Analytes included in that method are the nitroamines and other explosivesrelated organic compounds. Method 8330 is discussed in more detail in Section 4.6.1. 
Ammonium perfluorooctanoate does not contain a chromophore like the nitroaromatics listed in Method 8330 that makes it amenable to UV analysis at $254 \mathrm{~nm}$; therefore, it can not be analyzed by Method 8330 without major modifications. It is recommended that a method that has been developed for the analysis of highly fluorinated compounds in environmental samples ${ }^{\mathrm{a}}$ be used for ammonium perfluorooctanoate analysis. The method uses of solid phase extraction, a sample preparation technique, with subsequent analysis using electrospray mass spectrometry in the negative ion mode with selected ion monitoring. Electrospray ionization is a liquid chromatographic interface to a mass spectrometer in which the sample solution is sprayed across a high potential difference from a needle into an orifice in the interface. Heat and gas flows are used to desolvate the ions existing in the sample solution. A mass spectrometer is used as the detector. The highly fluorinated species respond very well under negative ion conditions. These preparation and analysis methods have not been extended to the analysis of tank wastes. In order for this method to be applied to tank waste, the radioactivity levels must be reduced prior to analysis to prevent severe instrumental contamination. As a result, a cleanup method involving cation exchange may have to be performed to reduce the radioactivity levels. Because there are no equivalent SW-846 methods involving electrospray mass spectrometry, modifications to Method 8330 for the analysis of ammonium perfluorooctanoate are designated as major. Therefore, analysis of ammonia perfluorooctanoate will proceed under a future test plan that addresses method development and major modifications to SW-846 methods.

It is not recommended to use Method 8330 without major modifications for methyl isocyanate analysis. Methyl isocyanate is a volatile compound but it does not have a chromaphore, which is required for HPCL analysis. Therefore, methyl isocyanate is not amenable to analysis by Method 8330 without major modifications. An alternative extraction method that can be used with HPLC has been identified from the Occupational Safety and Health Act (OSHA) document OSHA Index of Sampling and Analytical Methods (OSHA 2000). Samples are collected by drawing a known volume of air through XAD-7 tubes coated with 1-(2-pyridyl) piperazine. Samples are desorbed with acetonitrile and analyzed by HPLC using fluorescence or ultraviolet detectors. Possible interferences include anhydrides, amines, alcohols, and carboxylic acids. This method of analysis is considered a major modification to Method 8330 because it deviates from the extraction method delineated by Method 8330. Method 8330 also specifies HPCL with a UV detector. Use of a fluorescence detector would be a minor modification to the method. Methyl isocyanate analysis will proceed under a future test plan that addresses method development and major modifications to SW-846 methods.

${ }^{a}$ Campbell, J.A. and Y. Shi. 1999. Analysis of Highly Perfluorinated Organics Using Negative Ion Electrospray Mass Spectrometry. Unpublished data. 


\subsection{Inorganic Analysis}

In this section, six individual inorganic analysis methods and their respective preparatory methods are described. Each section provides a summary of the SW-846 method and minor modifications that will be made to the methods to accommodate the tank waste matrix. Also included is a list of the elements that will be analyzed by the specified method. A number provided in parenthesis after the subsection title indicates the number of Regulatory DQO priority compounds that will be determined by the method. Experience with tank waste analysis is also described.

\subsection{Metals Analysis (37)}

\subsubsection{Regulatory DQO Recommended Method}

The Regulatory DQO recommends SW-846 Method 6010B, "Inductively Coupled Plasma-Atomic Emission Spectrometry," for analyzing metals. Samples are first solubilized or digested by an appropriate SW-846 preparation method. The samples are then analyzed by ICP/AES using sequential or simultaneous optical systems and axial or radial viewing of the plasma. Samples are nebulized into an aerosol, which is transported to the plasma torch. A radio-frequency inductively coupled plasma torch produces element-specific emission spectra. The spectra are dispersed by a grating spectrometer, and photosensitive devices monitor the intensities of the emission lines. By this method, multi-element analysis can be achieved.

While not specifically recommended by the Regulatory DQO, SW-846 Method 6020, "Inductively Coupled Plasma-Mass Spectrometry (ICP/MS)," is another multi-element technique that is complimentary to ICP/AES and provides additional sensitivity. Samples are nebulized into an aerosol, transported to the plasma torch, and ionized by a radio-frequency plasma torch. The ions are then introduced into a mass-spectrometer and quantified based on their mass.

Of the 37 metals listed in the Regulatory DQO, 6 are not listed in Method 6010B. For these, the Regulatory DQO suggests Method 6010B as a method that can be adapted for their analysis. These compounds are indicated in Table 5-1.

\subsubsection{Target MDLs and EQLs for Metals}

Table 5-1 presents a list of metals that are on the Regulatory DQO priority compound list. Also included are target IDLs for the ICP/AES. IDLs are calculated statistically like an MDL; however, they are determined on samples of spiked reagent water containing each analyte of concern that has not been subjected to preliminary preparation. No MDLs or EQLs are provided in Method 6010B. Method 6020 for the ICP/MS suggests that the MDLs will be below $0.02 \mu \mathrm{g} / \mathrm{L}$. 
Table 5-1. Metals ICP/AES IDLs

\begin{tabular}{|c|c|c|}
\hline $\begin{array}{c}\text { CAS } \\
\text { Registry } \\
\text { Number }\end{array}$ & Compound & $\begin{array}{c}\text { Target IDL } \\
(\mu \mathrm{g} / \mathrm{L})\end{array}$ \\
\hline \multicolumn{3}{|c|}{ Compounds Listed in SW-846, Method 6010B } \\
\hline $18540-29-9$ & Chromium (hexavalent) ${ }^{(\mathrm{a})}$ & 4.7 \\
\hline $63705-05-5$ & Total Sulfur & N/A \\
\hline $7429-90-5$ & Aluminum & 30 \\
\hline $7439-89-6$ & Iron & 4.1 \\
\hline 7439-92-1 & Lead & 28 \\
\hline 7439-93-2 & Lithium & 2.8 \\
\hline 7439-95-4 & Magnesium & 20 \\
\hline $7439-96-5$ & Manganese & 0.93 \\
\hline 7439-98-7 & Molybdenum & 5.3 \\
\hline 7440-02-0 & Nickel & 10 \\
\hline 7440-09-7 & Potassium & N/A \\
\hline $7440-16-6$ & Rhodium & N/A \\
\hline $7440-21-3$ & Silicon (as silica) & N/A \\
\hline $7440-22-4$ & Silver (D011) & 4.7 \\
\hline $7440-23-5$ & Sodium & 19 \\
\hline $7440-25-7$ & Tantalum & N/A \\
\hline $7440-28-0$ & Thallium & 27 \\
\hline $7440-31-5$ & Tin & 17 \\
\hline 7440-36-0 & Antimony & 21 \\
\hline $7440-38-2$ & Arsenic & 35 \\
\hline $7440-39-3$ & Barium (D005) & 0.87 \\
\hline $7440-41-7$ & Beryllium & 0.18 \\
\hline $7440-42-8$ & Boron & 3.8 \\
\hline $7440-43-9$ & Cadmium (D006) & 2.3 \\
\hline $7440-48-4$ & Cobalt & 4.7 \\
\hline $7440-50-8$ & Copper & 3.6 \\
\hline $7440-66-6$ & Zinc & 1.2 \\
\hline $7440-69-9$ & Bismuth & N/A \\
\hline $7440-70-2$ & Calcium & 6.7 \\
\hline 7723-14-0 & Phosphorous & 51 \\
\hline $7782-49-2$ & Selenium (D010) & 50 \\
\hline \multicolumn{3}{|c|}{ Compounds Not Listed in SW-846, Method 6010B } \\
\hline $7553-56-2$ & Iodine & $\mathrm{N} / \mathrm{A}$ \\
\hline $7440-61-1$ & Uranium & N/A \\
\hline $7440-62-2$ & Vanadium & N/A \\
\hline $7440-33-7$ & Tungsten & N/A \\
\hline $7440-65-5$ & Yttrium & N/A \\
\hline $7440-67-7$ & Zirconium & N/A \\
\hline
\end{tabular}

(a) Cr to be measured as total chromium, as per the Regulatory DQO.

N/A $=$ Not available. Method 6010B does not provide an IDL for this element. 


\subsubsection{Preparative Methods for Liquids and Solids}

The pre-processing of both liquid and solids tank waste materials will be necessary before analyzing the metals by either ICP/AES or ICP/MS. Preparative methods are listed in Table 5-2 and will be discussed further below.

Table 5-2. EPA Preparative Methods

\begin{tabular}{|c|c|c|}
\hline \multicolumn{2}{|r|}{ SW-846 Method } & Applicability (As Stated in Method) \\
\hline $3005 \mathrm{~A}$ & $\begin{array}{l}\text { Acid Digestion of Waters for Total } \\
\text { Recoverable or Dissolved Metals } \\
\text { for Analysis by FLAA or ICP } \\
\text { Spectroscopy }\end{array}$ & $\begin{array}{l}\text { Surface and groundwaters: } \mathrm{Ag}, \mathrm{Al}, \mathrm{As} \text {, } \\
\mathrm{Ba}, \mathrm{Be}, \mathrm{Ca}, \mathrm{Cd}, \mathrm{Co}, \mathrm{Cr}, \mathrm{Cu}, \mathrm{Fe}, \mathrm{K}, \mathrm{Mg} \text {, } \\
\mathrm{Mn}, \mathrm{Mo}, \mathrm{Na}, \mathrm{Ni}, \mathrm{Pb}, \mathrm{Sb}, \mathrm{Se}, \mathrm{Tl}, \mathrm{V}, \mathrm{Zn}\end{array}$ \\
\hline $3010 \mathrm{~A}$ & $\begin{array}{l}\text { Acid Digestion of Aqueous } \\
\text { Samples and Extracts for Total } \\
\text { Metals for Analysis by FLAA or } \\
\text { ICP Spectroscopy }\end{array}$ & $\begin{array}{l}\text { Aqueous matrices, Toxicity Characteristic } \\
\text { Leach Procedure (TCLP) extracts, and } \\
\text { wastes containing suspended solids: } \mathrm{Al} \text {, } \\
\mathrm{As}, \mathrm{Ba}, \mathrm{Be}, \mathrm{Ca}, \mathrm{Cd}, \mathrm{Co}, \mathrm{Cr}, \mathrm{Cu}, \mathrm{Fe}, \mathrm{K} \text {, } \\
\mathrm{Mg}, \mathrm{Mn}, \mathrm{Mo}, \mathrm{Na}, \mathrm{Ni}, \mathrm{Pb}, \mathrm{Se}, \mathrm{Tl}, \mathrm{V}, \mathrm{Zn}\end{array}$ \\
\hline 3015 & $\begin{array}{l}\text { Microwave-Assisted Acid } \\
\text { Digestion of Aqueous Samples and } \\
\text { Extracts }\end{array}$ & $\begin{array}{l}\text { Aqueous matrices, TCLP extracts, and } \\
\text { wastes containing suspended solids: } \mathrm{Ag} \text {, } \\
\mathrm{Al}, \mathrm{As}, \mathrm{Ba}, \mathrm{Be}, \mathrm{Ca}, \mathrm{Cd}, \mathrm{Co}, \mathrm{Cr}, \mathrm{Cu}, \mathrm{Fe}, \mathrm{K} \text {, } \\
\mathrm{Mg}, \mathrm{Mn}, \mathrm{Mo}, \mathrm{Na}, \mathrm{Ni}, \mathrm{Pb}, \mathrm{Sb}, \mathrm{Se}, \mathrm{Tl}, \mathrm{V}, \\
\mathrm{Zn}\end{array}$ \\
\hline \multirow{2}{*}{ 3050B } & \multirow{2}{*}{$\begin{array}{l}\text { Dissolution of Sediments, Sludges, } \\
\text { and Soils }\end{array}$} & $\begin{array}{l}\text { FLAA/ICP/AES: Sediments, sludges, } \\
\text { and soils for Ag, Al, Ba, Be, Ca, Cd, Co, } \\
\mathrm{Cr}, \mathrm{Cu}, \mathrm{Fe}, \mathrm{K}, \mathrm{Mg}, \mathrm{Mn}, \mathrm{Mo}, \mathrm{Na}, \mathrm{Ni}, \mathrm{Pb} \text {, } \\
\mathrm{Sb}, \mathrm{Tl}, \mathrm{V}, \mathrm{Zn}\end{array}$ \\
\hline & & $\begin{array}{l}\text { Graphite furnace atomic absorption } \\
\text { (GFAA)/ICP/MS: sediments, sludges, and } \\
\text { soils for As, Be, Cd, Co, Cr, Fe, Mo, Pb, } \\
\text { Se, Tl. }\end{array}$ \\
\hline 3051 & $\begin{array}{l}\text { Microwave-Assisted Acid } \\
\text { Digestion of Sediments, Sludges, } \\
\text { Soils, and Oils }\end{array}$ & $\begin{array}{l}\text { Sediments, sludges, and soils for } \mathrm{Ag}, \mathrm{Al} \text {, } \\
\mathrm{As}, \mathrm{B}, \mathrm{Ba}, \mathrm{Be}, \mathrm{Ca}, \mathrm{Cd}, \mathrm{Co}, \mathrm{Cr}, \mathrm{Cu}, \mathrm{Fe}, \\
\mathrm{Hg}, \mathrm{K}, \mathrm{Mg}, \mathrm{Mn}, \mathrm{Mo}, \mathrm{Na}, \mathrm{Ni}, \mathrm{Pb}, \mathrm{Sb}, \mathrm{Sr} \text {, } \\
\text { Tl, V, } \mathrm{Zn}\end{array}$ \\
\hline 3052 & $\begin{array}{l}\text { Microwave-Assisted Acid } \\
\text { Digestion of Siliceous and } \\
\text { Organically Based Matrices }\end{array}$ & $\begin{array}{l}\text { Ashes, biological tissues, soils, sediment, } \\
\text { and sludges for } \mathrm{Ag}, \mathrm{Al}, \mathrm{As}, \mathrm{B}, \mathrm{Ba}, \mathrm{Be} \text {, } \\
\mathrm{Ca}, \mathrm{Cd}, \mathrm{Co}, \mathrm{Cr}, \mathrm{Cu}, \mathrm{Fe}, \mathrm{Hg}, \mathrm{K}, \mathrm{Mg}, \mathrm{Mn} \text {, } \\
\mathrm{Mo}, \mathrm{Na}, \mathrm{Ni}, \mathrm{Pb}, \mathrm{Sb}, \mathrm{Sr}, \mathrm{Tl}, \mathrm{V}, \mathrm{Zn}\end{array}$ \\
\hline \multicolumn{3}{|c|}{ ASTM Methods } \\
\hline D $4503^{(a)}$ & $\begin{array}{l}\text { Dissolution of Solid Waste by } \\
\text { Lithium Metaborate Fusion }\end{array}$ & $\begin{array}{l}\text { Fusion, solid waste, total digestion: } \mathrm{Al} \text {, } \\
\mathrm{Ba}, \mathrm{Cd}, \mathrm{Ca}, \mathrm{Cu}, \mathrm{Cr}, \mathrm{Fe}, \mathrm{Mg}, \mathrm{Mn}, \mathrm{Ni}, \mathrm{Si} \\
\mathrm{Ti}, \mathrm{V}, \mathrm{Zn}\end{array}$ \\
\hline D $4698^{(\mathrm{b})}$ & $\begin{array}{l}\text { Total Digestion of Sediment } \\
\text { Samples for Chemical Analysis of } \\
\text { Various Metals }\end{array}$ & $\begin{array}{l}\text { Fusion, sediment, and total digestion of } \\
\text { sediments: } \mathrm{Al}, \mathrm{As}, \mathrm{Ca}, \mathrm{Cu}, \mathrm{Cd}, \mathrm{Co}, \mathrm{Cr} \text {, } \\
\text { Fe, } \mathrm{Mg}, \mathrm{Mn}, \mathrm{Mo}, \mathrm{Ni}, \mathrm{P}, \mathrm{Pb}, \mathrm{K}, \mathrm{Si}, \mathrm{Sb}, \mathrm{Se} \text {, } \\
\mathrm{Na}, \mathrm{Ti}, \mathrm{Sr}, \mathrm{Li}, \mathrm{Zn} \text {, }\end{array}$ \\
\hline
\end{tabular}

(a) ASTM 1998.

(b) ASTM 1996. 


\subsubsection{Tank Waste Liquids}

The SW-846 preparative Methods 3005A, 3010A, and 3015 are listed as acid-digestion procedures for total recoverable or dissolved metals from aqueous samples and extracts. It should be noted that the preparative methods provide only an acid leach of suspended solids, not total digestion, which is required to determine the actual solids waste composition. The EPA preparative methods, with little or no modification, may be applicable to tank waste liquids; however, use of these methods for total dissolution of tank waste solids will require some modification or selection of alternate dissolution method(s). For solids, modification to preparative methods may include alternate acids and/or changes to dissolution parameters, such as temperature and pressure. An evaluation of applicability will be needed for those analytes not listed in the EPA methods.

\subsubsection{Tank Waste Solids}

Only one of the preparatory methods listed in Table 5-2, SW-846 Method 3052, "Microwave Assisted Acid Digestion of Siliceous and Organically Base Matrices," relates to total sample digestion. Analysis of tank waste solids necessitates the need to dissolve the entire sample. This procedure is applicable to the total dissolution of solids. This technique has not been developed for use on Hanford tank waste samples. One issue is that volatile digestion products create high pressure in the reaction vessels. This method is further discussed in the alternative methods section. The remaining SW-846 preparation methods, relative to solids, only relate to leached solids or "available" metals.

Current procedures used for preparing tank waste solids for ICP/AES or ICP/MS analysis are acid digestion and one or more caustic fusion procedures. For a few tank waste solids, acid digestion procedures can be used for total dissolution, whereas for most tank waste solids, acid dissolution is insufficient to totally dissolve the entire matrix, leaving significant quantities of undissolved solids. In these cases, the current approach to ensure total digestion of tank waste solids is to employ caustic fusion procedures. SW-846 methods do not contain fusion procedures; however, a potassium hydroxide fusion procedure is under review as part of the EPA/600 series methods. ASTM Methods D 4503 (ASTM 1998) and D 4698 (ASTM 1996) describe a fusion procedure using lithium metaborate. The caustic fusion techniques currently in use for Hanford tank waste analysis typically use sodium or potassium-based flux reagents. Measuring all analytes listed in Table 5-1 requires two sample aliquots and two fusion procedures. One fusion method uses zirconium crucibles and sodium reagents and the other fusion method uses nickel crucibles and potassium reagents. Two methods are needed to cover measurement of those analytes used as flux reagents or metal from the crucibles. Fusion-prepared samples typically use about $0.1 \mathrm{~g}$ to $0.2 \mathrm{~g}$ of sample and about $2 \mathrm{~g}$ of flux reagent. After high-temperature fusion, samples are diluted to a final volume of $100 \mathrm{~mL}$. Before samples can be analyzed by ICP/AES, they must be diluted by a factor of about five to keep total dissolved solids less than about $0.5 \mathrm{wt} \%$. The result is an MDL about 2,500 times the IDL.

\subsubsection{Analysis Methods}

Table 5-3 provides analysis methods for analyzing both solid and liquid samples by ICP/AES and ICP/MS. The requested elements listed in the Regulatory DQO are not entirely supported by any single preparative or analysis methods. All methods for both preparation and determination are limited in the analytes that can be analyzed by ICP/MS or ICP/AES. In the past, tank waste samples have been analyzed primarily by ICP/AES with analysis by ICP/MS on an "as needed" basis using an appropriate sample preparation procedure, such as acid digestion for liquids and caustic fusion for solids. These prepared solutions have been analyzed using QC methodology defined under SW-846 (6020) and EPA (200.8) protocols and guidelines. 
Table 5-3. EPA Analysis Methods

\begin{tabular}{|c|c|c|}
\hline \multicolumn{2}{|r|}{ SW-846 Method } & Applicability (As Stated in Method) \\
\hline $6010 \mathrm{~B}$ & (Analysis): ICP/AES & $\begin{array}{l}\text { Analysis following one of the } 3000 \text { Series } \\
\text { digestions }\end{array}$ \\
\hline 6020 & ICP/MS & $\begin{array}{l}\text { Analysis following one of the } 3000 \text { Series } \\
\text { digestions. Methods available include } \\
\mathrm{Ag}, \mathrm{Al}, \mathrm{As}, \mathrm{Ba}, \mathrm{Be}, \mathrm{Cd}, \mathrm{Co}, \mathrm{Cr}^{(\mathrm{a})}, \mathrm{Cu}, \mathrm{Mn} \text {, } \\
\mathrm{Ni}, \mathrm{Pb}, \mathrm{Sb}, \mathrm{Tl}, \mathrm{Zn}\end{array}$ \\
\hline $\begin{array}{l}7000 \\
\text { Series }\end{array}$ & $\begin{array}{l}\text { Atomic Absorption Method } \\
\text { including Direct Aspiration, } \\
\text { Furnace Technique, or Gaseous } \\
\text { Hydride }\end{array}$ & $\begin{array}{l}\text { Analysis following one of the } 3000 \text { Series } \\
\text { digestions. Methods available include } \\
\mathrm{Ag}, \mathrm{Al}, \mathrm{As}, \mathrm{Ba}, \mathrm{Be}, \mathrm{Ca}, \mathrm{Cd}, \mathrm{Co}, \mathrm{Cr}^{(\mathrm{a})}, \mathrm{Cu} \text {, } \\
\mathrm{Fe}, \mathrm{Li}, \mathrm{Mg}, \mathrm{Mn}, \mathrm{Mo}, \mathrm{Na}, \mathrm{Ni}, \mathrm{K}, \mathrm{Pb}, \mathrm{Sb} \text {, } \\
\mathrm{Se}, \mathrm{Sn}, \mathrm{Tl}, \mathrm{V}, \mathrm{Zn}\end{array}$ \\
\hline \multicolumn{3}{|c|}{ EPA/600 Methods for Chemical Analysis of Water and Waste } \\
\hline 200.7 & $\begin{array}{l}\text { (Preparative and Analysis): } \\
\text { Determination of Metals and Trace } \\
\text { Elements in Waters and Wastes by } \\
\text { ICP/AES }\end{array}$ & $\begin{array}{l}\text { Dissolved, suspended, and total elements } \\
\text { in waters, and domestic/industrial wastes: } \\
\mathrm{Ag}, \mathrm{Al}, \mathrm{As}, \mathrm{B}, \mathrm{Ba}, \mathrm{Be}, \mathrm{Ca}, \mathrm{Cd}, \mathrm{Co}, \mathrm{Cr}^{(\mathrm{a})} \text {, } \\
\mathrm{Cu}, \mathrm{Fe}, \mathrm{K}, \mathrm{Mg}, \mathrm{Mn}, \mathrm{Mo}, \mathrm{Na}, \mathrm{Ni}, \mathrm{Pb}, \mathrm{Sb} \text {, } \\
\mathrm{Se}, \mathrm{Si}, \mathrm{Tl}, \mathrm{V}, \mathrm{Zn}\end{array}$ \\
\hline 200.8 & $\begin{array}{l}\text { (Preparative and Analysis) } \\
\text { Determination of Trace Elements } \\
\text { in Waters and Wastes by ICP/MS }\end{array}$ & $\begin{array}{l}\text { Dissolved, suspended, and total elements } \\
\text { in waters, and domestic/industrial wastes: } \\
\mathrm{Ag}, \mathrm{Al}, \mathrm{Ag}, \mathrm{Sb}, \mathrm{As}, \mathrm{Ba}, \mathrm{Be}, \mathrm{Cd}, \mathrm{Cr}^{(\mathrm{a})}, \mathrm{Co} \text {, } \\
\mathrm{Cu}, \mathrm{Ni}, \mathrm{Mn} \mathrm{Pb}, \mathrm{Sb}, \mathrm{Se}, \mathrm{Tl}, \mathrm{Zn}\end{array}$ \\
\hline
\end{tabular}

(a) Cr to be measured as total chromium, as per the Regulatory DQO.

\subsubsection{ICP/AES}

ICP/AES has been a standard technique for measuring tank waste liquids. However, the high dissolved solids content of Hanford tank waste liquids results in the need for large dilution factors. Average sodium concentration in tank waste liquids is about $24 \mathrm{wt} \%$, resulting in high total dissolved solids (TDS).

Physical interference resulting from high TDS can cause changes in viscosity and surface tension in the nebulizer during sample analysis and lead to significant inaccuracies. To avoid this kind of interference, the TDS content of samples should generally be below $0.5 \mathrm{wt} \%$ TDS. A processing dilution factor of about fifty-fold is needed to ensure this level of TDS.

Recent results for analysis of tank waste supernatant samples from AW101 and AN107 (Urie et al. 1999a) suggest that 10 is an approximate matrix factor for ICP/AES. The IDLs published in Method 6010B are achievable with the current method. However, IDLs do not include sample preparation. No guidance is provided on MDLs or EQLs with this method; therefore, MDLs for metals will be determined on a besteffort basis. Success will be based on currently undefined criteria. For solids analysis, the need for fusion sample preparations results in a dilution of about 2,500 before analysis.

\subsubsection{ICP/MS}

In the past, for ICP/MS analysis, liquid tank solutions have been diluted by a factor of 100 and solid tank waste samples by 10,000 before introduction into the ICP/MS for analysis. These routine dilution factors are only meant to control the percent solids of the sample solution that are analyzed by ICP/MS. In most cases, the samples are diluted to greater levels because the instrument sensitivity is high. The target MDL $(0.02 \mu \mathrm{g} / \mathrm{L})$ recommended by Method 6020 can easily be achieved by ICP/MS, provided that a sample- 
preparation method can be used that reduces or eliminates molecular ion interferences and reagent contamination.

Because ICP/MS is a mass analyzer and not an element analyzer, those elements that exist between the mass ranges of $71 \mathrm{amu}$ to $165 \mathrm{amu}$ should be considered anthropogenic in isotopic composition, meaning that their isotopic abundance is not naturally occurring. Elements such as $\mathrm{Mo}, \mathrm{Rh} \mathrm{Ag}, \mathrm{Sn}, \mathrm{Sb}$, and $\mathrm{Ba}$, which are directly produced by fission and exist in the tank waste samples, will require prior separation and determination of their isotopic abundance before an elemental determination can be preformed by ICP/MS.

In general, the low mass elements suffer the most with respect to molecular ion production from the plasma gas, nitric acid, hydrochloric acid, and organic material. In most cases, these interferences cannot be removed by alternative sample preparation techniques. Most molecular ion interferences can be resolved with a mass spectrometer resolving power of up to 5000 .

\subsubsection{Modification to Current Method}

For sample preparation techniques applied to liquids, only minor modifications will be made to the SW-846 methods. The minor modifications involve using smaller sample sizes because of ALARA concerns. Typically, the SW-846 acid-dissolution methods have not been successful in preparing Hanford waste samples; i.e., for many tank solids matrices, significant solids residues remain following attempts to solubilize the solids by acid digestion. Microwave digestion (Method 3052) may be applicable to the tank waste solids matrix, but would need to be developed to optimize dissolution for a radioactive waste sample. Modifications to Method 3052 may require minor to major modifications, depending on the results of method development.

Fusion methods are also applicable and have been used for many years on Hanford waste samples. ASTM methods describe a lithium borate fusion technique. The caustic fusion techniques currently in use for tank waste analysis typically use sodium or potassium-based flux reagents. This may be considered a minor modification to the ASTM method.

In the ICP/AES Method (6010B), minor modifications, including equipment parameters and data analysis, will be necessary. All SW-846 methods and other EPA methods require the use of off-peak background-interference correction. The intent of this technique is to remove unwanted detector response (background signal) from the desired detector response (analyte signal). The technique of off-peak background correction is effective for reducing interference effects from various types of broad-spectral response as long as an interference-free wavelength region on either side of the channel peak is available. Unfortunately, line-rich spectra generated by uranium, iron, and lanthanide preclude the use of off-peak background correction for Hanford tank waste analyses. There are no off-peak channels/wavelengths free of spectral interference for this instrument. Presently, only inter-element corrections can be used to estimate and correct for background elevation and spectral interference. Inter-element interference correction can be relatively effective when used, provided the concentration of all elements causing interference can be determined. Post-analysis correction can also be applied provided accurate interference response to all channels/wavelengths is known, and the concentration of the interfering element is also known. A post-analysis technique has been used occasionally to correct for interferences from moderate concentrations of plutonium. This modification is considered to be minor.

The ICP/MS method in current use for measuring selected cations is based specifically on SW-846 Method 6020 analysis following one of the 3000 Series digestions. For typical environmental samples, the method is suitable as written for analyzing most cations listed in this DQO document. For the highly complex and unknown tank waste materials, the method is still applicable for a wide range of elements, 
but is impacted by a number of instrument issues, such as abundance sensitivity, interfering ions, many orders of magnitude variations in the concentrations, and matrix element issues, such as altered isotopic elements produced by fission. Any modifications to the SW-846 method would involve sample dilution or changes in equipment parameters. These are considered to be minor.

\subsubsection{Experience with Analysis of Tank Waste Matrices}

Past and recent tank waste analyses have used ICP/AES for cation quantitation. The caustic fusion techniques for solids were specifically developed for dissolving typical waste solids. Most analyses did not require the low MDL and EQLs shown in Table 5-1. Often the ICP/MS technique was used as a complimentary analysis to achieve greater sensitivity for waste analysis.

Both liquids and solids from various tank wastes have been analyzed by ICP/MS, using a method essentially identical to SW-846 Method 6020 and EPA (200.8) protocols for a limited number of elements. Early investigation of tank waste sample analyses using ICP/MS has shown that elements below 71 amu can be considered naturally occurring with respect to their isotopic abundance. Those elements between 71 and 165 amu are highly altered (depending on whether ${ }^{233} \mathrm{U},{ }^{235} \mathrm{U}$ or ${ }^{239} \mathrm{Pu}$ were processed) in their atomic abundance.

Small studies have been performed that have applied IC-ICP/MS to Hanford tank waste (Farmer et al. 1995; Smith et al. 1995). The studies involved online ICP/MS separation of tank wastes for long- and short-lived radionuclides and altered fission yield elements in Hanford tank waste samples.

\subsubsection{Limitations}

\subsubsection{ICP/AES}

In general, the measurement precision for tank waste solids (based on RPD between duplicates) and accuracy (based on matrix spikes) is reasonably good for most analytes measured by ICP/AES. However, some data suggest that there are matrix effects that are not fully being addressed (i.e., some spike recoveries measure low) and some heterogeneity may exist within the tank waste matrix (i.e., RPDs are outside the acceptance criteria of $20 \%$ when using sample sizes of about $0.2 \mathrm{~g}$ ).

The use of relatively small sample sizes to minimize exposure dose to personnel tends to produce poor RPDs; this has been observed for some analyses of tank waste metals. Typically, the larger the sample, the better the reproducibility between duplicates. Sizing and/or improved mixing techniques are options to improve RPDs. Additional sub-sample aliquot analysis may provide both statistical evidence of sample heterogeneity and a better estimate of the average concentration.

\section{Chemical effects}

To ensure that QC parameters are met for all tank waste types, it may be necessary to fully evaluate the source of the matrix-interference effects or expand the matrix-spike recovery beyond the current $75 \%$ to $125 \%$ acceptance criteria. Chemical interference can affect QC parameters. Very low or very high chloride ion concentration will keep silver soluble in dilute nitric acid solutions. An intermediate range of chloride concentration will cause silver to precipitate from solution even in very low $\mathrm{pH}$ conditions. Evaluation needs to be made to determine how little or how much chloride is needed to maintain silver soluble without the use of excessive amounts of chloride. Solubility of tin and antimony are also sensitive to the amount of chloride in solution. Moderate-to-high concentrations of sulfate ions cause barium to precipitate from solution, resulting in low spike recovery. The effect is sometimes observed following serial dilution. Fluoride ions affect certain analytes, particularly lanthanides (rare earth 
elements) such as yttrium, causing them to precipitate from solution. Silicon, tantalum, and tungsten require fluoride to keep them from precipitating.

\section{Physical effects}

Sample viscosity and surface tension can significantly impact the precision and accuracy of ICP/AES analyses. The viscosity effects usually become apparent when analyzing samples containing greater than $0.5 \mathrm{wt} \%$ TDS. Surface-tension effects change with increasing viscosity, acid type, acid concentration, and dissolved organic material. The combined effect of changes in viscosity and/or surface tension affects the instrument nebulizer (converts liquids to aerosols) and aerosol transport efficiency to the plasma torch. Over all accuracy is affected if significant differences exist between samples and calibration solutions.

Nebulizers capable of handling higher levels of TDS (e.g., up to 20\%) are available. However, their use for tank waste liquid samples and solids-fusion preparations is not considered viable, primarily due to frequent plugging and the need to matrix-match the standards to the samples. That is, effects of viscosity and surface tension must be similar between the standards and the prepared samples; otherwise, accuracy and precision are significantly impacted. Also, analyzing samples at higher TDS levels (i.e., minimizing sample dilutions before analysis) provides little benefit when only a few analytes constitute the majority of the TDS content. In this case, these analytes significantly exceed the dynamic range of the ICP/AES and cannot be quantified without dilution; nor can accurate interelement corrections be applied to other analytes measured unless the major analytes are diluted to within their linear calibration range.

\section{Spectral interference}

All SW-846 methods and other EPA methods essentially require the use of off-peak background interference correction. The intent of this technique is to remove unwanted detector response (background signal) from the desired detector response (analyte signal). To accomplish this task, the instrument is programmed to acquire measurements at the desired analytical wavelength (channel peak) and at specific distances on either or both sides (off-peak channels) of the analytical wavelength. The instrument then estimates the background response occurring at the analytical wavelength (channel peak) and subtracts it from the total response (analyte plus background). The net (corrected) response is then converted to concentration based upon calibration information and displayed. High concentrations of calcium, magnesium, and aluminum will produce elevated background intensities (known as "recombination continuum"). Recombination continuum produces elevated background intensities from mid-range analytical wavelengths $(\sim 350 \mathrm{~nm})$ and below. Tank waste contains sufficient aluminum $(\sim 5 \mathrm{wt} \%)$ and calcium $(\sim 0.4 \mathrm{wt} \%)$ concentrations to produce this effect. If left uncorrected, this will cause false-positive results.

The technique of off-peak background correction described above is effective for reducing interference effects from various types of broad-spectral response as long as interference-free wavelength regions on either side of the channel peak are available. Unfortunately, line-rich spectra generated by uranium, iron, and lanthanides preclude the use of off-peak background correction for Hanford tank waste analyses. Uranium (and cerium) is particularly problematic because every wavelength (channel) of the ICP/AES instrument presently in use is affected. There are no off-peak channels/wavelengths free of spectral interference for this instrument. Presently, only inter-element corrections can be used to estimate and correct for background elevation and spectral interference. Inter-element interference correction can be relatively effective when used provided the concentration of all elements causing interference can be determined. Post-analysis correction can also be applied, provided accurate interference response to all channels/wavelengths is known and the concentration of the interfering element also known. A post analysis technique has been used occasionally to correct for interferences from moderate concentrations of plutonium. 


\subsubsection{ICP/MS}

Based on the ICP/MS analyses of liquid and solid matrices, there are numerous problems with applying the SW-846 ICP/MS methods directly to tank waste samples.

Atomic and polyatomic ion interferences are produced not only from the sample matrix material (high organic material, high levels of sulfate, and hydrochloric acid), but also from the ICP plasma gas (argon). High resolution ICP/MS in most cases can resolve the polyatomic ion interferences, but is not capable of resolving atomic interferences, for example, ${ }^{40} \mathrm{Ar}$ ions from ${ }^{40} \mathrm{Ca}$ ions.

A fission-yield product results in altered isotopic abundance. A proposed high-pressure ion chromatography (HPIC)-ICP/MS method of online ratio analysis will allow for proper interference correction to be developed and will provide for a total elemental analysis of fission yield elements by ICP/MS.

Low limits of detection for ICP/MS are problematic due to blank limitations and large dilution factors applied to the sample solutions. If fusion preparation techniques (used for solids preparation) are used for ICP/MS analysis and not acid dissolution procedures, a larger dilution factor will be needed on the sample solution to reduce the solids introduced by the flux material. The analysis blank limitations (reagent and crucible contamination) for fusions are higher than for acid dissolution methods using ultra-pure acids in metal inert beakers. Methods of reagent cleaning will need to be evaluated for fusion preparation techniques. Crucibles used in fusion techniques are often the major source of reagent contamination, especially at ICP/MS detection capabilities. High TDS content, as discussed in Section 5.1.7.1, is also a limitation for ICP/MS analysis.

Because of the many orders of magnitude variation in the concentrations of the analytes of interest, the different sample preparation procedures and wide range of required MDLs, multiple data acquisition parameters, and dilutions will be required.

For both liquid and solid samples, ICP/MS analysis of $\mathrm{Si}, \mathrm{P}, \mathrm{S}, \mathrm{K}, \mathrm{Ca}$, and $\mathrm{Fe}$ is difficult, if not impossible, because of plasma ion interferences. The analyses of these elements are possible if high resolution (HR)-ICP/MS is used to resolve the molecular ion interferences. This would allow for the direct determination in solution of the elements of interest and meet the required MDLs and EQLs.

For both liquid and solid samples, ICP/MS analysis of Mo, $\mathrm{Rh}, \mathrm{Ag}, \mathrm{Cd}, \mathrm{Sn}, \mathrm{Sb}$, and $\mathrm{Ba}$ will require HPIC online with ICP/MS to determine the isotopic abundance of each element listed above. Once the elemental isotopic abundance is known, then a direct analysis can be made for total elemental concentration.

For liquid samples, appropriate total sample dissolution procedures for the analysis by either ICP/MS or ICP/AES are readily available. Solids, however, will require evaluation and comparison of current and past work done on and off the site. No single sample preparation will give a complete dissolution of all elements of interest. For example, those elements that suffer from chloro-molecular ion interferences produced from hydrochloric acid digests should be evaluated to eliminate or control the amount of interfering elements introduced into the sample solution.

\subsubsection{Summary}

For analyzing the metals, ICP/AES is anticipated to meet the published IDLs. No guidance is provided on MDLs or EQLs with this method; therefore, MDLs for metals will be determined on a best effort basis. Success will be based on currently undefined criteria. The target MDL $(0.02 \mu \mathrm{g} / \mathrm{L})$ recommended 
by Method 6020 for ICP/MS analysis can easily be achieved by ICP/MS. QC criteria listed in Tables 3-1 and 3-2 can be met by the ICP/MS method.

A variety of preparation techniques may be required to dissolve the metals in solid matrices. Past work indicates that caustic fusions are successful for the majority of the metals. Preparation techniques will also require minor modifications over the standard published methods from ASTM. However, fusion techniques result in large dilution factors and interferences from flux materials. It is proposed that SW-846 Method 3052, a microwave-assisted acid digestion technique, be investigated for its applicability to tank waste analysis and its capability to be remotely operated. Equipment and methods development would be required. There are benefits over caustic fusion in that small dilution factors are required, and less interferences would be present.

\subsection{Anions Analysis (7)}

\subsubsection{Regulatory DQO Recommended Method}

The Regulatory DQO suggests Method 9056, which is an IC method for analyzing inorganic anions. The method is summarized in Section 4.6 above, and again briefly in Section 5.2.4 below.

\subsubsection{Target MDLs and EQLs for Anions}

Table 5-4 presents the inorganic anions listed as priority constituents in the Regulatory DQO and their target MDLs as published in SW-846 Method 9056. The MDLs listed in Table 5-4 are for a liquid matrix. No guidance is provided for a solids matrix.

Table 5-4. Target MDLs for Inorganic Anions

\begin{tabular}{|c|l|c|}
\hline $\begin{array}{c}\text { CAS Registry } \\
\text { Number }\end{array}$ & \multicolumn{1}{|c|}{ Compound } & $\begin{array}{c}\text { Target } \mathbf{M D L} \\
(\boldsymbol{\mu g} / \mathbf{L})\end{array}$ \\
\hline $24959-67-9$ & Bromide $(\mathrm{Br})$ & 100 \\
\hline $16887-00-6$ & Chloride $(\mathrm{Cl})$ & 100 \\
\hline $16984-48-8$ & Fluoride $(\mathrm{F})$ & 50 \\
\hline $7697-37-2$ & Nitrate $\left(\mathrm{NO}_{3}\right)$ & 100 \\
\hline $14797-65-0$ & Nitrite $\left(\mathrm{NO}_{2}\right)$ & 100 \\
\hline $14265-44-2$ & Phosphate $\left(\mathrm{PO}_{4}\right)$ & 100 \\
\hline $14808-79-8$ & Sulfate $\left(\mathrm{SO}_{4}\right)$ & 100 \\
\hline
\end{tabular}

(a) $100 \mu \mathrm{L}$ sample loop and $10 \mu \mathrm{ohm} / \mathrm{cm}$ full-scale setting on the conductivity detector.

\subsubsection{Preparative Methods for Liquids and Solids}

The pre-processing (e.g., dilution, separations, leaching, or dissolution) of both liquid and solids tank waste materials will be necessary. A literature search will be performed to determine the best preparative processing method(s) to be used for both the liquids and solids. The literature search is to be used to identify the best preparative methods applicable for each of the various SW-846 or other EPA anion analysis methods.

For tank waste liquid samples, the anions of interest are assumed to be soluble in the matrix, and no additional dissolution processing, other than dilutions, is generally necessary for either IC or ion selective 
electrode (ISE) methods. Analyzing tank waste liquid samples by IC suffers from most of the problems identified below (Section 5.2.6), and approaches to eliminate or minimize these effects need to be identified before meeting the required MDL can be assured (particularly for fluoride and chloride).

Water-based extraction procedures are applicable to tank waste solids by either IC or ISE, but they only extract soluble anions from the waste matrix. SW-846 does not address leaching or extraction methods for preparing analytical samples for subsequent analysis by Method 9056; however, EPA/600 (EPA 1995) Method 300.0 provides for leaching of solids with water before analysis. For analyzing anions in solids by ISE, SW-846 recommends ASTM procedures D4646-87 (ASTM 1993), D5233-92 (ASTM 1999b), or D3987-85 (ASTM 1999a) that extract soluble anions into either reagent water or dilute acetic acid fluids (pH 2.88 or 4.93$)$.

Total anion concentrations of the solids are of interest; therefore, it will be necessary to dissolve the solids or extract the anion of interest into a liquid matrix. Subsequent analysis by IC, ISE, or other analysis methods may include peak profiling with a surrogate trace complex radioactive ion or even direct analysis by ICP/MS or ICP/AES after chromatographic separation using time-based fraction collection. In solids and dissolved solutions, the most difficult anions are those that form water-insoluble and water-soluble complex compounds with metals typical of tank waste materials, such as barium $\left(\mathrm{BaSO}_{4}\right)$, zirconium $\left(\mathrm{ZrF}_{\mathrm{x}}{ }^{-\mathrm{y}}\right)$, and iron $\left(\mathrm{FeCl}_{\mathrm{x}}{ }^{-\mathrm{y}}\right)$. Since water-based extraction methods cannot be used to provide total anion concentrations for tank waste solids, alternate dissolution methods and redox chemistry evaluation are required; alternate analysis methods may also be required, based on the dissolution method(s) selected. From the literature search, alternate solids preparative methods, such as total dissolution for selective anions (or elements), and pyro-hydrolysis and $\mathrm{NH}_{4} \mathrm{OH}$ precipitation will be evaluated for all halides.

For halides by IC, SW-846 identifies a bomb-preparation method for determining total chlorine (and other halides) in solid waste and oils. This method may have some applicability to dried (or nearly dried) solids for analyzing halides; however, bomb methods are not considered viable for processing of highly radioactive materials because of possible high-pressure rupture.

\subsubsection{Analysis Methods}

Historically for tank waste analyses, IC techniques equivalent to SW-846 Method 9056 have been the method of choice because of the capability to measure multiple free ion and ion complexes during a single analysis at a reasonable sensitivity (i.e., IDLs in the range of $100 \mu \mathrm{g} / \mathrm{L}$ ). The tank waste liquids are measured after significant dilution, and tank waste solid material is water leached to provide an aqueous matrix for analysis. Besides IC, the primary methods applicable to these analyzes are ISE and capillary ion electrophoresis (CIE), each having advantages and disadvantages. Typically, titrimetric or colorimetric methods for tank waste materials are not considered viable due to the chemical complexity of the tank material and the inherent color of many tank liquids. The SW-846 and EPA/600 methods for analyzing the target anions of interest along with their applicable matrices are included in Table 5-5. The methods listed in the table are applicable only to an aqueous matrix, either as a liquid sample or as an aqueous extraction from a solid sample. 
Table 5-5. SW-846 Analysis Methods

\begin{tabular}{|c|c|c|c|c|}
\hline \multicolumn{2}{|r|}{ SW-846 Method } & Analyte(s) & $\begin{array}{c}\text { Aqueous } \\
\text { Matrix }\end{array}$ & $\begin{array}{c}\text { Solids } \\
\text { Matrix }\end{array}$ \\
\hline 9056 & $\begin{array}{l}\text { Determination of Inorganic Anions } \\
\text { by Ion Chromatography }\end{array}$ & $\begin{array}{l}\mathrm{F}, \mathrm{Cl}, \mathrm{Br} \\
\mathrm{NO}_{2}, \mathrm{NO}_{3} \\
\mathrm{PO}_{4}, \mathrm{SO}_{4} \\
\end{array}$ & All & $\begin{array}{l}\text { Halides following bomb } \\
\text { combustion } 5050\end{array}$ \\
\hline 9035 & $\begin{array}{l}\text { Sulfate (Colorimetric, Automated, } \\
\text { Chloranilate) }\end{array}$ & $\mathrm{SO}_{4}$ & All & Not addressed \\
\hline 9036 & $\begin{array}{l}\text { Sulfate (Colorimetric, Automated, } \\
\text { Methylthymol Blue, AA II) }\end{array}$ & $\mathrm{SO}_{4}$ & All & Not addressed \\
\hline 9210 & $\begin{array}{l}\text { Potentiometric Determination of } \\
\text { Nitrate in Aqueous Samples with } \\
\text { Ion-Selective Electrode }\end{array}$ & $\mathrm{NO}_{3}$ & All & $\begin{array}{l}\text { Soluble } \mathrm{NO}_{3} \text { extracted by } \\
\text { ASTM D4646 } \\
\text { or D } 3987^{(\mathrm{c})}, \mathrm{D}^{\text {(b) }}\end{array}$ \\
\hline 9211 & $\begin{array}{l}\text { Potentiometric Determination of } \\
\text { Bromide in Aqueous Samples with } \\
\text { Ion-Selective Electrode }\end{array}$ & $\mathrm{Br}$ & All & $\begin{array}{l}\text { Soluble Br extracted by } \\
\text { ASTM D4646 } \\
\text { or D3987 } \\
\text { (c) }\end{array}$ \\
\hline 9212 & $\begin{array}{l}\text { Potentiometric Determination of } \\
\text { Chloride in Aqueous Samples with } \\
\text { Ion-Selective Electrode }\end{array}$ & $\mathrm{Cl}$ & All & $\begin{array}{l}\text { Soluble Cl extracted by } \\
\text { ASTM D } 4646^{(a)}, \text { D5233 } \\
\text { or D3987 }\end{array}$ \\
\hline 9214 & $\begin{array}{l}\text { Potentiometric Determination of } \\
\text { Fluoride in Aqueous Samples with } \\
\text { Ion-Selective Electrode }\end{array}$ & $\mathrm{F}$ & All & $\begin{array}{l}\text { Soluble F extracted by } \\
\text { ASTM D4646 } \\
\text { or D } 3987^{(\mathrm{c})}, \text { D5233 }\end{array}$ \\
\hline 9250 & $\begin{array}{l}\text { Chloride (Colorimetric, Automated } \\
\text { Ferricyanide AA I) }\end{array}$ & $\mathrm{Cl}$ & All & Not addressed \\
\hline 9251 & $\begin{array}{l}\text { Chloride (Colorimetric, Automated } \\
\text { Ferricyanide AA II) }\end{array}$ & $\mathrm{Cl}$ & All & Not addressed \\
\hline 9252 & $\begin{array}{l}\text { Chloride (Titrimetric, Silver } \\
\text { Nitrate) }\end{array}$ & $\mathrm{Cl}$ & $\begin{array}{l}\text { All, high } \\
\text { conc. }\end{array}$ & $\begin{array}{l}\text { Halides following bomb } \\
\text { combustion } 5050\end{array}$ \\
\hline \multicolumn{5}{|c|}{ Proposed SW-846 Methods } \\
\hline 6500 & $\begin{array}{l}\text { Dissolved Inorganic Anions in } \\
\text { Aqueous Matrices by Capillary Ion } \\
\text { Electrophoresis }\end{array}$ & $\begin{array}{l}\mathrm{F}, \mathrm{Cl}, \mathrm{Br}, \\
\mathrm{NO}_{2}, \mathrm{NO}_{3}, \\
\mathrm{PO}_{4}, \mathrm{SO}_{4} \\
\text { and } \mathrm{CHO}_{2}\end{array}$ & All & Not addressed \\
\hline 9216 & $\begin{array}{l}\text { Potentiometric Determination of } \\
\text { Nitrite in Aqueous Samples with } \\
\text { Ion-Selective Electrode }\end{array}$ & $\mathrm{NO}_{2}$ & All & Not addressed \\
\hline \multicolumn{5}{|c|}{ EPA/600 Methods for Chemical Analysis of Water and Wastes } \\
\hline 300.0 & $\begin{array}{l}\text { Determination of Inorganic Anions } \\
\text { by Ion Chromatography }\end{array}$ & $\begin{array}{l}\mathrm{F}, \mathrm{Cl}, \mathrm{Br} \\
\mathrm{NO}_{2}, \mathrm{NO}_{3} \\
\mathrm{PO}_{4}, \mathrm{SO}_{4} \\
\end{array}$ & All & $\begin{array}{l}\text { Following 10:1 extraction } \\
\text { with water }\end{array}$ \\
\hline
\end{tabular}
(a) ASTM 1993.
(b) ASTM 1999b.
(c) ASTM 1999a

\subsubsection{Modification to Regulatory DQO Recommended Method}

The method in current use for measuring the anions of interest is based on IC, specifically on the SW-846 Method 9056. The method requires an aqueous sample that is injected into a dilute carbonate/bicarbonate eluent. The sample is injected into a series of ion exchangers (guard and analytical columns), and the 
anions of interest are separated based on their relative affinity for a strong base quantinary-amine anion exchanger. The separated anions are passed through a micro-membrane suppressor that protenates the halogen-complex elements to their acid form, and the anions are measured by their relative conductivity response. The identification of the separated anions is based on retention time compared to a known reference standard.

For typical environmental samples, the method is suitable, as written, for analyzing all the anions of interest. For the highly complex and unknown tank waste materials, the method is still usable, but is impacted by a number of matrix issues, such as abundance sensitivity, interfering ions, large baseline deflection, and many orders of magnitude variation in the concentrations of the measured analytes. Changing IC parameters (e.g., columns, eluents, eluent strength, gradient elution) and introducing inline or offline processing (e.g., removal of $\mathrm{M}^{+}$and $\mathrm{M}^{++}$metal ion) is anticipated to significantly enhance the use of IC to measure selected inorganic (and organic) anions of interest. However, a single set of parameters most likely will not provide for a single injection, interference-free analysis of all inorganic anions of interest.

\subsubsection{Experience with Analysis of Tank Waste Matrices}

Both liquids and solids have been analyzed from various waste tanks by IC using a method that is essentially identical to SW-846 Method 9056. Although not specified by Method 9056, IC samples are prepared from tank waste solids following a method similar to ASTM D3987 (ASTM 1999a) (but without the same mechanical agitation). Based on the IC analyses of these wastes (liquids and leachates), there are numerous problems with applying the SW-846 IC method directly to the tank waste liquids and solids leachates, such as the following:

1) Very high $\mathrm{M}^{+}$and $\mathrm{M}^{++}$metal ion concentrations cause severe chromatogram distortion (water dip) that makes the measurement of fluoride and chloride particularly difficult; the addition of concentrated eluent to minimize this problem is only marginally effective. A proposed method of reducing this effect is to remove metal ions that are ionized in solution before injection. This will reduce the water production from the membrane suppressor and level the system baseline for early eluting ions, allowing for lower detection.

2) Very high concentrations of one or more anions require significant dilution to avoid column overloading; results in increased method detection limit due to high sample dilution; no preprocessing of sample is suggested in SW-846 methods.

3) Bromide is extremely difficult to detect and/or quantify in the presence of a very high concentration of nitrate, and vise versa; ICP/MS is a good alternative for analysis of $\mathrm{Br}$.

4) Interferes with fluoride, and less severely chloride, from tank waste common organic anions such as formate, glycolate, and acetate; alternate eluents and/or gradient elution are not addressed in this method; ICP/MS is a good alternative for analyzing $\mathrm{Cl}$.

5) High concentrations of M+ and M++ ions typically degrade column performance, particularly for the measurement of phosphate.

Most of these problems have been minimized through adequate dilution of the liquid or leachate samples; however, this approach raises the EQL for all reported anions. Typically, tank wastes have very high concentrations of one or more of the following: hydroxide, carbonate, nitrate, nitrite, and oxalate. Nitrate, nitrite, and oxalate are measured directly by the current IC method, and excessive concentration requires 
significant sample dilution to prevent column overload, which significantly affects the capability to accurately quantify the anions of interest.

\subsubsection{Limitations}

For liquids, the IC analysis of fluoride and chloride are particularly difficult in the presence of high concentrations of interfering organic acid (e.g., formic, carbonic) and in the presence of very high concentration of other measured anions (i.e., total concentration of anions measured are limited by column overloading). Online or offline separation techniques may provide some relief for this problem; however, alternate analysis methods (e.g., ISE) can be used to meet the target MDLs if necessary. Typically, IC is not recommended for analyzing fluoride in unknown matrices, specifically because of the "water dip" problem and the interfering organic acids. However, eluent dilution or gradient elution using a $\mathrm{NaOH}$ eluent for fluoride analysis is an alternative to ISE.

For solids, the capability to solubilize all anions of interest is a concern. For many anions, there is little flexibility for processing the solid since very little dilution can be incorporated into the processing. Leaching the solids at one-part solids to five-parts leach solution will make some anion measurements extremely difficult (e.g., chloride, nitrate, and nitrite). If solids processing involves a total dissolution method that requires significant dilution of the sample, then it is likely that only phosphate and sulfate will benefit. The analysis of water-insoluble anions (e.g., phosphates and sulfates) requires further study, and no evaluation of analysis limitation can be made at this time. However, analysis of acid digestions or caustic fusions of the solids by ICP/AES may provide information on the total phosphorus and total sulfur present in the sample matrix. Limitations of dissolution and ICP/AES analysis are similar to the waterleach limitations for IC analysis; e.g., barium sulfate at high concentrations is largely insoluble in either the water leach, acid digestion, or acidified fusion dissolution.

It is not anticipated that any of the QC parameters will be difficult to achieve, whether the analysis method employed is IC, ISE, or another standard or novel analysis technique. Precision measured by duplicate reproducibility and accuracy measured by LCS and matrix spikes should meet specified requirements.

\subsubsection{Summary}

For analyzing anions, SW-846 Method 9056 can be used with minor modifications. These modifications would involve changing IC parameters and introducing inline or offline processing. These modifications are anticipated to significantly enhance the use of IC to measure selected inorganic (and organic) anions of interest. There may be limitations in analyzing solids, which depends on the capability to leach the analytes of interest. It is not recommended, however, that effort be placed on achieving the MDLs for nitrate and nitrite, which are typically found in high concentrations in the tank waste.

\subsection{Ammonia, Ammonium Analysis}

\subsubsection{Regulatory DQO Recommended Method}

The Regulatory DQO recommends EPA Method 350.3, "Nitrogen, Ammonia -Potentiometric, Ion Selective Electrode" (EPA 1995). In this method, ammonia is determined potentiometrically using an ion selective ammonia electrode and a pH meter with an expanded millivolt scale or a specific ion meter. The ammonia electrode uses a hydrophobic gas-permeable membrane to separate the sample solution from an ammonium chloride internal solution. Ammonia in the sample diffuses through the membrane and alters the $\mathrm{pH}$ of the internal solution, which is sensed by a $\mathrm{pH}$ electrode. The constant level of chloride in the 
internal solution is sensed by a chloride selective ion electrode, which acts as the reference electrode. This method is applicable to the measurement of ammonia in water and wastes. The ammonia measurement will measure the sum of free ammonia, ammonium ion, and any LMW amines in the sample.

\subsubsection{Target MDLs and EQLs for Ammonia/Ammonium}

EPA Method 350.3 provides no guidance for target MDLs or EQLs. Therefore, MDLs for ammonia will be determined on a best effort basis. Success will be based on currently undefined criteria.

\subsubsection{Preparative Methods for Liquids and Solids}

No extensive sample preparation is normally necessary for either solids or liquids. Free ammonia can be measured directly in liquids and following distillation in solids. Ammonium ion can be readily measured by adding a strong base to convert it to free ammonia. The strong base used for this normally has a strong complexing agent (such as ethylenediaminetetraacetic acid [EDTA]) added to free bound ammonia from metal ammines, eliminating a potential source of low bias. This addition of strong base is already included in the distillation and ISE procedures so that no procedure changes would normally be necessary.

If necessary, the ammonia and ammonium can be distilled out of a sample from a strong base solution and caught in a dilute acid solution where it can be readily measured (EPA/600 Method 350.2). The distillation is straightforward, but distillation is not normally necessary, even for samples with high dissolved solids. Distillation could be used to eliminate high dose, so that a large sample size could be used to obtain a low detection limit.

Because Hanford tank wastes have very high dose, samples usually must be diluted with water before analysis to reduce dose to the staff. Sample dilution greater than tenfold is not normally necessary.

\subsubsection{Analysis Methods}

SW-846 does not include a method for determining ammonia/ammonium. However, EPA/600 methods for analyzing ammonia are included in Table 5-6, and the current analysis method used for tank waste liquids is equivalent to EPA Method 350.3. The EPA/600 methods do not specifically address determination of ammonia from solid matrices; however, all ammonium compounds are readily water soluble and can be measured using water methods. Other Standard Methods, such as those from "Standard Methods for Examination of Water and Wastewater - 4500- $\mathrm{NH}_{3}$ Nitrogen Series," are also applicable for analyzing ammonia/ammonium in aqueous matrices. Any of these methods would probably work well for Hanford tank wastes. 
Table 5-6. EPA Analysis Methods

\begin{tabular}{||c|l|l||}
\hline \multicolumn{2}{|c|}{ Method } & \multicolumn{1}{c|}{ Applicability } \\
\hline 350.1 & $\begin{array}{l}\text { EPA/600 Methods for Chemical Analysis of Water and Waste } \\
\text { Aitrogen, Ammonia (Colorimetric, } \\
\text { Automated Phenate) }\end{array}$ & $\begin{array}{l}\text { Waters and domestic/industrial } \\
\text { wastes }\end{array}$ \\
\hline 350.2 & $\begin{array}{l}\text { Nitrogen, Ammonia (Colorimetric, } \\
\text { Titrimetric, Potentiometric, } \\
\text { Distillation Procedure) }\end{array}$ & $\begin{array}{l}\text { Waters and domestic/industrial } \\
\text { wastes }\end{array}$ \\
\hline 350.3 & $\begin{array}{l}\text { Nitrogen, Ammonia } \\
\text { (Potentiometric, Ion Selective } \\
\text { Electrode) }\end{array}$ & $\begin{array}{l}\text { Waters and domestic/industrial } \\
\text { wastes }\end{array}$ \\
\hline
\end{tabular}

\subsubsection{Modification to Current Method}

No modifications to the methods will likely be necessary other than mechanical details necessary to minimize dose to staff. Hanford tank wastes sometimes have such a high dose that only a few milligrams of material can be handled in an open-faced hood, affecting the detection limit. These types of modifications would be considered minor.

Dose considerations could force the laboratory to use shielding around the sample and analytical instrumentation, but this would probably not affect the EQL.

\subsubsection{Experience with Analysis of Tank Waste Matrices}

In 1999, ammonia was measured in several Hanford tank wastes, including liquids, solids, and slurries, using an ISE method equivalent to EPA Method 350.3. The analyses have always run within QA acceptance criteria. Distillation has not been necessary. Reported detection limits have been typically well below $1 \mathrm{mg} \mathrm{NH}_{3}$ per $\mathrm{kg}$ of sample. Precision at ten or more times the detection limit has been approximately $\pm 10 \%$.

\subsubsection{Limitations}

The simple ISE method (without distillation) will measure the sum of free ammonia, ammonium ion, and LMW amines. To measure only one, the method would have to be modified and tested. Ammonia and ammonium could be measured separately, but the cost would be much higher, and the reliability would surely be worse.

Low-molecular-weight amines behave like ammonia and will cause a high bias. Currently, insufficient data are available to assess the effects of these amines on the ammonia results. The LMW amines will be evaluated for interference and matrix effects, and organic-analysis data will be evaluated to assess whether these amines are at sufficient concentrations to produce a high bias in the reported results.

Most other nitrogen compounds would not interfere. Nitrate and nitrite would not interfere as long as strong reducing agents (such as metallic aluminum or zinc) were absent.

Using an ISE, analytical accuracy is typically very good, and the data will probably be unbiased on the average. Precision is typically on the order of $\pm 10 \%$ by ISE at ammonia concentrations above about $1 \mathrm{mg} / \mathrm{kg}$. 


\subsubsection{Summary}

The ammonia concentration in Hanford tank wastes can be readily measured using standard methods, such as direct measurement by ISE. Recent analysis of actual tank wastes using an ISE gave reliable data, with no significant procedure modifications. EPA Method 350.3 provides no guidance for target MDLs or EQLs. Therefore, MDLs for ammonia will be determined on a "best effort" basis. Success will be based on currently undefined criteria.

\subsection{Cyanide Analysis}

\subsubsection{Regulatory DQO Recommended Method}

The Regulatory DQO suggests Method 9010B, "Total And Amenable Cyanide: Distillation,” with minor modification. Method 9010 is reflux-distillation procedure used to extract soluble CN salts and many insoluble $\mathrm{CN}$ complexes from wastes and leachates. It is based on the decomposition of nearly all CNs by a reflux distillation procedure using a strong acid and a magnesium catalyst. $\mathrm{CN}$, in the form of hydrocyanic acid ( $\mathrm{HCN})$, is purged from the sample and captured into an alkaline scrubber solution. The $\mathrm{CN}$ concentration in the absorbing solution is then determined colorimetrically or titrametrically by Method 9014 or by ion-selective electrode by Method 9213. Method 9010 may be used as a refluxdistillation procedure for both total $\mathrm{CN}$ and $\mathrm{CN}$ amenable to chlorination. The "reactivity" of the waste due to CN (i.e., SW-846 Chapter 7, Section 7.3.3) is not within the scope of the Regulatory DQO.

Footnotes in the DQO indicate that Method 9010B has been modified by the dissolution of complexed stable CNs, followed by microdistillation, when used to analyze tank waste (HAS 1997). The DQO also cautions the reader that SW-846 Method 9010B does not discuss how to deal with extremely complexed CNs. The $\mathrm{CN}$ method used for the tank waste includes a procedure for the dissolution of insoluble $\mathrm{Na}_{(2-\mathrm{X})} \mathrm{Cs}_{(\mathrm{X})} \mathrm{NiFe}(\mathrm{CN})_{6}$ (nickel ferrocyanide) compounds found in the waste. Insoluble nickel ferrocyanide compounds are not decomposed by the standard EPA CN method, which is based solely on decomposition through the use of a strong acid and a magnesium catalyst. Therefore, a predissolution is required for any tank materials known or suspected to contain these complex, insoluble CN compounds. If insoluble $\mathrm{CN}$ compounds are known, through process knowledge, to be absent from the waste, then the modified version of Method 9010B is not necessary.

\subsubsection{Target MDLs and EQLs for CN}

Table 5-7 presents the target MDLs for CN using titration and colorimetry. For titration, Method 9010B also provides a target MDL for waste analysis.

Table 5-7. CN Target MDLs as Published in Method 9010B

\begin{tabular}{|c|c|c|c|c|c|}
\hline \multirow[b]{2}{*}{$\begin{array}{c}\text { CAS } \\
\text { Registry } \\
\text { Number }\end{array}$} & \multirow[b]{2}{*}{ Compound } & \multicolumn{2}{|c|}{ Titration } & \multicolumn{2}{|c|}{ Colorimetry } \\
\hline & & $\begin{array}{l}\text { Liquid } \\
\text { Target } \\
\text { MDL } \\
(\mu \mathrm{g} / \mathrm{L})\end{array}$ & $\begin{array}{c}\text { Solids } \\
\text { Target } \\
\text { MDL } \\
(\mu \mathrm{g} / \mathrm{L})\end{array}$ & $\begin{array}{l}\text { Liquid } \\
\text { Target } \\
\text { MDL } \\
(\mu \mathrm{g} / \mathrm{L})\end{array}$ & $\begin{array}{c}\text { Solids } \\
\text { Target } \\
\text { MDL } \\
(\mu \mathrm{g} / \mathrm{L})\end{array}$ \\
\hline $57-12-5$ & $\mathrm{CN}$ [amenable] & 100 & 200 & 20 & N/A \\
\hline
\end{tabular}

N/A - Not available. Method 9010B does not provide a target MDL for solids by colorimetry. 


\subsubsection{Preparative Methods for Liquids and Solids}

Except for those tank wastes anticipated to contain alkali nickel-ferrocyanide compounds, no preprocessing of either the liquids or solids should be necessary. For those tank wastes suspected to contain these complex, insoluble CN compounds, an EDTA/Ethylenediamine pretreatment dissolution method developed by PNNL (HAS 1997) is to be used to dissolve the CN compounds before distillation. This dissolution method has been used successfully on tank waste material, and its use is prescribed in the Regulatory DQO, Attachment IV (Wiemers 1998b), as described above. It should be noted that it is not part of the SW-846 or EPA published methods and would be considered a minor modification.

\subsubsection{Analysis Methods}

SW-846 and EPA/600 methods for analyzing CN are included in Table 5-8. The SW-846 methods are applicable for analyzing aqueous matrixes, oils, and solids, whereas the EPA/600 methods are only applicable to aqueous matrices. However, the CN analysis from either SW-846 or EPA/600 is restricted to soluble $\mathrm{CN}$ salts and many, but not all, insoluble $\mathrm{CN}$ complexes.

The EPA CN methods are reasonably rugged and are generally applicable to Hanford tank waste matrices. These methods employ titration, spectrophotometry, or colorimetry for analyzing CN. The methods attempt to address samples with high nitrate and/or nitrite concentrations, which is typical of Hanford tank wastes. However, the EPA methods are not directly applicable to those Hanford tank wastes containing highly complex CN compounds (e.g., nickel ferrocyanides). These types of waste are not anticipated during the implementation of Step 1 of the Regulatory DQO.

The EPA methods are used in combination for analyzing CN. Method 9010B provides a procedure for distilling CN. A modification of this method is used for tank waste analysis. The modification is the use of micro-distillation by a separation membrane versus a standard distillation apparatus. This allows smaller sample sizes to be distilled. The $\mathrm{CN}$ is analyzed using an equivalent $9012 \mathrm{~A}$ method if automated colorimetry is performed, or 9014 if manual spectrophotometry is used.

\subsubsection{Modification to Current Method}

Besides adding a pretreatment method to dissolve ferrocyanide complexes, it is recommended that microdistillation methods be used in place of the large volume, flask distillation methods detailed in the SW-846 and EPA/600 methods. Micro-distillation used separation membranes instead of traditional distillation equipment.

The EPA methods for measuring $\mathrm{CN}$ in solids and liquids use reasonably large sample volumes for distillation, e.g., $500 \mathrm{~mL}$. At these large volumes, the dose generated by most of the tank waste material generally precludes safe handling and analysis outside shielded hot cell facilities. Since the EPA methodology is applicable to tank waste materials, the goal is to retain this methodology while being able to safely handle and analyze the material according to ALARA principles. There are essentially two viable options:

1) Use the SW-846 methods as written (with the addition of the pretreatment procedure, when necessary) and perform the distillation in a shielded facility. The $\mathrm{CN}$ analysis (i.e., titrimetric or colorimetric) of the distillation trap solutions may be performed outside this shielded facility. 
Table 5-8. EPA Analysis Methods

\begin{tabular}{|c|c|c|}
\hline \multicolumn{2}{|r|}{ SW-846 Method } & Applicability \\
\hline $9010 \mathrm{~B}$ & $\begin{array}{l}\text { Total and Amenable CN: } \\
\text { Distillation }\end{array}$ & $\begin{array}{l}\text { Soluble CN salts and many insoluble } \\
\mathrm{CN} \text { complexes in liquid/solid wastes } \\
\text { and leachates }\end{array}$ \\
\hline $9012 \mathrm{~A}$ & $\begin{array}{l}\text { Total and Amenable CN } \\
\text { (Automated Colorimetric, with } \\
\text { Off-Line Distillation) }\end{array}$ & $\begin{array}{l}\text { Soluble CN salts and many insoluble } \\
\text { CN complexes in liquid/solid wastes }\end{array}$ \\
\hline 9013 & $\begin{array}{l}\text { CN Extraction Procedure for } \\
\text { Solids and Oils }\end{array}$ & Extractable $\mathrm{CN}$ in solids and oils \\
\hline 9014 & $\begin{array}{l}\text { Titrimetric and Manual } \\
\text { Spectrophotometric Determinative } \\
\text { Method for CN }\end{array}$ & Distillates from 9010B \\
\hline 9213 & $\begin{array}{l}\text { Potentiometric Determination of } \\
\text { CN in Aqueous Samples with Ion- } \\
\text { Selective Electrode }\end{array}$ & $\begin{array}{l}\text { Distillates from } 9010 \mathrm{~B} \text {, free } \mathrm{CN} \text { in } \\
\text { undistilled waters/wastes; soluble } \\
\text { CN extracted from solids by ASTM } \\
\text { D4646 }^{(\mathrm{a})}, \mathrm{D} 5233^{\text {(b) }} \text {, or D3987 }\end{array}$ \\
\hline \multicolumn{3}{|c|}{ EPA/600 Methods for Chemical Analysis of Water and Waste } \\
\hline 335.1 & $\begin{array}{l}\mathrm{CN}, \text { Amenable to Chlorination } \\
\text { (Titrimetric: Spectrophotometric) }\end{array}$ & $\begin{array}{l}\mathrm{CN} \text { amenable to chlorination in } \\
\text { waters and domestic/industrial } \\
\text { wastes }\end{array}$ \\
\hline 335.2 & $\begin{array}{l}\text { CN, Total (Titrimetric: } \\
\text { Spectrophotometric) }\end{array}$ & $\begin{array}{l}\text { Waters and domestic/industrial } \\
\text { wastes }\end{array}$ \\
\hline 335.3 & $\begin{array}{l}\text { CN, Total (Colorimetric: } \\
\text { Automated ultraviolet [UV]) }\end{array}$ & $\begin{array}{l}\text { Waters and domestic/industrial } \\
\text { wastes }\end{array}$ \\
\hline
\end{tabular}
(a) ASTM 1993.
(b) ASTM 1999b.
(c) ASTM 1999a

(2) Modify the SW-846 methods to include the use of micro-distillation methodology. With micro-distillation, the sample size is reduced, and the distillation and analysis can be performed outside a shielded facility.

Micro-distillation/membrane methods are accepted as being equivalent to high-volume classical distillation methods, and the results for both the soluble and insoluble CN compounds should be the same from either approach.

To measure both the total $\mathrm{CN}$ and the $\mathrm{CN}$ amenable to chlorination, a portion of the sample must be subjected to a chlorination pretreatment. Both the pretreated portion and an original portion of the tank waste sample are analyzed to determine the $\mathrm{CN}$ amenable to chlorination. The micro-distillation followed by automated spectrophotometric analysis of the distillate is applicable to either the original (unchlorinated) sample or the pretreated (chlorinated) sample.

\subsubsection{Experience with Analysis of Tank Waste Matrices}

$\mathrm{CN}$ in tank waste matrices has been measured successfully on numerous tanks. The micro-distillation methods used for these measurements include: 
- LA-9695-103. Determination of Cyanide by EDTA/EN Dissolution Followed by Microdistillation and Spectrophotometric Analysis. ${ }^{\text {(a) }}$

- PNL-AL0-285. Total Cyanide by Remote Microdistillation and Argentometric Titration; includes EDTA/Ethylenediamine dissolution. ${ }^{(b)}$

- $\quad$ PNL-ALO-287. Midi and Micro Distillation of Cyanide in Liquid and Solid Samples (Equivalent to SW-846 Method 9010B). ${ }^{\text {(c) }}$

- PNL-ALO-289. Total Cyanide Determination by Spectrophotometry, Manual or Automated, or Argentometric Titration (Equivalent to SW-846 Method 9012A and 9014). ${ }^{(\mathrm{d})}$

In general, there have been very few problems identified in the use of these methods on the Hanford tank waste matrices. Typical interferences that impact the method (e.g., chlorine and sulfide) are not considered to be resident in any significant quantities in the Hanford tank wastes. Although not considered to be a problem, chlorine and sulfide interferences can be mitigated by adding excess sodium arsenite and bismuth nitrate, respectively, should the need arise.

Experience with micro-distillation and automated spectrophotometric analysis indicates that the approximately 2 to $4 \mathrm{ppb}$ (parts per billion) $\mathrm{CN}$ can be detected in the distilled trap solution. Using a 3-ppb MDL, a sample size of $0.25 \mathrm{~g}$ (or $0.25 \mathrm{~mL}$ ) and the sample dilution required by the method, the typical EQL is approximately $0.07 \mathrm{mg} / \mathrm{kg}$ (or $0.07 \mathrm{mg} / \mathrm{L}$ ), which is well within the EQL requirements. Due to varying dose levels, typical sample sizes range from 0.1 to $0.8 \mathrm{~g}$, and even at $0.1 \mathrm{~g}$, the analysis has little difficulty in meeting the required MDL.

Typically, only total CN has been reported on Hanford tank waste.

\subsubsection{Limitations}

In general, the measurement precision (based on RPD between duplicates) and accuracy (based on matrix spikes) is reasonably good for the micro-distillation and automated spectrophotometric method.

However, some data suggest that there are some matrix effects that are not fully being addressed (e.g., some spike recoveries measure low), and significant $\mathrm{CN}$ heterogeneity may exist within the tank waste matrix (i.e., RPDs are outside the acceptance criteria of $20 \%$ when using sample sizes of about $0.5 \mathrm{~g}$ ).

To ensure that the QC parameters are met for all tank waste types, it may be necessary to fully evaluate the source of the matrix interference effects or to expand the MS recovery beyond the current $75 \%$ to $125 \%$ acceptance criteria. The excessively high nitrite/nitrate concentrations in combination of certain organics may generate HCN during the distillation. Although pretreatment of the sample with sulfamic acid before the distillation should eliminate this interference, there is some uncertainty to the total effectiveness of this pretreatment for all of the complex Hanford tank waste types.

(a) Hanford Analytical Services (HAS). 1997. Determination of Cyanide by EDTA/EN Dissolution Followed by Microdistillation and Spectrophotometric Analysis, LA-695-103, Richland, Washington.

(b) Battelle-PNL Technical Procedure. 1993. Total Cyanide by Remote Microdistillation and Argentometric Titration. PNL-AL0-285, Rev. 0, Pacific Northwest National Laboratory, Richland, Washington.

(c) Battelle-PNL Technical Procedure. 1995. Midi and Micro Distillation of Cyanide in Liquid and Solid Sample, PNL-ALO-287, Rev. 0, Pacific Northwest National Laboratory, Richland, Washington.

(d) Battelle-PNL Technical Procedure. 1995. Total Cyanide Determination by Spectrophotometry, Manual or Automated, or Argentometric Titration, PNL-ALO-289, Rev. 0, Pacific Northwest National Laboratory, Richland, Washington. 
The use of relatively small sample sizes to minimize exposure dose to personnel and sample heterogeneity at a macro particle-size level tend to produce poor RPDs; this has been observed for some tank waste $\mathrm{CN}$ analyses. Typically, the larger the sample, the better the reproducibility between duplicates. Sizing and/or improved mixing techniques are options to improve the RPDs.

\subsubsection{Summary}

The EPA CN analysis methods are considered to be analytically rugged methods that are directly applicable to Hanford tank waste matrices with only minor modifications. Modifications to the method include the use of pretreatment (chlorination) when the presence of ferrocyanide complexes are suspected and the use of micro-distillation (i.e., Section 5.4.5, Option 2) to keep the dose ALARA. Under routine conditions using well mixed and homogenized samples, the modified method should meet or exceed the required MDLs for both the amenable and total CN.

\subsection{Hydroxide Analysis}

\subsubsection{Regulatory DQO Recommended Method}

The Regulatory DQO recommends the EPA/600 Method 310.1, "Alkalinity," for analyzing hydroxide in the tank waste (EPA 1995). This method determines the alkalinity of an unaltered sample though titration to a $\mathrm{pH}$ of 4.5 with a standardized acid (hydrochloric or sulfuric acid).

\subsubsection{Target MDLs and EQLs for Hydroxide}

EPA Method 310.1 provides no guidance for target MDLs or EQLs. Therefore, MDLs for hydroxide will be determined on a best-effort basis. Success will be based on currently undefined criteria.

\subsubsection{Preparative Methods for Liquids and Solids}

No pre-processing is necessary for liquid or slurry samples. Method 310.1 specifies that the sample should not be filtered, diluted, concentrated, or altered in any other way before analysis. However, due to radiation-dose issues, sample size is limited for the liquid analysis, and small aliquots may need to be diluted with water so that the entire tip of the $\mathrm{pH}$ probe is covered. Since tank wastes are generally highly alkaline, the aliquot used for analysis against a dilute $(0.1-0.2 \mathrm{M})$ acid is minimal (usually $<0.5 \mathrm{~mL}$ ). A dilute acid is required if weak base species are to be identified. The nominal 0.2-g sample sizes used for the solids analysis may be applicable in most cases; i.e., only the highest activity wastes may require reduced sample sizes.

\subsubsection{Analysis Methods}

SW-846 does not include any method for determining hydroxide. However, other EPA/600 methods exist for determining alkalinity and are listed in Table 5-9. The EPA/600 methods do not specifically address determination of hydroxide in solid matrices. Other standard methods, such as those from "Standard Methods for Examination of Water and Wastewater - 2320 Alkalinity Series," are also applicable for analyzing alkalinity in aqueous matrices. These methods all use titration to measure hydroxide. 
Table 5-9. EPA Analysis Methods

\begin{tabular}{||c|l|l||}
\hline \multicolumn{2}{|c|}{ Method } & \multicolumn{1}{c|}{ Applicability } \\
\hline 310.1 & EPA/600 Methods for Chemical Analysis of Water and Waste \\
\hline 310.2 & $\begin{array}{l}\text { Alkalinity (Colorimetric, } \\
\text { Automated Methyl Orange) }\end{array}$ & $\begin{array}{l}\text { Waters and domestic/industrial } \\
\text { wastes }\end{array}$ \\
\hline
\end{tabular}

The method that will be used to measure hydroxide under the Regulatory DQO is an adaptation of the EPA titration method and is applicable to samples with high hydroxide and/or other weak base concentrations, such as Hanford tank wastes. This method uses an auto-titrator (similar to EPA/600 Method 310.2) and a standardized dilute acid (usually 0.1 to $0.2 \mathrm{M}$ hydrochloric acid), to identify any alkaline species in a sample. The method will chart and record inflection points and milliequivalents required for each species, but will not absolutely identify each base compound in the sample.

Hanford tank wastes contain many species that consume acid and record inflection points, such as carbonate, bicarbonate, phosphate, aluminate, organic acids, and others, thus making it very difficult to quantify the concentration of the free hydroxide. The titration data could be combined with other data, such as metals, mass-balance, and anions, to identify the most likely species at each inflection point. Also, pre-tritration processing options, such as additives to precipitate interfering species, can be evaluated and implemented if shown to be effective.

The sample may be unaltered for analysis, and the resulting matrix factor between the MDL and EQL would be near 1 . However, the matrix factor is more reasonably set at 3 to 5 , since significant interfering species typically exist in the Hanford tank waste, making accurate quantification of the hydroxide difficult. Also, the measurement precision (based on RPD between duplicates) and accuracy (based on matrix spikes) indicates excellent agreement on all analyses of tank wastes to date. Therefore, the method will be able to attain the required QA criteria.

\subsubsection{Modification to Current Method}

The high-dose-rate tank waste may require additional shielded processing or smaller sample sizes. This is necessary to ensure safe handling and analysis outside shielded hot cell facilities, since the goal is to retain this methodology while being able to safely handle and analyze the material. For high-activity waste, sample sizes in the range of 0.5 to $2 \mathrm{~mL}$ for liquids and 0.05 to $0.15 \mathrm{~g}$ for high-solids slurries is considered acceptable for non-shielded facilities. Also, to minimize exposure, an automated system is used for analysis. For heterogeneous waste samples, the use of small sample sizes to minimize dose typically impacts the measurement precision, and in such cases, analysis of multiple aliquots may be required to meet the desired precision criteria.

With the exception of volume reduction to keep doses ALARA, and the addition of water to ensure that the $\mathrm{pH}$ probe is kept wet, no modification to the current method is necessary; however, the data generated from the method will be used to calculate the hydroxide concentration, not the alkalinity of the sample in terms of $\mathrm{mg} / \mathrm{L}$ of $\mathrm{CaCO}_{3}$ as Method 310.1 specifies.

\subsubsection{Experience with Analysis of Tank Waste Matrices}

Hydroxide in tank waste matrices has been measured successfully on several Hanford tank waste samples. The auto-titration method used for these measurements is essentially equivalent to EPA/600 Method 
310.2. Recently the method was applied to analysis of hydroxide in AP101, AN107, AW101, and C104 (Urie et al. 1999b; Urie et al. 2000; Fiskum et al. 2000).

No problems have been experienced with the actual analysis and, in general, the QC applied to the method demonstrated good method performance. The method poses no mechanical difficulties, but the data interpretation may require more effort if other specific weak-base identifications are required beyond carbonate and bicarbonate, which have been noted to this point. These weak bases associated with tank waste in addition to hydroxide can be readily identified on the plotted titration curve and summarized on the report.

\subsubsection{Limitations}

The hydroxide method is applicable for measuring soluble hydroxide in liquids or slurries. Data interpretation becomes more complicated for highly buffered, high-concentration samples with several bases.

High concentrations of carbonate, bicarbonate, phosphate, and other basic compounds will affect the apparent concentration of free hydroxide, but most likely not enough to measurably change the data for Hanford tank wastes.

\subsubsection{Summary}

The hydroxide anion can be measured using EPA Method 310.1 with only minor modification. EPA Method 310.1 provides no guidance for target MDLs or EQLs. Therefore, MDLs for hydroxide will be determined on a best-effort basis. Success will be based on currently undefined criteria. QA criteria specified in Tables 3-1 and 3-2 can be met.

\subsection{Mercury Analysis}

\subsubsection{Regulatory DQO Recommended Method}

The Regulatory DQO suggests Method 7470/7471A, "Mercury in Liquid Waste (Manual Cold-Vapor Technique)/Mercury in Solids or Semisolid Waste (Manual Cold-Vapor Technique)." Both methods are cold-vapor atomic absorption methods based on the absorption of radiation at the 253.7-nm wavelength by mercury vapor. The mercury is reduced to the elemental state and aerated from solution in a closed system. The mercury vapor passes through a cell positioned in the light path of an atomic absorption spectrophotometer. Absorbance (peak height) is measured as a function of mercury concentration. Specific acid-digestion preparations for liquids and solids must be performed on the samples before coldvapor atomic absorption analysis; the digestion methods are defined as part of each method.

\subsubsection{Target MDLs and EQLs for Mercury}

Table 5-10 presents the target MDL for mercury by Method 7470. An instrument detection level is given for Method 7471A; however, no guidance for MDLs is provided. Therefore, the MDL for mercury will be determined on a best-effort basis. Success will be based on currently undefined criteria. 
Table 5-10. Mercury Target MDL for Method 7470 and Target IDL for Method 7471A

\begin{tabular}{||c|c|c|c||}
\hline $\begin{array}{c}\text { CAS } \\
\text { Registry } \\
\text { Number }\end{array}$ & Compound & $\begin{array}{c}\text { Method 7470 } \\
\text { Target MDL } \\
\text { for Liquids } \\
(\boldsymbol{\mu g} / \mathrm{L})\end{array}$ & $\begin{array}{c}\text { Method 7471A } \\
\text { Target IDL } \\
\text { for solids } \\
(\boldsymbol{\mu g} / \mathrm{L})\end{array}$ \\
\hline $7439-97-6$ & Mercury & 0.2 & 0.2 \\
\hline
\end{tabular}

\subsubsection{Preparative Methods for Liquids and Solids}

The SW-846 methods include acid digestion of the sample and typically use 100-mL liquid samples and 0.2-g solid samples. The IDL stated in SW-846 Method 7471A is $0.0002 \mathrm{mg} / \mathrm{L}$ in the digestate; this equates to a total of $0.00002 \mathrm{mg}$ of mercury for a $100-\mathrm{mL}$ sample. Therefore, the equivalent limit in the solids is about $0.1 \mathrm{mg} / \mathrm{kg}$.

The acid-digestion preparation of the liquids and solids is reasonably robust and is applicable to Hanford tank waste materials. However, due to radiation dose issues, it is unlikely that $100-\mathrm{mL}$ samples can be used for the liquid analysis. The nominal 0.2 -g sample sizes used for the solids analysis may be applicable in most cases; i.e., only the highest activity wastes may require reduced sample sizes.

\subsubsection{Analysis Methods}

SW-846 and EPA/600 methods for analyzing mercury are included in Table 5-11. Of the methods listed, only SW-846 Method 7472 is not considered viable as a method for analyzing mercury in Hanford tank waste matrices. This is primarily because Method 7472 has been developed specifically for waste waters.

Table 5-11. EPA Analysis Methods

\begin{tabular}{|c|c|c|}
\hline & Method & Applicability \\
\hline \multicolumn{3}{|c|}{ SW-846 } \\
\hline $7470 \mathrm{~A}$ & $\begin{array}{l}\text { Mercury in Liquid Waste (Manual } \\
\text { Cold Vapor Technique) }\end{array}$ & Aqueous matrices, TCLP extracts \\
\hline $7471 \mathrm{~A}$ & $\begin{array}{l}\text { Mercury in Solids or Semisolid } \\
\text { Waste (Manual Cold Vapor } \\
\text { Technique) }\end{array}$ & $\begin{array}{l}\text { Soils, sediments, bottom deposits, and } \\
\text { sludge-type materials }\end{array}$ \\
\hline 7472 & $\begin{array}{l}\text { Mercury in Aqueous Samples and } \\
\text { Extracts by Anodic Stripping } \\
\text { Voltammetry }\end{array}$ & $\begin{array}{l}\text { Dissolved divalent } \mathrm{Hg} \text { in waters and } \\
\text { domestic/industrial wastes }\end{array}$ \\
\hline \multicolumn{3}{|c|}{ EPA/600 Methods for Chemical Analysis of Water and Waste } \\
\hline 245.1 & $\begin{array}{l}\text { Mercury (Cold Vapor Technique: } \\
\text { Manual) }\end{array}$ & $\begin{array}{l}\text { Waters, and domestic/industrial wastes } \\
\text { (excluding organic mercurials) }\end{array}$ \\
\hline 245.2 & $\begin{array}{l}\text { Mercury (Cold Vapor Technique: } \\
\text { Automated) }\end{array}$ & $\begin{array}{l}\text { Waters, effluents, and domestic sewages } \\
\text { (excluding organic mercurials) }\end{array}$ \\
\hline 245.5 & $\begin{array}{l}\text { Mercury (Cold Vapor Technique: } \\
\text { Sediments) }\end{array}$ & $\begin{array}{l}\text { Soils, sediments, bottom deposits, and } \\
\text { sludge-type materials }\end{array}$ \\
\hline
\end{tabular}

\subsubsection{Modification to Regulatory DQO Recommended Method}

The SW-846 methods are "total" release methods where all the mercury in the sample digested for analysis is measured. That is, the digestate is not sub-aliquotted for cold-vapor atomic-absorption 
analysis, but the total mercury in the entire digestate is released and measured. Unfortunately, these highsample-volume methods do not lend themselves well to automation or remote processing/analysis. Once these methods are adapted for automation or remote processing, the sample MDL typically increases since the automated methods typically "sub-sample" the digestate (i.e., the digestate volume changes due to processing must be factored into to the MDL).

Since it is unlikely that large volumes of Hanford tank waste, either solid or liquid, can safely be processed or analyzed outside a shielded facility, it is necessary to attempt to optimize (or modify) the existing SW-846 methods. For high-activity waste, sample sizes in the range of 0.5 to $2 \mathrm{~mL}$ for liquids and 0.05 to $0.15 \mathrm{~g}$ for solids or high-solids slurries are considered acceptable for non-shielded facilities. Also, to minimize exposure, automated systems should be used for digestion and analysis. With the use of automated mercury analyzers (available from multiple vendors) that are based on SW-846 methodology, anticipated MDLs are nominally $5 \mu \mathrm{g} / \mathrm{L}$ for liquids and $50 \mu \mathrm{g} / \mathrm{kg}$ for solids. SW-846 Method 7471 A and 7470A prescribes 0.2-g sample sizes for solids and 100-mL sample sizes for liquids, respectively. For heterogeneous waste samples, the use of small sample sizes to minimize dose typically impacts the measurement precision, and in such a case, analysis of multiple aliquots may be required to meet the desired precision criteria.

Also, although the SW-846 mercury cold-vapor method is a robust method and considered applicable to Hanford tank waste materials, alternate measurement methods (i.e., following an appropriate digestion), such as ICP/MS, may provide significant cost savings (e.g., mercury can be obtained during routine metals analysis by ICP/MS) and should be investigated during the method evaluation processes.

\subsubsection{Experience with Analysis of Tank Waste Matrices}

Numerous Hanford tank waste materials have been analyzed for mercury, both by Hanford Analytical Services and Battelle. The methods used by both organizations are essentially equivalent to the SW-846 7470/7471 A methods. There have been very few problems experienced with the actual analysis and, in general, the QC applied to the method demonstrated good method performance.

The actual EQLs for mercury have been demonstrated to be a factor of 5 to 20 times the MDL. The mercury method is very robust and highly sensitive, and the matrix has only a moderate effect on the EQL. Based on a nominal 10 times MDL factor, the current automated cold-vapor-analysis systems have EQLs of about $50 \mu \mathrm{g} / \mathrm{L}$ for liquids and $200 \mu \mathrm{g} / \mathrm{kg}$ for solids.

\subsubsection{Limitations}

The SW-846 mercury methods have minimal limitation, except for some interferences. The potential interferences include high chloride, sulfide, and copper, as well as volatile organic compounds that absorb at a wavelength of $253.7 \mathrm{~nm}$. Except for the volatile organic compounds, these interferences can be easily mitigated.

High organic concentrations have been shown to impact the analysis by requiring additional oxidizing reagents. Failure to recognize the need for the additional reagents can lead to incorrect results.

\subsubsection{Summary}

The SW-846 7470/7471A mercury methods are considered to be analytically robust and directly applicable to Hanford tank waste matrices with only minor to moderate modification. Applicable QA/QC requirements for Method 7470/7471 A would be extended to the modified method. The anticipated modifications to the method are instrumentation/optimization-based, not methodology-based. That is, the 
primary approach to the measurement of mercury in Hanford tank waste matrices is by cold-vapor atomic absorption spectrophotometry. It is anticipated that a modified cold-vapor atomic-absorption method should meet or exceed the required MDL. It is recommended that these methods be applied first. If MDLs are not met, then alternate methodologies (e.g., ICP/AES or ICP/MS) can be pursued. The ICP/AES suffers from low sensitivity and the ICP/MS from possible mass interferences; however, mercury will be included in the suite of analytes evaluated during the ICP/MS methods development activities. 


\subsection{References}

40 CFR 136. 2000. US Environmental Protection Agency, "Guidelines Establishing Test Procedures for the Analysis of Pollutants." U.S. Code of Federal Regulations.

ASTM. 1993. Standard Test Method for 24-h Batch-Type Measurement of Contaminant Sorption by Soils and Sediments. D4646-87(1993), American Society For Testing and Materials, West

Conshohocken, Pennsylvania.

ASTM. 1996. Standard Practice for Total Digestion of Sediment Samples for Chemical Analysis of Various Metals. D4698-92(1996), American Society For Testing and Materials, West Conshohocken, Pennsylvania.

ASTM. 1998. Standard Practice for Dissolution of Solid Waste by Lithium Metaborate Fusion. D450386(1998), American Society For Testing and Materials, West Conshohocken, Pennsylvania.

ASTM. 1999a. Standard Test Method for Shake Extraction of Solid Waste with Water. D398785(1999), American Society For Testing and Materials, West Conshohocken, Pennsylvania.

ASTM. 1999b. Standard Test Method for Single Batch Extraction Method for Wastes. D5233-92(1999), American Society For Testing and Materials, West Conshohocken, Pennsylvania.

Campbell JA, SA Clauss, KE Grant, V Hoopes, GM Mong, J Rau, R Steele, and KH Wahl. 1996. Flammable Gas Safety Program: Actual Waste Organic Analysis, FY 1996 Progress Report.

PNNL-11307, Pacific Northwest National Laboratory, Richland, Washington.

Campbell JA, EW Hoppe, AK Sharma, SC Clauss, MW Urie, and GS Klinger. 2000. "Analysis of Regulatory Organic Compounds in Hanford Tank Wastes." In Proceedings of WM 2000, Tucson, Arizona. In Press.

DOE 1998. See U.S. Department of Energy

EPA 1989, 1989, 1995, 1997. See U.S. Environmental Protection Agency.

Farmer OT III, JH Reeves, EJ Wyse, CJ Clemetson, CJ Barinaga, MR Smith, and DW Koppenaal. 1995. "Analysis of Radioactive Waste Samples by Ion Chromatography-beta-ICP/MS." pp. 38-37 in Applications of Inductively Coupled Plasma-Mass Spectrometry. STP 1291, American Society for Testing and Materials, Philadelphia.

Fiskum SK, PR Bredt, JA Campbell, LR Greenwood, OT Farmer, GJ Lumetta, GM Mong, RT Ratner, CZ Soderquist, RG Swoboda, MW Urie, and JJ Wagner. 2000. Inorganic, Radioisotopic, and Organic Analysis of 241-AP-101 Tank Waste. PNWD-2463, Battelle Pacific Northwest Division, Richland, Washington.

Grant KE, RB Lucke, SA Clauss, GM Mong, BD Lerner, and JA Campbell. 1996a. "Qualitative Determination of Low-Molecular Weight Organic Acids in Mixed Hazardous Wastes Using Thermospray Liquid Chromatography/Mass Spectrometry." J. of Radioanaltyical and Nucl. Chem, 207, 247-261. 
Grant KE, GM Mong, RB Lucke, and JA Campbell. 1996b. “Quantitative Determination of Chelators and Their Degradation Products in Mixed Hazardous Wastes from Tank 241-SY-101 Using Derivatization GC/MS." J. of Radioanalytical and Nuclear Chem., 211, 383-402.

Hoppe EW, RB Lucke, GA Ross, and JA Campbell. 1992. Development and Validation of a Preparation and Cleanup Method for Hydrocarbon-Containing Samples for the Analysis of Volatile Organic Compounds. PNL-8099, Pacific Northwest Laboratory, Richland, Washington.

Klinger GS, MW Urie, JA Campbell, SA Clauss, TW Clauss, EW Hoppe, GM Mong, and AK Sharma. 2000. Organic Analysis of AW101 and AN107 Tank Waste. PNWD-2461, Battelle, Pacific Northwest National Laboratory, Richland, Washington.

Lucke RB, JA Campbell, GA Ross, SC Goheen, and EW Hoppe. 1993. "Closed-System, Solid-Phase Extraction Cleanup Method for Removal of Normal Paraffin Hydrocarbon from Samples Prior to Purgeand-Trap Volatile Analysis." Anal. Chem, 65, 2229-2235.

Mong GM, JA Campbell, RD Orr, SA Clauss, KL Wahl, and FV Hoopes. 1997. "Activity Reduction of Radioactive Mixed Wastes for Subsequent Carboxylate Determinations." J. of Radioanalytical and Nuclear Chem., 219, 41-45.

OSHA. 2000. OSHA Sampling and Analysis Methods; Method 54, Methyl Isocyanate. Donald Burright, ed., online document, http://www.osha-slc.gov/dts/sltc/methods/index.html

Resource Conservation and Recovery Act (RCRA) of 1976. 42 USC 6901 et seq., as amended.

Sharma AK, SA Clauss, GM Mong, and JA Campbell. 1998. "Analysis and Quantification of Organic Acids in Simulated Hanford Tank Waste and Hanford Tank Waste," J. Chromatography 805:101-107.

Smith MR, OT Farmer III, and DW Koppenaal. 1995. "Radioanalytical Methods Applied to the Nuclear Fuel Cycle (continued)." Journal of Radioanalytical and Nuclear Chemistry 194(1):7-13.

Stromatt RW, EW Hoppe, and MJ Steele. 1993. Sample Preparation for Semivolatile Organics Aanlysis of Hanford Single-Shell Tank Waste with High Nitrate/Nitrite and Water Content. PNL-8927, Pacific Northwest Laboratory, Richland, Washington.

Urie MW, LR Greenwood, OT Farmer, SK Fiskum, RT Rather, CZ Soderquist, and JJ Wagner. 1999a. Inorganic and Radiochemical Analysis of AW101 and AN107 Diluted Feed Materials. PNWD-2463, Battelle, Pacific Northwest Division, Richland, Washington.

Urie MW, LR Greenwood, JJ Wagner, OT Farmer, SK Fiskum, RT Ratner, and CZ Soderquist. 1999b. Inorganic and Radiochemical Analysis of AW101 and AN107 Tank Waste. PNWD-2462, Battelle Pacific Northwest Division, Richland, Washington.

Urie MW, JP Bramson, SK Fiskum, KJ Carson, JR DesChane, OT Farmer, LR Greenwood, FV Hoopes, RT Ratner, DR Sanders, CZ Soderquist, MJ Steele, RT Steele, RW Swoboda, KK Thomas, TL Trang-Le, and JJ Wagner. 2000. Inorganic and Radiochemical Analysis of C104 Tank Waste. PNNL-13364, Battelle, Pacific Northwest Division, Richland, Washington.

U.S. Department of Energy (DOE). 1998. Hanford Analytical Services Quality Assurance Requirements Document, DOE/RL-96-68, Rev 2., U.S. Department of Energy, Richland, Washington. 
U.S. Environmental Protection Agency (EPA). 1989. Volatile Organic Compounds by Isotope Dilution GCMS," Method 1624, Revision C, Washington, D.C.

U.S. Environmental Protection Agency (EPA). 1997. Test Methods for Evaluation of Solid Waste Physical/Chemical Methods," SW-846, $3^{\text {rd }}$ Edition, as amended by updates I, IIA, IIB, III and 4A (draft), Washington, D.C.

Washington Administrative Code (WAC). 1984. Dangerous Waste Regulations, WAC 173-303, Olympia, Washington.

Wiemers KD, M Lerchen, M Miller, and K Meier. 1998a. Regulatory Data Quality Objectives Supporting Tank Waste Remediation System Privatization Project. PNNL-12040, Rev. 0, Pacific Northwest National Laboratory, Richland, Washington.

Wiemers KD, M Miller, and ME Lerchen. 1998b. An Approach for the Analysis of Regulatory Analytes in High Level Radioactive Waste Stored at Hanford, Richland, Washington. PNNL-11942, Pacific Northwest National Laboratory, Richland, Washington. 
Appendix A -

Summary Tables for Method and Sample Requirements 
Table A-1. Sample Quantity Estimates by Analysis Method for MDL/EQL Determinations

\begin{tabular}{|l|c|c|c|c||}
\hline \multirow{4}{*}{\multicolumn{1}{c|}{ Analysis }} & \multicolumn{2}{c|}{$\begin{array}{c}\text { Liquid Matrix } \\
\text { (AN102 Supernatant) }\end{array}$} & \multicolumn{2}{c|}{$\begin{array}{c}\text { Solid Matrix } \\
\text { AY102 solids) }\end{array}$} \\
\cline { 2 - 5 } & $\begin{array}{c}\text { Single Sample } \\
\text { Volume } \\
(\mathbf{m L})\end{array}$ & $\begin{array}{c}\text { Total Sample } \\
\text { Volume } \\
(\mathbf{m L})\end{array}$ & $\begin{array}{c}\text { Single Sample } \\
\text { Mass } \\
(\mathbf{g})\end{array}$ & $\begin{array}{c}\text { Total Sample } \\
\text { Mass } \\
(\mathbf{g})\end{array}$ \\
\hline \hline Metals & 5 & $270^{(\mathrm{a})}$ & 1 & $54^{(\mathrm{a})}$ \\
\hline Anions & 2 & $32^{(\mathrm{b})}$ & 2 & $32^{(\mathrm{b})}$ \\
\hline Mercury & 1 & $16^{(\mathrm{b})}$ & 0.5 & $8^{(\mathrm{b})}$ \\
\hline Ammonia & 5 & $80^{(\mathrm{b})}$ & 2 & $16^{(\mathrm{b})}$ \\
\hline Cyanide & 5 & $80^{(\mathrm{b})}$ & 1 & 0 \\
\hline Hydroxide & 5 & $80^{(\mathrm{b})}$ & 0 & $17.6^{(\mathrm{b})}$ \\
\hline Volatiles & 1.1 & $17.6^{(\mathrm{b})}$ & 1.1 & $80^{(\mathrm{b})}$ \\
\hline Semivolatiles & 5 & $80^{(\mathrm{b})}$ & 5 & $16^{(\mathrm{b})}$ \\
\hline Pesticides & 100 & $1600^{(\mathrm{b})}$ & 1 & $16^{(\mathrm{b})}$ \\
\hline PCBs & 100 & $1600^{(\mathrm{b})}$ & 1 & $17.6^{(\mathrm{b})}$ \\
\hline Polar volatiles & 1.1 & $17.6^{(\mathrm{b})}$ & 1.1 & $17.6^{(\mathrm{b})}$ \\
\hline Organic Acids & 1.1 & $17.6^{(\mathrm{b}}$ & 1.1 & $17.6^{(\mathrm{b})}$ \\
\hline Picric Acid & 1.1 & $17.6^{(\mathrm{b})}$ & 1.1 & $324.4^{(\mathrm{c})}$ \\
\hline Total & -- & $3908.4^{(\mathrm{c})}$ & -- & \\
\hline
\end{tabular}

Notes:

a) Assumes 27 analyses/spikes, 2 preparations, and 1 iterations.

b) Assumes 16 analyses/spikes, 1 preparation, and 1 iteration.

c) Requests for sample have included approximately $20 \%$ contingency.

Table A-2. Summary of Proposed Approaches to MDL/EQL Determination

\begin{tabular}{|c|c|c|c|c|c|}
\hline $\begin{array}{l}\text { Analytes of } \\
\text { Interest }\end{array}$ & $\begin{array}{l}\text { Reg. DQO } \\
\text { Proposed } \\
\text { Analytical } \\
\text { Method }\end{array}$ & $\begin{array}{l}\text { Test Plan } \\
\text { Proposed } \\
\text { Prep } \\
\text { Method }\end{array}$ & $\begin{array}{l}\text { Test Plan } \\
\text { Proposed } \\
\text { Analytical } \\
\text { Method }\end{array}$ & $\begin{array}{l}\text { Degree of } \\
\text { Modification }\end{array}$ & Modification Summary \\
\hline \multicolumn{6}{|c|}{ Organics } \\
\hline Volatiles & $8260 \mathrm{~B}$ & 5035 & $8260 \mathrm{~B}$ & minor & $\begin{array}{l}\text { Minor modifications include } \\
\text { using isotope dilution (EPA } \\
\text { Method 1624) and ion } \\
\text { monitoring. Use of alternative } \\
\text { sample preparations may } \\
\text { include the use of SW-846 } \\
\text { methods or development of } \\
\text { new methods. }\end{array}$ \\
\hline Semivolatiles & $\begin{array}{l}8270 \mathrm{C} \\
8151 \mathrm{~A} \\
\text { (Dinoseb) }\end{array}$ & $\begin{array}{l}\text { Liquids: } \\
\text { 3510C } \\
\text { Solids: 3550B }\end{array}$ & $8270 \mathrm{C}$ & minor & $\begin{array}{l}\text { Preparations include } \mathrm{pH} \\
\text { determination by titration with } \\
\text { phosphoric acid and } \\
\text { ultrsonification methylene } \\
\text { chloride:acetone. Gas } \\
\text { chromatography/mass } \\
\text { spectrometry (GC/MS) } \\
\text { equivalent to SW-846 Method } \\
\text { 8270C. N-nitroso compound } \\
\text { extraction under basic } \\
\text { conditions. }\end{array}$ \\
\hline Pesticides and & $8081 \mathrm{~A}$ and & Liquids: & $8081 \mathrm{~A}$ and & minor & Minor modifications may \\
\hline
\end{tabular}




\begin{tabular}{|c|c|c|c|c|c|}
\hline $\begin{array}{l}\text { Analytes of } \\
\text { Interest }\end{array}$ & $\begin{array}{l}\text { Reg. DQO } \\
\text { Proposed } \\
\text { Analytical } \\
\text { Method }\end{array}$ & $\begin{array}{l}\text { Test Plan } \\
\text { Proposed } \\
\text { Prep } \\
\text { Method }\end{array}$ & $\begin{array}{l}\text { Test Plan } \\
\text { Proposed } \\
\text { Analytical } \\
\text { Method }\end{array}$ & $\begin{array}{l}\text { Degree of } \\
\text { Modification }\end{array}$ & Modification Summary \\
\hline PCBs & 8082 & $\begin{array}{l}\text { 3510C } \\
\text { Solids: 3550B }\end{array}$ & 8082 & & $\begin{array}{l}\text { include modified preparation or } \\
\text { clean up method to improve } \\
\text { sensitivity }\end{array}$ \\
\hline $\begin{array}{l}\text { Polar } \\
\text { Volatiles }\end{array}$ & $8260 \mathrm{~B}$ & $8260 \mathrm{~B}$ & 5021 & minor & $\begin{array}{l}\text { Isotope dilution and ion } \\
\text { monitoring (EPA Method 1624) }\end{array}$ \\
\hline $\begin{array}{l}\text { Organic } \\
\text { Acids }\end{array}$ & 9056 & $\begin{array}{l}\text { clean up ion } \\
\text { exchange }\end{array}$ & 9056 & minor & $\begin{array}{l}\text { IX for radionuclide } \\
\text { reduction/removal. Optimized } \\
\text { instrument settings. }\end{array}$ \\
\hline \multicolumn{6}{|c|}{ Inorganics } \\
\hline Metals & 6010B & $\begin{array}{l}\text { Liquids: } \\
\text { 3005A, 3010A } \\
\text { or equivalent } \\
\text { Solids: 3052, } \\
\text { ASTM D4503 } \\
\text { or D4698 }\end{array}$ & $\begin{array}{l}6020 \\
(\mathrm{ICP} / \mathrm{MS}) \\
6010 \mathrm{~B} \\
\text { (ICP/AES) }\end{array}$ & minor & $\begin{array}{l}\text { For liquids, only minor } \\
\text { modifications to accommodate } \\
\text { processing small samples. } \\
\text { For solids, fusion techniques } \\
\text { would use Na and } \mathrm{K} \text { based } \\
\text { caustic flux agents instead of } \\
\text { lithium metaborate. } \\
\text { Microwave digestion (3052) } \\
\text { would need to be adapted to } \\
\text { remote processing. }\end{array}$ \\
\hline Anions & 9056 & $\begin{array}{l}\text { ASTM } \\
\text { D3987-85 }\end{array}$ & 9056 & $\begin{array}{l}\text { Minor or } \\
\text { alternate EPA } \\
\text { method }\end{array}$ & $\begin{array}{l}\text { IC parameter adjustment to } \\
\text { optimize method. Possible } \\
\text { methods development for } \mathrm{Br} \text {, } \\
\mathrm{Cl}, \mathrm{NO}_{3}^{-}, \mathrm{NO}_{2}^{-} \text {. }\end{array}$ \\
\hline Ammonia & $\begin{array}{l}\mathrm{EPA} / 600 \\
350.3\end{array}$ & $\begin{array}{l}\text { EPA/600 } \\
\text { Method } 350.2 \\
\text { if needed }\end{array}$ & $\begin{array}{l}\text { EPA 600/ } \\
350.1,350.2 \\
350.3\end{array}$ & minor & $\begin{array}{l}\text { Only sample-size } \\
\text { modifications. }\end{array}$ \\
\hline Cyanide & 9010B & $\begin{array}{l}\text { EDTA/Ethyl- } \\
\text { enediamine } \\
\text { pretreatment } \\
\text { for waste with } \\
\text { ferrocyanide }\end{array}$ & $\begin{array}{l}9010 \mathrm{~B}, \\
9012 \mathrm{~A}, \\
9013,9014 \\
\text { or } 9213\end{array}$ & minor & $\begin{array}{l}\text { Pretreatment for ferrocyanide } \\
\text { waste. }\end{array}$ \\
\hline Hydroxide & $\begin{array}{l}\mathrm{EPA} / 600 \\
310.1\end{array}$ & None required & $\begin{array}{l}\text { EPA/600 } \\
310.1 \text { or } \\
310.2\end{array}$ & minor & $\begin{array}{l}\text { Data interpretation to determine } \\
\text { hydroxide concentration instead } \\
\text { of alkalinity. }\end{array}$ \\
\hline Mercury & 7470/7471A & 7470/7471A & 7470/7471A & minor & $\begin{array}{l}\text { Equipment parameter } \\
\text { modifications to optimize the } \\
\text { analysis. }\end{array}$ \\
\hline
\end{tabular}


Table A-3. Target MDLs/EQLs for Volatile Organics as Published in SW-846 Method 8260B

\begin{tabular}{|c|c|c|c|c|}
\hline $\begin{array}{c}\text { CAS } \\
\text { Registry } \\
\text { Number } \\
\end{array}$ & Compound & $\begin{array}{l}\text { Target } \\
\text { Value }\end{array}$ & units & Comments \\
\hline \multicolumn{5}{|c|}{ General Guidance for EQLs and Matrix Factors by Method 8260B } \\
\hline-- & $\begin{array}{l}\text { All volatiles -general guidance } \\
\text { for ground water matrix }\end{array}$ & 5 & $\mu \mathrm{g} / \mathrm{L}$ & 5-mL sample, purge \& trap GC/MS \\
\hline-- & $\begin{array}{l}\text { All volatiles - general guidance } \\
\text { low soil/sediment matrix }\end{array}$ & 5 & $\mu \mathrm{g} / \mathrm{kg}$ & $\begin{array}{l}\text { Purge \& trap GC/MS, based on wet weight. (no sample } \\
\text { size provided) }\end{array}$ \\
\hline-- & $\begin{array}{l}\text { Matrix Factor - water miscible } \\
\text { liquid waste }\end{array}$ & 50 & -- & Factor to be applied to EQL for low soil/sediment \\
\hline-- & $\begin{array}{l}\text { Matrix Factor - high } \\
\text { concentration soil and sludge }\end{array}$ & 125 & -- & Factor to be applied to EQL for low soil/sediment \\
\hline $\begin{array}{c}\text { CAS } \\
\text { Registry } \\
\text { Number }\end{array}$ & Compound & $\begin{array}{c}\text { Target } \\
\text { Value } \\
\text { Wide-bore } \\
\text { Column } \\
(\mu \mathrm{g} / \mathrm{L})\end{array}$ & $\begin{array}{c}\text { Target } \\
\text { Value } \\
\text { Narrow- } \\
\text { bore } \\
\text { Column } \\
(\mu \mathrm{g} / \mathrm{L})\end{array}$ & Comments \\
\hline \multicolumn{5}{|c|}{ Specific Guidance for MDLs by Method 8260B } \\
\hline $100-41-4$ & Ethyl benzene & 0.06 & 0.03 & 25-mL sample, purge \& trap GC/MS. \\
\hline $100-42-5$ & Styrene & 0.04 & 0.27 & 25-mL sample, purge \& trap GC/MS. \\
\hline $10061-01-5$ & cis-1,3-Dichloropropene & -- & -- & $\begin{array}{l}\text { Compound included in method list, but no MDL } \\
\text { provided. }\end{array}$ \\
\hline $10061-02-6$ & trans-1,3-Dichloropropene & -- & -- & $\begin{array}{l}\text { Compound included in method list, but no MDL } \\
\text { provided. }\end{array}$ \\
\hline $106-35-4$ & 3-Heptanone & -- & -- & Compound not included on method list. \\
\hline $106-42-3$ & p-Xylene (Dimethylbenzene) & 0.13 & 0.06 & 25-mL sample, purge \& trap GC/MS. \\
\hline $106-46-7$ & 1,4-Dichlorobenzene & 0.03 & 0.04 & 25-mL sample, purge \& trap GC/MS. \\
\hline $106-93-4$ & $\begin{array}{l}\text { Ethylene dibromide } \\
\text { (Dibromoethane) }\end{array}$ & 0.06 & 0.10 & 25-mL sample, purge \& trap GC/MS. \\
\hline $106-97-8$ & Butane & -- & -- & Compound not included on method list. \\
\hline $106-99-0$ & 1,3-Butadiene & -- & -- & Compound not included on method list. \\
\hline $107-02-8$ & Acrolein & -- & -- & $\begin{array}{l}\text { Compound included in method list, but no MDL } \\
\text { provided. }\end{array}$ \\
\hline $107-05-1$ & 3-Chloropropene (Allyl chloride) & -- & -- & $\begin{array}{l}\text { Compound included in method list, but no MDL } \\
\text { provided. }\end{array}$ \\
\hline $107-06-2$ & $\begin{array}{l}\text { 1,2-Dichloroethane (Ethylene } \\
\text { chloride) }\end{array}$ & 0.06 & 0.02 & 25-mL sample, purge \& trap GC/MS. \\
\hline $107-12-0$ & Propionitrile & -- & -- & $\begin{array}{l}\text { Compound included in method list, but no MDL } \\
\text { provided. }\end{array}$ \\
\hline $107-13-1$ & Acrylonitrile & -- & -- & $\begin{array}{l}\text { Compound included in method list, but no MDL } \\
\text { provided. }\end{array}$ \\
\hline $107-87-9$ & 2-Pentanone & -- & -- & $\begin{array}{l}\text { Compound included in method list, but no MDL } \\
\text { provided. }\end{array}$ \\
\hline $108-10-1$ & $\begin{array}{l}\text { Hexone (4-Methyl-2-pentanone } \\
\text { or MIBK) }\end{array}$ & -- & -- & $\begin{array}{l}\text { Compound included in method list, but no MDL } \\
\text { provided. }\end{array}$ \\
\hline $108-38-3$ & m-Xylene (Dimethylbenzene) & 0.05 & 0.03 & 25-mL sample, purge \& trap GC/MS. \\
\hline $108-87-2$ & Methylcyclohexane & -- & -- & Compound not included on method list. \\
\hline $108-88-3$ & Toluene & 0.11 & 0.08 & 25-mL sample, purge \& trap GC/MS. \\
\hline $108-90-7$ & Chlorobenzene & 0.04 & 0.03 & 25-mL sample, purge \& trap GC/MS. \\
\hline 108-94-1 & Cyclohexanone & -- & -- & Compound not included on method list. \\
\hline $109-66-0$ & n-Pentane & -- & -- & Compound not included on method list. \\
\hline $109-99-9$ & Tetrahydrofuran & -- & -- & Compound not included on method list. \\
\hline $110-12-3$ & 5-Methyl-2-hexanone & -- & -- & Compound not included on method list. \\
\hline $110-43-0$ & 2-Heptanone & -- & -- & Compound not included on method list. \\
\hline $110-54-3$ & n-Hexane & -- & -- & Compound not included on method list. \\
\hline $110-82-7$ & Cyclohexane & -- & -- & Compound not included on method list. \\
\hline $110-83-8$ & Cyclohexene & -- & -- & Compound not included on method list. \\
\hline
\end{tabular}




\begin{tabular}{|c|c|c|c|c|}
\hline $\begin{array}{c}\text { CAS } \\
\text { Registry } \\
\text { Number }\end{array}$ & Compound & $\begin{array}{c}\text { Target } \\
\text { Value } \\
\text { Wide-bore } \\
\text { Column } \\
(\mu \mathrm{g} / \mathrm{L})\end{array}$ & $\begin{array}{c}\text { Target } \\
\text { Value } \\
\text { Narrow- } \\
\text { bore } \\
\text { Column } \\
(\mu g / L)\end{array}$ & Comments \\
\hline $111-65-9$ & n-Octane & 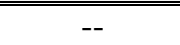 & -- & Compound not included on method list. \\
\hline $111-84-2$ & n-Nonane & -- & -- & Compound not included on method list. \\
\hline $120-82-1$ & 1,2,4-Trichloro-benzene & -- & -- & Compound not included on method list. \\
\hline $123-19-3$ & 4-Heptanone & -- & -- & Compound not included on method list. \\
\hline $123-38-6$ & n-Propionaldehyde & -- & -- & Compound not included on method list. \\
\hline $123-86-4$ & Acetic acid n-butyl ester & -- & -- & Compound not included on method list. \\
\hline $123-91-1$ & 1,4-Dioxane & -- & -- & $\begin{array}{l}\text { Compound included in method list, but no MDL } \\
\text { provided. }\end{array}$ \\
\hline $126-98-7$ & $\begin{array}{l}\text { 2-Methyl-2-propenenitrile } \\
\text { (Methacrylonitrile) }\end{array}$ & -- & -- & $\begin{array}{l}\text { Compound included in method list, but no MDL } \\
\text { provided. }\end{array}$ \\
\hline $127-18-4$ & $\begin{array}{l}\text { Perchloroethylene (tetrachloro- } \\
\text { ethylene) }\end{array}$ & -- & -- & $\begin{array}{l}\text { Compound included in method list, but no MDL } \\
\text { provided. }\end{array}$ \\
\hline $141-78-6$ & $\begin{array}{l}\text { Acetic acid ethyl ester (Ethyl } \\
\text { acetate) }\end{array}$ & -- & -- & $\begin{array}{l}\text { Compound included in method list, but no MDL } \\
\text { provided. }\end{array}$ \\
\hline $142-82-5$ & n-Heptane & -- & -- & Compound not included on method list. \\
\hline $287-92-3$ & Cyclopentane & -- & -- & Compound not included on method list. \\
\hline $4170-30-3$ & $\begin{array}{l}\text { 2-Butenaldehyde (2-Butenal or } \\
\text { Crotonaldehyde) }\end{array}$ & -- & -- & $\begin{array}{l}\text { Compound included in method list, but no MDL } \\
\text { provided. }\end{array}$ \\
\hline 541-73-1 & 1,3-Dichlorobenzene & 0.12 & 0.05 & 25-mL sample, purge \& trap GC/MS. \\
\hline $56-23-5$ & Carbon tetrachloride & 0.21 & 0.02 & 25-mL sample, purge \& trap GC/MS. \\
\hline $563-80-4$ & 3-Methyl-2-butanone & -- & -- & Compound not included on method list. \\
\hline \begin{tabular}{|l|l|}
$57-14-7$ \\
\end{tabular} & 1,1-Dimethylhydrazine & -- & -- & Compound not included on method list. \\
\hline $591-78-6$ & 2-Hexanone & -- & -- & $\begin{array}{l}\text { Compound included in method list, but no MDL } \\
\text { provided. }\end{array}$ \\
\hline $60-34-4$ & Methylhydrazine & -- & -- & Compound not included on method list. \\
\hline $627-13-4$ & Nitric acid, propyl ester & -- & -- & Compound not included on method list. \\
\hline $67-64-1$ & 2-Propanone (Acetone) & -- & -- & $\begin{array}{l}\text { Compound included in method list, but no MDL } \\
\text { provided. }\end{array}$ \\
\hline $67-66-3$ & Chloroform & 0.03 & 0.04 & 25-mL sample, purge \& trap GC/MS. \\
\hline $684-16-2$ & Hexafluoroacetone & -- & -- & Compound not included on method list. \\
\hline $71-43-2$ & Benzene & 0.04 & 0.03 & 25-mL sample, purge \& trap GC/MS. \\
\hline $71-55-6$ & $\begin{array}{l}\text { Methyl chloroform }(1,1,1- \\
\text { Trichloroethane) }\end{array}$ & 0.08 & 0.04 & 25-mL sample, purge \& trap GC/MS. \\
\hline $74-83-9$ & Bromomethane (Methyl bromide) & 0.11 & 0.03 & 25-mL sample, purge \& trap GC/MS. \\
\hline $74-87-3$ & Chloromethane (Methyl chloride) & 0.13 & 0.05 & 25-mL sample, purge \& trap GC/MS. \\
\hline $75-00-3$ & Chloroethane & 0.10 & -- & 25-mL sample, purge \& trap GC/MS \\
\hline $75-01-4$ & Vinyl chloride (1-Chloroethene) & 0.07 & 0.04 & 25-mL sample, purge \& trap GC/MS. \\
\hline $75-05-8$ & Acetonitrile & -- & -- & $\begin{array}{l}\text { Compound included in method list, but no MDL } \\
\text { provided. }\end{array}$ \\
\hline $75-09-2$ & $\begin{array}{l}\text { Dichloromethane (Methylene } \\
\text { chloride) }\end{array}$ & 0.03 & -- & 25-mL sample, purge \& trap GC/MS \\
\hline $75-15-0$ & Carbon disulfide & -- & -- & $\begin{array}{l}\text { Compound included in method list, but no MDL } \\
\text { provided. }\end{array}$ \\
\hline $75-21-8$ & Ethylene oxide (Oxirane) & -- & -- & $\begin{array}{l}\text { Compound included in method list, but no MDL } \\
\text { provided. }\end{array}$ \\
\hline $75-34-3$ & 1,1-Dichloroethane & 0.04 & 0.03 & 25-mL sample, purge \& trap GC/MS. \\
\hline $75-35-4$ & $\begin{array}{l}\text { 1,1-Dichloroethene (Vinylidene } \\
\text { chloride) }\end{array}$ & 0.12 & -- & 25-mL sample, purge \& trap GC/MS \\
\hline $75-43-4$ & Dichlorofluoro-methane & 0.08 & -- & 25-mL sample, purge \& trap GC/MS \\
\hline $75-45-6$ & Chlorodifluoro-methane & -- & -- & Compound not included on method list. \\
\hline $75-69-4$ & Trichlorofluoromethane & 0.08 & -- & 25-mL sample, purge \& trap GC/MS \\
\hline $75-71-8$ & Dichlorodifluoromethane & 0.10 & 0.11 & 25-mL sample, purge \& trap GC/MS. \\
\hline
\end{tabular}




\begin{tabular}{||l|l|c|c|l||}
\hline $\begin{array}{c}\text { CAS } \\
\text { Registry } \\
\text { Number }\end{array}$ & \multicolumn{1}{|c|}{ Compound } & $\begin{array}{c}\text { Target } \\
\text { Value } \\
\text { Wide-bore } \\
\text { Column } \\
(\boldsymbol{\mu g} / \mathbf{L})\end{array}$ & $\begin{array}{c}\text { Target } \\
\text { Value } \\
\text { Narrow- } \\
\text { bore } \\
\text { Column } \\
(\boldsymbol{\mu g} / \mathbf{L})\end{array}$ & \multicolumn{1}{|c||}{ Comments } \\
\hline \hline $76-13-1$ & $\begin{array}{l}1,2,2-\text { Trichloro-1,1,2-trifluoro- } \\
\text { ethane (Freon 113) }\end{array}$ & -- & -- & $\begin{array}{l}\text { Compound included in method list, but no MDL } \\
\text { provided. }\end{array}$ \\
\hline $76-14-2$ & $\begin{array}{l}1,2-\text { Dichloro-1,1,2,2- } \\
\text { tetrafluoroethane }\end{array}$ & -- & -- & $\begin{array}{l}\text { Compound included in method list, but no MDL } \\
\text { provided. }\end{array}$ \\
\hline $78-87-5$ & $1,2-$ Dichloropropane & 0.04 & 0.02 & 25-mL sample, purge \& trap GC/MS. \\
\hline $78-93-3$ & $\begin{array}{l}\text { Methyl ethyl ketone (MEK, 2- } \\
\text { Butanone) }\end{array}$ & -- & -- & $\begin{array}{l}\text { Compound included in method list, but no MDL } \\
\text { provided. }\end{array}$ \\
\hline $79-00-5$ & 1,1,2-Trichloroethane & 0.01 & 0.08 & 25-mL sample, purge \& trap GC/MS. \\
\hline $79-01-6$ & Trichloroethylene & -- & -- & $\begin{array}{l}\text { Compound included in method list, but no MDL } \\
\text { provided. }\end{array}$ \\
\hline $79-34-5$ & 1,1,2,2-Tetrachloroethane & 0.04 & 0.20 & $25-\mathrm{mL}$ sample, purge \& trap GC/MS. \\
\hline $87-68-3$ & Hexachlorobutadiene & 0.11 & 0.10 & $25-\mathrm{mL}$ sample, purge \& trap GC/MS. \\
\hline $95-47-6$ & o-Xylene & 0.11 & 0.06 & 25-mL sample, purge \& trap GC/MS. \\
\hline $95-50-1$ & $\begin{array}{l}\text { o-Dichlorobenzene (1,2- } \\
\text { Dichlorobenzene) }\end{array}$ & 0.03 & 0.05 & 25-mL sample, purge \& trap GC/MS. \\
\hline $96-22-0$ & 3-Pentanone & -- & -- & Compound not included on method list. \\
\hline \hline
\end{tabular}


Table A-4. Target EQLs for Semivolatile Organics as Published in SW-846 Method 8270C

\begin{tabular}{|c|c|c|c|c|}
\hline $\begin{array}{c}\text { CAS } \\
\text { Registry } \\
\text { Number } \\
\end{array}$ & Compound & $\begin{array}{l}\text { Target } \\
\text { Value }\end{array}$ & Units & Comments \\
\hline \multicolumn{5}{|c|}{ General Guidance for EQLs and Matrix Factors by Method 8270C } \\
\hline-- & $\begin{array}{l}\text { All semivolatiles -general } \\
\text { guidance for ground water matrix }\end{array}$ & 10 & $\mu \mathrm{g} / \mathrm{L}$ & 30-g sample, gel permeation chromatography cleanup \\
\hline-- & $\begin{array}{l}\text { All semivolatiles - general } \\
\text { guidance low soil/sediment } \\
\text { matrix }\end{array}$ & 660 & $\mu \mathrm{g} / \mathrm{kg}$ & $\begin{array}{l}\text { Based on wet weight, } 30 \text {-g sample, gel permeation } \\
\text { chromatography cleanup }\end{array}$ \\
\hline-- & $\begin{array}{l}\text { All semivolatiles - general } \\
\text { guidance waste matrix }\end{array}$ & $\begin{array}{l}1000 \text { to } \\
200,000\end{array}$ & $\mu \mathrm{g} / \mathrm{kg}$ & $\begin{array}{l}\text { Based on wet weight, } 30 \text {-g sample, gel permeation } \\
\text { chromatography cleanup }\end{array}$ \\
\hline-- & $\begin{array}{l}\text { Matrix Factor - high- } \\
\text { concentration soil/sludge by } \\
\text { ultrasonic extractor }\end{array}$ & 7.5 & -- & Factor to be applied to EQL for low soil/sediment \\
\hline-- & $\begin{array}{l}\text { Matrix Factor - non-water } \\
\text { miscible waste }\end{array}$ & 75 & -- & Factor to be applied to EQL for low soil/sediment \\
\hline $\begin{array}{c}\text { CAS } \\
\text { Registry } \\
\text { Number }\end{array}$ & Compound & $\begin{array}{l}\text { Target } \\
\text { Value } \\
\text { Ground } \\
\text { Water } \\
(\mu \mathrm{g} / \mathrm{L})\end{array}$ & $\begin{array}{c}\text { Target } \\
\text { Value } \\
\text { Low Soil/ } \\
\text { Sediment } \\
(\mu \mathrm{g} / \mathrm{kg})\end{array}$ & Comments \\
\hline \multicolumn{5}{|c|}{ Specific Guidance for EQLs by Method 8270C } \\
\hline $100-00-5$ & p-Nitrochlorobenzene & -- & -- & Compound not included on method list. \\
\hline $100-25-4$ & 1,4-Dinitrobenzene & 40 & -- & 30-g sample, gel permeation chromatography cleanup \\
\hline $108-95-2$ & Phenol & 10 & 660 & $\begin{array}{l}\text { 30-g sample, gel permeation chromatography cleanup. } \\
\text { For low soil/sediment -based on wet weight }\end{array}$ \\
\hline $110-86-1$ & Pyridine & -- & -- & Compound included in method list, but no EQL provided. \\
\hline $122-39-4$ & N,N-Diphenylamine & -- & -- & Compound included in method list, but no EQL provided. \\
\hline $126-73-8$ & Tributyl phosphate & -- & -- & Compound not included on method list. \\
\hline $128-37-0$ & $\begin{array}{l}\text { 2,6-Bis(tert-butyl)-4- } \\
\text { methylphenol }\end{array}$ & -- & -- & Compound not included on method list. \\
\hline $1321-64-8$ & Pentachloronaphthalene & -- & -- & Compound not included on method list. \\
\hline $1335-87-1$ & Hexachloronaphthalene & -- & -- & Compound not included on method list. \\
\hline $1335-88-2$ & Tetrachloronaphthalene & -- & -- & Compound not included on method list. \\
\hline $50-32-8$ & Benzo(a)pyrene & 10 & 660 & $\begin{array}{l}\text { 30-g sample, gel permeation chromatography cleanup. } \\
\text { For low soil/sediment -based on wet weight }\end{array}$ \\
\hline $53-70-3$ & Dibenzo(a,h)anthracene & 10 & 660 & $\begin{array}{l}\text { 30-g sample, gel permeation chromatography cleanup. } \\
\text { For low soil/sediment -based on wet weight }\end{array}$ \\
\hline $62-75-9$ & $\begin{array}{l}\text { N-Nitroso-N,N-dimethylamine } \\
\text { (Dimethylnitrosamine) }\end{array}$ & -- & -- & Compound included in method list, but no EQL provided. \\
\hline $82-68-8$ & $\begin{array}{l}\text { Pentachloronitrobenzene (PCBN } \\
\text { or quintobenzene) }\end{array}$ & 20 & -- & 30-g sample, gel permeation chromatography cleanup. \\
\hline $87-86-5$ & Pentachlorophenol & 50 & 3300 & $\begin{array}{l}\text { 30-g sample, gel permeation chromatography cleanup. } \\
\text { For low soil/sediment -based on wet weight }\end{array}$ \\
\hline $88-85-7$ & \begin{tabular}{|l|}
$\begin{array}{l}\text { 2-sec-Butyl-4,6-dinitrophenol } \\
\text { (Dinoseb) }\end{array}$ \\
\end{tabular} & 20 & -- & 30-g sample, gel permeation chromatography cleanup. \\
\hline $92-52-4$ & 1,1`-Biphenyl & -- & -- & Compound not included on method list. \\
\hline $98-86-2$ & Acetophenone & 10 & -- & 30-g sample, gel permeation chromatography cleanup. \\
\hline $98-95-3$ & Nitrobenzene & 10 & 660 & $\begin{array}{l}\text { 30-g sample, gel permeation chromatography cleanup. } \\
\text { For low soil/sediment -based on wet weight }\end{array}$ \\
\hline
\end{tabular}


Table A-5. Target MDLs/EQLs for Pesticides and PCBs as Published in SW-846 Methods 8081A and 8082

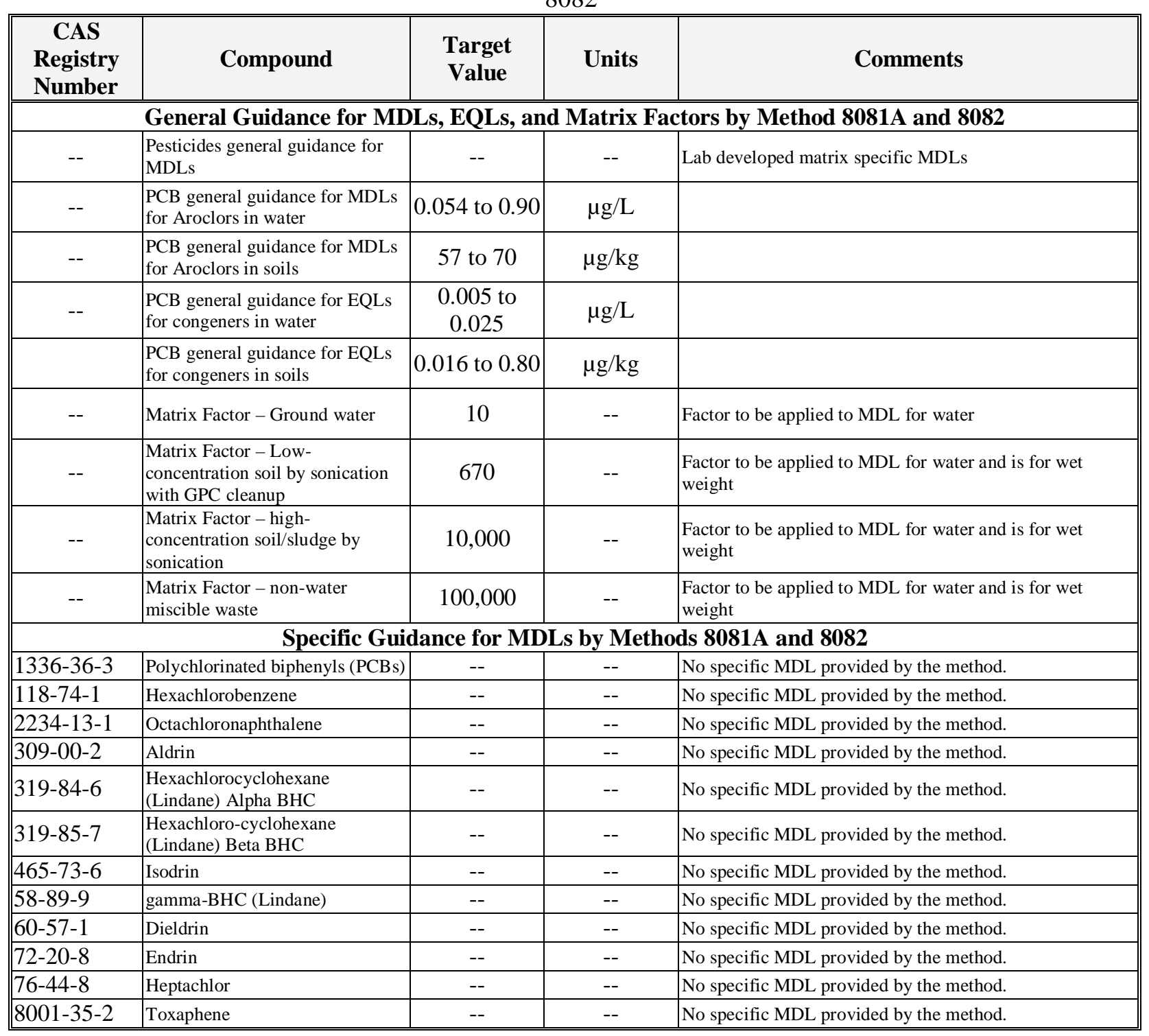


Table A-6. Other Organic Compounds with No Specific Guidance for MDLs or EQLs in SW-846

\begin{tabular}{|c|c|c|c|c|}
\hline $\begin{array}{c}\text { CAS } \\
\text { Registry } \\
\text { Number }\end{array}$ & Compound & $\begin{array}{l}\text { Target } \\
\text { Value }\end{array}$ & Units & Comments \\
\hline \multicolumn{5}{|c|}{ Polar Volatile Compounds by Method 8260B } \\
\hline $121-44-8$ & Triethylamine & -- & -- & Compound not included on method list. \\
\hline $64-17-5$ & Ethyl alcohol & -- & -- & Compound not included on method list. \\
\hline $67-56-1$ & Methyl alcohol (Methanol) & -- & -- & Compound not included on method list. \\
\hline $67-63-0$ & $\begin{array}{l}\text { 2-Propyl alcohol (Isopropanol; } \\
\text { Propan-2-01) }\end{array}$ & -- & -- & Compound not included on method list. \\
\hline $71-23-8$ & n-Propyl alcohol & -- & -- & Compound not included on method list. \\
\hline $71-36-3$ & n-Butyl alcohol & -- & -- & Compound not included on method list. \\
\hline $75-65-0$ & 2-Methyl-2-propanol & -- & -- & Compound not included on method list. \\
\hline $78-92-2$ & $\begin{array}{l}\text { 1-Methylpropyl alcohol (2- } \\
\text { Butanol) }\end{array}$ & -- & -- & Compound not included on method list. \\
\hline \multicolumn{5}{|c|}{ Organic Acids by Method 9056} \\
\hline $144-62-7$ & Oxalic acid & -- & -- & Compound not included on method list. \\
\hline $64-18-6$ & Formic acid & -- & -- & Compound not included on method list. \\
\hline $64-19-7$ & Acetic acid & -- & -- & Compound not included on method list. \\
\hline $79-10-7$ & 2-propenoic acid & -- & -- & Compound not included on method list. \\
\hline \multicolumn{5}{|c|}{ Other Compounds } \\
\hline $3825-26-1$ & Ammonium perfluoro-octanoate & -- & -- & Compound not included on method list. \\
\hline $624-83-9$ & Methyl isocyanate & -- & -- & Compound not included on method list. \\
\hline $88-89-1$ & Picric acid & -- & -- & Compound not included on method list. \\
\hline
\end{tabular}

Table A-7. Target IDLs and MDLs for Metals as Published in SW-846 Method 6010B and 6020

\begin{tabular}{|c|c|c|c|}
\hline $\begin{array}{c}\text { CAS } \\
\text { Registry } \\
\text { Number } \\
\end{array}$ & Compound & $\begin{array}{c}\text { Target } \\
\text { Value } \\
(\mu \mathrm{g} / \mathrm{L})\end{array}$ & Comments \\
\hline \multicolumn{4}{|c|}{ "General Guidance for MDLs by Method 6020} \\
\hline-- & $\begin{array}{l}\text { MDLs by Method } 6020- \\
\text { ICP/MS }\end{array}$ & $<0.02 \mu \mathrm{g} / \mathrm{L}$ & Simple matrices. \\
\hline \multicolumn{4}{|c|}{ Specific Guidance for IDLs by Method 6010B } \\
\hline 18540-29-9 & Chromium (hexavalent) ${ }^{\mathrm{b}}$ & 4.7 & \\
\hline $63705-05-5$ & Total Sulfur & -- & Element included in method list, but no IDL provided. \\
\hline $7429-90-5$ & Aluminum & 30 & \\
\hline $7439-89-6$ & Iron & 4.1 & \\
\hline $7439-92-1$ & Lead & 28 & \\
\hline $7439-93-2$ & Lithium & 2.8 & \\
\hline $7439-95-4$ & Magnesium & 20 & \\
\hline $7439-96-5$ & Manganese & 0.93 & \\
\hline $7439-98-7$ & Molybdenum & 5.3 & \\
\hline $7440-02-0$ & Nickel & 10 & \\
\hline $7440-09-7$ & Potassium & -- & Element included in method list, but no IDL provided. \\
\hline $7440-16-6$ & Rhodium & -- & Element included in method list, but no IDL provided. \\
\hline $7440-21-3$ & Silicon (as silica) & 17 & \\
\hline $7440-22-4$ & Silver & 4.7 & \\
\hline $7440-23-5$ & Sodium & 19 & \\
\hline $7440-25-7$ & Tantalum & -- & Element included in method list, but no IDL provided. \\
\hline $7440-28-0$ & Thallium & 27 & \\
\hline $7440-31-5$ & Tin & 17 & \\
\hline 7440-33-7 & Tungsten & -- & Element not included on method list. \\
\hline $7440-36-0$ & Antimony & 21 & \\
\hline $7440-38-2$ & Arsenic & 35 & \\
\hline $7440-39-3$ & Barium & 0.87 & \\
\hline
\end{tabular}




\begin{tabular}{||c|l|c|l||}
\hline $\begin{array}{c}\text { CAS } \\
\text { Registry } \\
\text { Number }\end{array}$ & $\begin{array}{c}\text { Target } \\
\text { Value } \\
(\boldsymbol{\mu g} / \mathbf{L})\end{array}$ & Comments \\
\hline \hline $7440-41-7$ & Beryllium & 0.18 & \\
\hline $7440-42-8$ & Boron & 3.8 & \\
\hline $7440-43-9$ & Cadmium & 2.3 & \\
\hline $7440-48-4$ & Cobalt & 4.7 & \\
\hline $7440-50-8$ & Copper & 3.6 & \\
\hline $7440-61-1$ & Uranium & -- & Element not included on method list. \\
\hline $7440-62-2$ & Vanadium & -- & Element not included on method list. \\
\hline $7440-65-5$ & Yttrium & -- & Element not included on method list. \\
\hline $7440-66-6$ & Zinc & 1.2 & \\
\hline $7440-67-7$ & Zirconium & -- & Element not included on method list. \\
\hline $7440-69-9$ & Bismuth & -- & Element included in method list, but no IDL provided. \\
\hline $7440-70-2$ & Calcium & 6.7 & \\
\hline $7723-14-0$ & Phosphorous & 51 & \\
\hline $7782-49-2$ & Selenium & 50 & \\
\hline $7553-56-2$ & Iodine & -- & Element not included on method list. \\
\hline
\end{tabular}

Table A-8. Target MDLs for Anions as Published in SW-846 Method 9056

\begin{tabular}{||c|l|c|l||}
\hline $\begin{array}{c}\text { CAS } \\
\text { Registry } \\
\text { Number }\end{array}$ & Compound & $\begin{array}{c}\text { Target MDL } \\
(\mu \mathrm{g} / \mathrm{L})\end{array}$ & \multicolumn{1}{||}{ Comments } \\
\hline \hline \multicolumn{3}{|c||}{ Specific Guidance for MDLs by Method 9056 } \\
\hline $14265-44-2$ & Phosphate & 100 & $100-\mu \mathrm{L}$ sample loop and 10- $\mu \mathrm{mho} / \mathrm{cm}$ full scale setting, reagent water \\
\hline $14797-65-0$ & Nitrite & 100 & $100-\mu \mathrm{L}$ sample loop and 10- $\mu \mathrm{mho} / \mathrm{cm}$ full scale setting, reagent water \\
\hline $14808-79-8$ & Sulfate & 100 & $100-\mu \mathrm{L}$ sample loop and $10-\mu \mathrm{mho} / \mathrm{cm}$ full scale setting, reagent water \\
\hline $16887-00-6$ & Chloride & 100 & $100-\mu \mathrm{L}$ sample loop and $10-\mu \mathrm{mho} / \mathrm{cm}$ full scale setting, reagent water \\
\hline $16984-48-8$ & Fluoride & 50 & $100-\mu \mathrm{L}$ sample loop and $10-\mu \mathrm{mho} / \mathrm{cm}$ full scale setting, reagent water \\
\hline $24959-67-9$ & Bromide & 100 & $100-\mu \mathrm{L}$ sample loop and $10-\mu \mathrm{mho} / \mathrm{cm}$ full scale setting, reagent water \\
\hline $7697-37-2$ & Nitrate & 100 & $100-\mu \mathrm{L}$ sample loop and $10-\mu \mathrm{mho} / \mathrm{cm}$ full scale setting, reagent water \\
\hline
\end{tabular}

Table A-9. Target MDLs for Cyanide as Published in SW-846 Method 9010B

\begin{tabular}{|c|c|c|c|c|c|c|}
\hline \multirow{2}{*}{$\begin{array}{c}\text { CAS } \\
\text { Registry } \\
\text { Number }\end{array}$} & \multirow[b]{2}{*}{ Compound } & \multicolumn{2}{|c|}{ Titration } & \multicolumn{2}{|c|}{ Colorimetry } & \multirow[b]{2}{*}{ Comments } \\
\hline & & $\begin{array}{c}\text { Liquid } \\
\text { Target MDL } \\
(\mu \mathrm{g} / \mathrm{L})\end{array}$ & $\begin{array}{c}\text { Solids } \\
\text { Target MDL } \\
(\mu \mathrm{g} / \mathrm{L})\end{array}$ & $\begin{array}{c}\text { Liquid } \\
\text { Target MDL } \\
(\mu \mathrm{g} / \mathrm{L})\end{array}$ & \begin{tabular}{|c} 
Solids \\
Target MDL \\
$(\mu \mathrm{g} / \mathrm{L})$
\end{tabular} & \\
\hline \multicolumn{7}{|c|}{ Specific Guidance for MDLs by Method 9010B } \\
\hline $57-12-5$ & $\begin{array}{l}\text { Cyanides } \\
\text { (amenable) }\end{array}$ & 100 & 200 & 20 & -- & \\
\hline
\end{tabular}

Table A-10. Target MDLs and IDLs for Mercury as Published in SW-846 Methods 7470 and 7471A

\begin{tabular}{|c|l|c|c|c||}
\hline $\begin{array}{c}\text { CAS } \\
\text { Registry } \\
\text { Number }\end{array}$ & Compound & $\begin{array}{c}\text { Method 7470 } \\
\text { Target IDL } \\
(\boldsymbol{\mu g} / \mathrm{L})\end{array}$ & $\begin{array}{c}\text { Method 7471A } \\
\text { Target IDL } \\
(\boldsymbol{\mu g} / \mathrm{L})\end{array}$ & Comments \\
\hline $7439-97-6$ & Mercury & 0.2 & 0.2 & \\
\hline
\end{tabular}


Table A.11. Other Inorganic Constituents with No Specific Guidance for MDLs or EQLs in SW-846

\begin{tabular}{||c|l|c|c|l||}
\hline $\begin{array}{c}\text { CAS } \\
\text { Registry } \\
\text { Number }\end{array}$ & \multicolumn{1}{|c|}{ Compound } & $\begin{array}{c}\text { Target } \\
\text { Value }\end{array}$ & Units & \multicolumn{1}{|c|}{ Comments } \\
\hline \hline $7664-41-7$ & Ammonia/ Ammonium & -- & -- & No MDLs or EQLs provided by method. \\
\hline $14280-30-9$ & Hydroxide & -- & -- & No MDLs or EQLs provided by method. \\
\hline
\end{tabular}

\section{References}

U.S. Environmental Protection Agency (EPA). 1997. Test Methods for Evaluation of Solid Waste Physical/Chemical Methods," SW-846, $3^{\text {rd }}$ Edition, as amended by updates I, IIA, IIB, III and 4A (draft), Washington, D.C. 
PNNL - 13429

WTP-TP-41500-003, Rev. 0

\section{Distribution}

No. of

Copies

\section{OFFSITE}

2 DOE/Office of Scientific and Technical Information
No. of

Copies

\section{ONSITE}

$7 \quad$ CH2M Hill Hanford Group, Inc.

D. B. Blumenkranz (4) H4-20

L. L. Bostic H4-20

M. E. Johnson H4-02

A. N. Thompson H4-02

9 DOE-ORP

M. E. Burandt H6-60

N. R. Brown (5) H6-60

R. Carreon H6-60

L. A. Huffman H6-60

L. J. Kovach H6-61

$3 \quad \underline{\mathrm{HND}}$

K. D. Wiemers (3) H6-61

23 Pacific Northwest National Laboratory

T. L. Almeida P7-22

I. E. Burgeson P7-25

J. A. Campbell P8-08

O. T. Farmer P8-08

E. W. Hoppe P8-08

D. E. Kurath P7-28

M. E. Lerchen H6-61

G. M. Mong P8-08

G. K. Patello (5) K6-24

C. Z. Soderquist P7-22

M. P. Thomas P8-08

M. W. Urie P7-22

J. J. Wagner P7-22

Project File P7-28

Information Release (5) K1-06 